Florida International University

FIU Digital Commons

FIU Electronic Theses and Dissertations

University Graduate School

9-30-2014

\title{
Numerical Modeling of the Effects of Hydrologic Conditions and Sediment Transport on Geomorphic Patterns in Wetlands
}

Mehrnoosh Mahmoudi

Earth and Environment, nmahm001@fiu.edu

DOI: $10.25148 /$ etd.FI14110750

Follow this and additional works at: https://digitalcommons.fiu.edu/etd

Part of the Environmental Engineering Commons, Environmental Monitoring Commons, Hydrology Commons, Numerical Analysis and Computation Commons, $\underline{\text { Partial Differential }}$ Equations Commons, and the Water Resource Management Commons

\section{Recommended Citation}

Mahmoudi, Mehrnoosh, "Numerical Modeling of the Effects of Hydrologic Conditions and Sediment Transport on Geomorphic Patterns in Wetlands" (2014). FIU Electronic Theses and Dissertations. 1656.

https://digitalcommons.fiu.edu/etd/1656 


\section{FLORIDA INTERNATIONAL UNIVERSITY}

Miami, Florida

NUMERICAL MODELING OF THE EFFECTS OF HYDROLOGIC CONDITIONS AND SEDIMENT TRANSPORT ON GEOMORPHIC PATTERNS IN WETLANDS

A dissertation submitted in partial fulfillment of

the requirements for the degree of

DOCTOR OF PHILOSOPHY

in

GEOSCIENCE

by

Mehrnoosh Mahmoudi 
To: Interim Dean Michael R. Heithaus

College of Arts and Sciences

This dissertation, written by Mehrnoosh Mahmoudi, and entitled Numerical Modeling of the Effects of Hydrologic Conditions and Sediment Transport on Geomorphic Patterns in Wetlands, having been approved in respect to style and intellectual content, is referred to you for judgment.

We have read this dissertation and recommend that it be approved.

Francisco R. Garcia

Assefa Melesse

Rene M. Price

Rosanna Rivero

Leonard J. Scinto

Shimon Wdowinski

$\overline{\text { Fernando Miralles-Wilhem, Major Professor }}$

Date of Defense: September 30, 2014

The Dissertation of Mehrnoosh Mahmoudi is approved.

Interim Dean Michael R. Heithaus

College of Arts and Sciences

Dean Lakshmi N. Reddi

University Graduate School

Florida International University, 2014 
CCopyright 2014 by Mehrnoosh Mahmoudi

All rights reserved. 


\section{DEDICATION}

I dedicate this dissertation to my father who I never met, to my grandfather who I never

forget, and to my family as they have always encouraged me to follow my dreams. I am excited to share with them what comes next. 


\section{ACKNOWLEDGMENTS}

I would like to thank my major advisor, Dr. Fernando Miralles-Wilhelm, for his guidance, understanding, patience, and most importantly, his friendship during my graduate studies at Florida International University. Although his decision to take a leave of absence from school caused a great deal of distress for me at the time, in the long run, I believe that his actions provided me with the unique opportunity to gain a wider range of experience while still a graduate student. He encouraged me to not only grow as a numerical modeler, but also as an instructor and an independent thinker. I am not sure many graduate students are given the opportunity to develop their own individuality and self-sufficiency by being allowed to work with such independence. I thank you for that.

I also would like to gratefully and sincerely thank Dr. Reinaldo Garcia, who was my greatest help on the model development and computer programming. His genuine guidance, good nature, and down-to-earth humility has made it possible to complete this artwork and I am truly fortunate to have had the opportunity to work with him.

In similar vein, I would like to express my deep appreciation and gratitude to Dr. Assefa Melesse, Dr. Rene Price, Dr. Rosanna Rivero, Dr. Leonard Scinto, and Dr. Shimon Wdowinski, members of my committee, for their support and contribution into fieldwork, data collection, and remote sensing part of my dissertation. Without their help, it was impossible to achieve my objectives. I would like to spatially thank Dr. Shimon Wdowinski for his assistance and guidance in getting my first paper started. In addition to my committee members, I would like to thank Eric Cline and Dr. Fred Sklar for their help and support in providing guidance in fieldwork and data collection, and would like to acknowledge Dian Johnson, Pam Sullivan, David Lagomasino, Nicole 
Tucker, Sepideh Kazemi, and the rest of members of Biogeochemistry Lab at Florida International University.

Finally, and most importantly, I would like to thank my husband and my daughter for their infinite support, encouragement, quiet patience and love over the past five years. Their tolerance of my occasional rough moods is a proof of their unyielding devotion and love. I thank my parents, for their faith in me and for allowing me to be as ambitious as I wanted my entire life.

My dissertation research was made possible thanks to funding from the Southeast Environmental Research Center (SERC), the National Aeronautics and Space Administration's (NASA) Water Science of Coupled Aquatic Processes in Ecosystems from Space (WaterSCAPES) Program, the department of Civil and Environmental engineering, and the Department of Earth and Environment at Florida International University (FIU). 


\begin{abstract}
OF THE DISSERTATION
NUMERICAL MODELING OF THE EFFECTS OF HYDROLOGIC CONDITIONS

AND SEDIMENT TRANSPORT ON GEOMORPHIC PATTERNS IN WETLANDS
\end{abstract}

\author{
by \\ Mehrnoosh Mahmoudi \\ Florida International University, 2014 \\ Miami, Florida

\section{Professor Fernando Miralles-Wilhelm, Major Professor}

This dissertation focused on developing a numerical model of spatial and temporal changes in bed morphology of ridge and slough features in wetlands with respect to hydrology and sediment transport when a sudden change in hydrologic condition occurs. The specific objectives of this research were: (1) developing a two-dimensional hydrology model to simulate the spatial distribution of flow depth and velocity over time when a pulsed flow condition is applied, (2) developing a process-based numerical model of sediment transport coupled with flow depth and velocity in wetland ecosystems, and (3) use the developed model to explore how sediment transport may affect the changes in bed elevation of ridge and slough landscape patterns observed in wetlands when a conditional pulsed flow was applied. The results revealed the areas within deep sloughs where flow velocities and directions change continuously. This caused enhanced mixing areas within the deep slough. These mixing areas may have had the potential to affect processes such as sediment redistribution and nutrient transport. The simulation results of solute/sediment transport model also supported the existence of areas within the domain where the mixing processes happened. These areas may have caused that 
nutrients and suspended particles stay longer time rather than entraining toward downstream and exiting the system. The results of bed simulation have shown very small magnitude of change in bed elevation inside deep slough and no changes on the ridge portion of the study area, when a conditional pulsed flow is applied. These findings may suggest that implementing pulsed flow condition did not increase suspended sediment concentration, which results in insignificant changes in bed morphology of a ridge and slough landscape. Therefore sediment transport may not play an important role in wetland bed morphology and ridge and slough stability. Results from the model development and numerical simulations from this research will provide an improved understanding of how wetland features such as ridge may have formed and degraded by changes in water management that resulted from increasing human activity in wetlands such as The Florida Everglades, over the past decades. 


\section{TABLE OF CONTENTS}

CHAPTER

PAGE

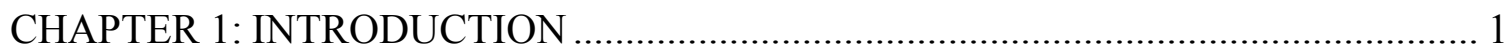

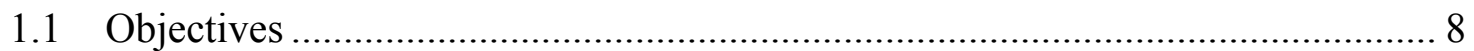

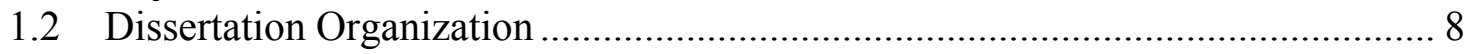

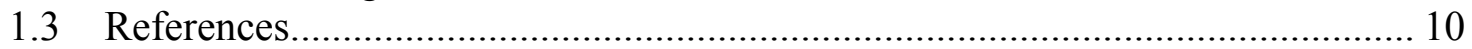

\section{CHAPTER 2: HIGH RESOLUTION TWO-DIMENSIONAL MODELING OF FLOW} PULSE DISCHARGES INTO WETLANDS...................................................... 12

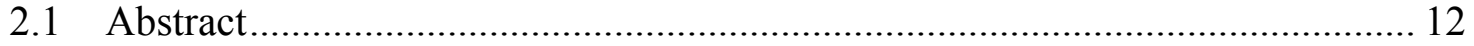

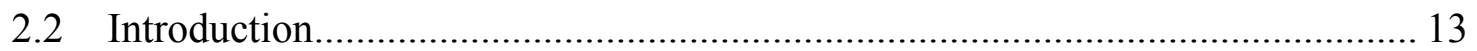

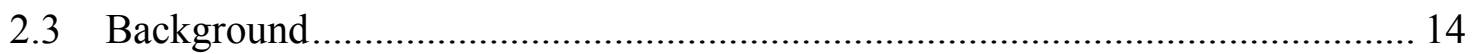

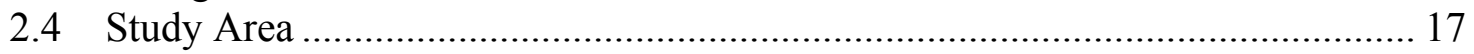

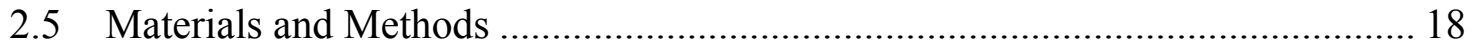

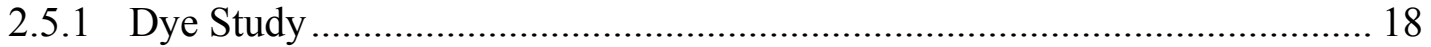

2.5.2 FLO-2D Model Description .................................................................. 20

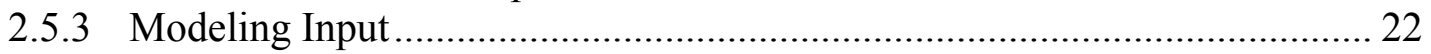

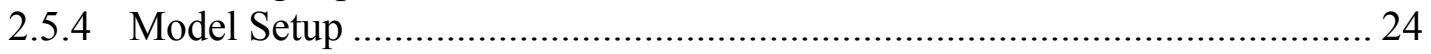

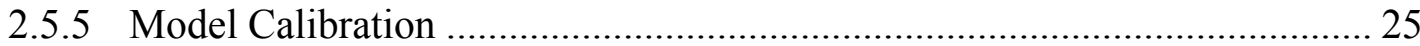

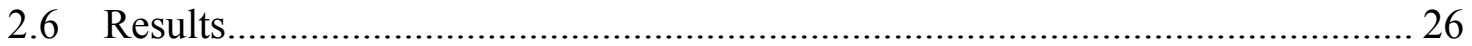

2.6.1 Model Application 1: Dye Study Flow Condition ........................................ 26

2.6.2 Model Application 2: High Intensity Pulsed Flow Condition........................ 27

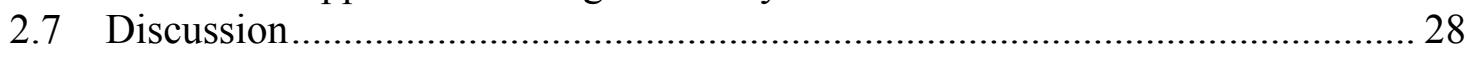

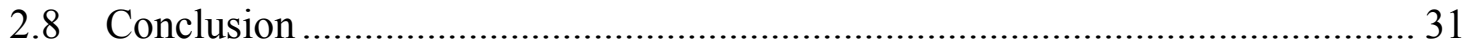

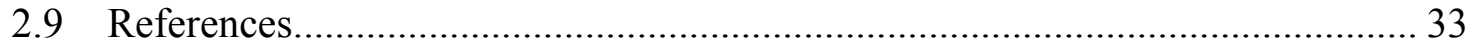

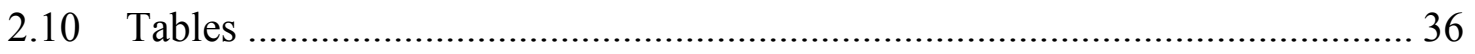

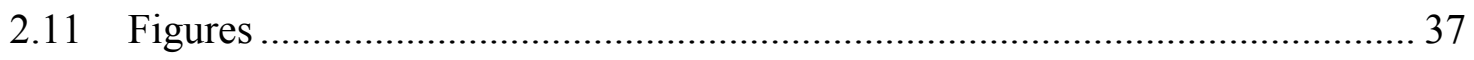

CHAPTER 3: NUMERICAL MODELING OF SOLUTE TRANSPORT IN WETLANDS: QUALITATIVE APPROACH TO A TRACER TEST AT THE LOXAHATCHEE IMPOUNDMENT LANDSCAPE ASSESSMENT (LILA) SITE .... 49

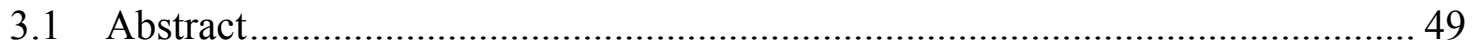

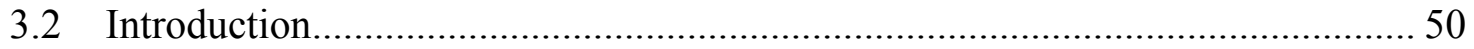

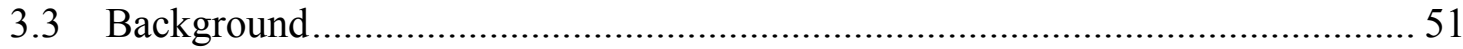

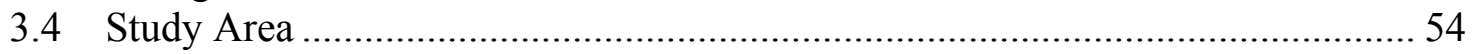

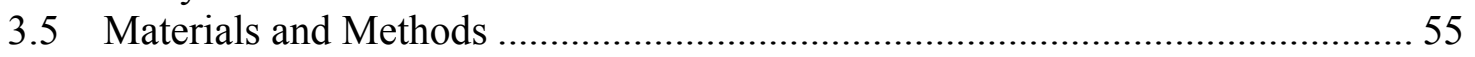

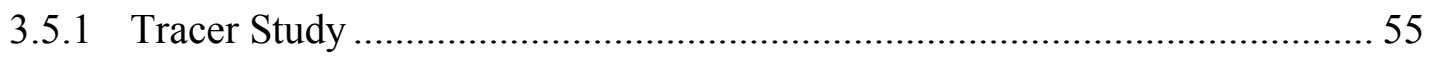

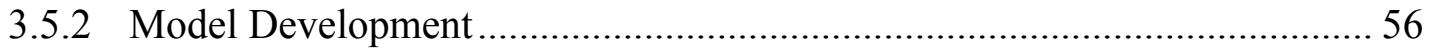

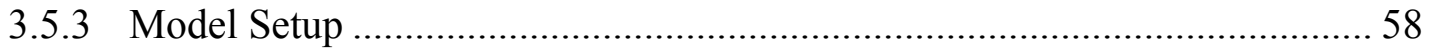

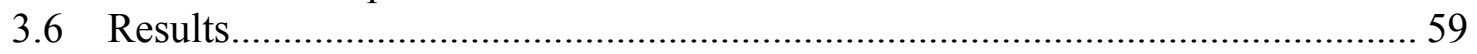

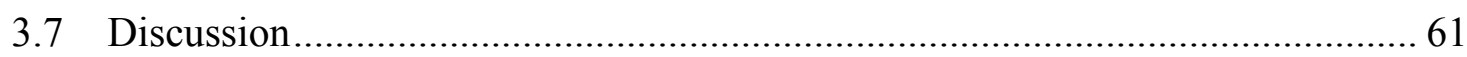

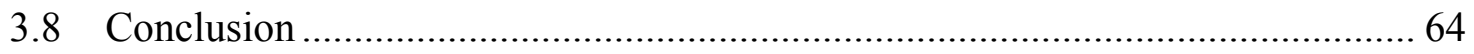

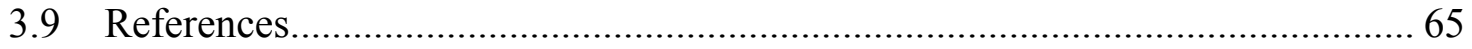




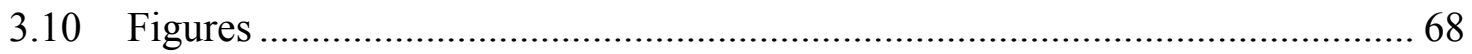

CHAPTER 4: NUMERICAL MODELING OF SEDIMENT TRANSPORT IMPACTS ON SPATIOTEMPORAL VARIATION OF BED MORPHOLOGY IN WETLANDS: CASE STUDY IN THE LOXAHATCHEE IMPOUNDMENT LANDSCAPE

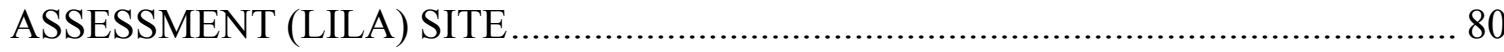

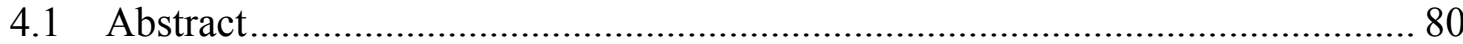

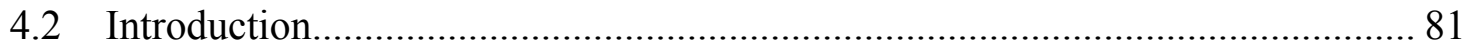

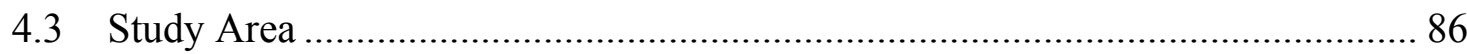

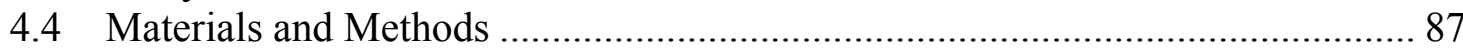

4.4.1 Numerical Model Development ............................................................. 87

4.4.2 Pulsed Flow in LILA ................................................................................ 91

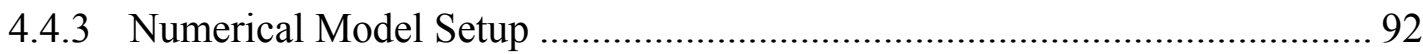

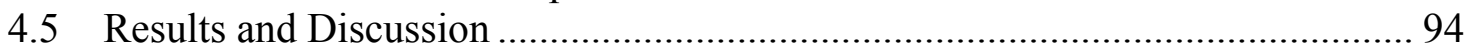

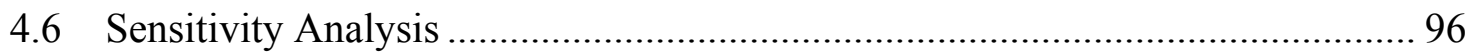

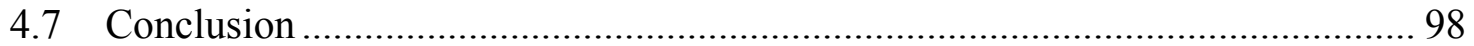

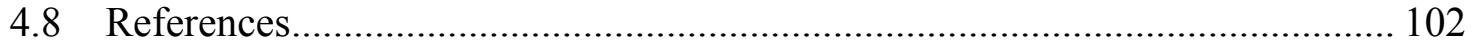

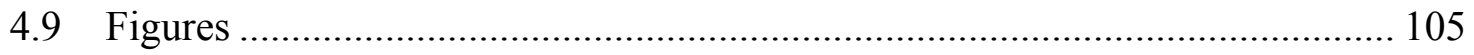

CHAPTER 5: SUMMARY AND CONCLUSION .................................................... 116

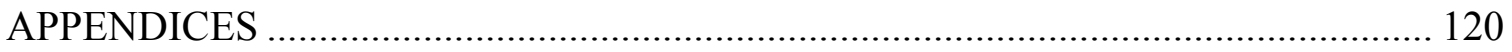

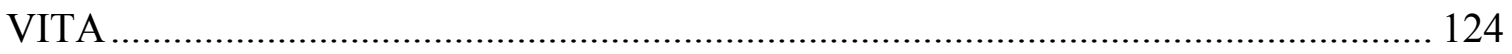




\section{LIST OF FIGURES}

FIGURE

PAGE

Fig. 2.1: (a) LILA location at the eastern boundary of WCA-1. The location with respect to southern Florida is shown in the insert. (b) Air plot showing the four macrocosms of LILA

Fig. 2.2: $\quad$ landscape features in LILA-M2

Fig. 2.3: Air photo showing macrocosm 2 (M2), grid system, cross section, and inflow/outflow locations.

Fig. 2.4: $\quad$ M2 inflow (a) and outflow (b) hydrograph

Fig. 2.5:

Areal images of dye study overlaid on areal image of the study area: (a) 25 mins, (b) $1 \mathrm{hr}$, (c), $2 \mathrm{hrs,} \mathrm{(d)} 3 \mathrm{hrs,}$ (e), $4 \mathrm{hrs}$, (f) $5 \mathrm{hrs}$, (g) $6 \mathrm{hrs}$, (h) $7 \mathrm{hrs}$. White lines in (a), (c), and (h) are the result of the overlaying dye images in Arc Map

Fig. 2.6:

Approximate location of projected dye head from hourly areal photos and ADVs location. Red dots represent dye head.

Fig. 2.7: $\quad$ FLO-2D discharge directions at element

Fig. 2.8: $\quad$ M2 ground elevation contours

M2 Manning's roughness coefficient distribution driven from vegetation map

Fig. 2.10: $\quad$ Simulation results of water surface elevation for dye experiment at: (a) before pulse and dye release, (b) 5 mins after opening culvert, (c) 12 mins after pulse, (d) 30 mins after pulse. No change in water surface elevation is detected at the area near to inflow discharge.

Fig. 2.11: Dye study hydrology simulation results. Left column represents water surface elevation after (a) $1 \mathrm{hr}$, (b) $3 \mathrm{hrs}$, (c) $5 \mathrm{hrs}$, (d) $7 \mathrm{hrs,} \mathrm{and} \mathrm{right} \mathrm{column} \mathrm{illustrates}$ velocity vectors after (e) $1 \mathrm{hr}$, (f) $3 \mathrm{hrs}$, (g) $5 \mathrm{hrs}$, (h) 7 hrs. Red circles indicate the mixing zones within the deep slough 
Fig. 2.12: $\quad$ Increase in depth of water when 1-hour pulsed flow discharge of $3 \mathrm{~m}^{3} / \mathrm{s}$ is applied at inflow culvert. Each image shows water flows after (a) 2 mins, (b) 10 mins, (c) 15 mins, and (d) 30 mins of pulse implementation

Fig. 2.13: $\quad$ Velocity vector when 1-hr pulse condition with $3.0 \mathrm{~m}^{3} / \mathrm{s}$ discharge magnitude is applied after (a) 2 mins, (b) 10 mins, (c) 15 mins, and (d) 30 mins.

Fig. 2.14: $\quad$ Depth results from FLO-2D at locations 1, 4, 8, 13, and 15 (Fig. 2.6). It shows slight increase of $1.0 \mathrm{~cm}$ in water depth at these locations.

Fig. 3.1: $\quad$ (a) LILA location at the eastern boundary of WCA-1. The location with respect to southern Florida is shown in the insert. (b) Air plot showing the four macrocosms of LILA

Fig. 3.2:

Air photo of M2 in LILA site, showing the main landscape features

Fig. 3.3: $\quad$ Finite Difference Upwinding discretization. Flow can enter or exit an element in both horizontal and vertical dimension. Elements are rectangular with length and width of $\Delta \mathrm{x}$ and $\Delta \mathrm{y}$ respectively.

Fig. 3.4: $\quad$ Air photo showing macrocosm 2 (M2), grid system, and inflow/outflow locations

Fig. 3.5: Areal photo of M2 showing the observed (a) and simulated (b) of the dye transport 25 minutes after dye injection

Fig. 3.6: Dye transport, one hour after injection, a) areal photo, b) simulated results

Fig. 3.7: Dye transport, 2 hours after injection, a) areal photo, b) simulated results

Fig. 3.8: $\quad$ Dye transport, 3 hours after injection

Fig. 3.9:

Dye transport, 4 hours after injection

Fig. 3.10:

Dye transport, 5 hours after injection 77

Fig. 3.11: $\quad$ Dye transport, 6 hours after injection 
Fig. 3.12: $\quad$ Dye transport, 7 hours after injection

Fig. 4.1: The Everglades wetland boundary (yellow polygon) in South Florida. It starts from Orlando and ends at Florida Bay

Fig. 4.2: Ridge and Slough of the Everglades photographed by: Robert Sobczak (www.gohydrology.org)

Fig. 4.3: $\quad$ Cross section schematic of ridge and slough illustrating the elevation difference between top of a ridge and bottom of a slough $(\Delta \mathrm{h})$

Fig. 4.4:

(a) LILA location at the eastern boundary of WCA-1. The location with respect to southern Florida is shown in the insert. (b) Air plot showing the four macrocosms of LILA

Fig. 4.5: $\quad$ LILA features

Fig. 4.6: $\quad$ Erosion-deposition proportionality factor $(\mathrm{F})$ relation with erosion and velocity (Lago et al., 2010)

Fig. 4.7: $\quad$ Pulsed flow condition imposed at inflow location in LILA macrocosm 2

Fig. 4.8: $\quad$ Air photo showing macrocosm 2 (M2), grid system, and inflow/outflow locations

Fig. 4.9: Changes in bed elevation during normal flow conditions

Fig. 4.10: $\quad$ Changes in bed elevation when an 8-hour pulsed flow condition is applied

Fig. 4.11: Results of simulation with various Resuspension rate while Proportionality factor and vegetation filtration is zero. (1) $\varepsilon_{\text {res }}=2.0 \times 10^{-11} \mathrm{Kg} / \mathrm{m}^{2} \mathrm{~s}$, (2) $\varepsilon_{\text {res }}=2.0 \times 10^{-9}$ $\mathrm{Kg} / \mathrm{m}^{2} \mathrm{~s}$, (3) $\varepsilon_{\text {res }}=2.0 \times 10^{-6} \mathrm{Kg} / \mathrm{m}^{2} \mathrm{~s}$, (4) $\varepsilon_{\text {res }}=2.0 \times 10^{-}$ ${ }^{5} \mathrm{Kg} / \mathrm{m}^{2} \mathrm{~s}$

Fig. 4.12: $\quad$ Changes in Proportionality Factor while Resuspension and vegetation filtration are zero. (1) $F=1.5 \times 10^{-11}$ $\mathrm{Kg} / \mathrm{m}^{2} \mathrm{~s}$, (2) $F=1.5 \times 10^{-10} \mathrm{Kg} / \mathrm{m}^{2} \mathrm{~s}$, (3) $F=1.5 \times 10^{-9}$ $\mathrm{Kg} / \mathrm{m}^{2} \mathrm{~s}$ 
Fig. 4.13: The effect of vegetation filtration factor. (1) $F=0.0, \varepsilon_{\text {res }}$ $=2.0 \times 10^{-5} \mathrm{Kg} / \mathrm{m}^{2} \mathrm{~s}, \Phi=3 \times 10^{-11} \mathrm{~s}^{-1}$ (2) $F=1.5 \times 10^{-}$

${ }^{10} \mathrm{Kg} / \mathrm{m}^{2} \mathrm{~s}, \varepsilon_{\text {res }}=2.0 \times 10^{-5} \mathrm{Kg} / \mathrm{m}^{2} \mathrm{~s}, \Phi=3 \times 10^{-11} \mathrm{~s}^{-1}$ 


\section{CHAPTER 1: INTRODUCTION}

Wetlands have been historically drained for land development, recreational, and agricultural purposes. It is believed that in the 1600 s, over 220 million acres of wetlands existed in the United States and more than half has been lost since then (US Environmental Protection Agency). According to the US Environmental Protection Agency (EPA), major wetland loss and degradation has happened from the mid-1950 till the mid-1970 as a result of human actions (e.g., drainage, channelization, levees construction, and excess nutrient) and natural threat (e.g., erosion, sea level rise, hurricanes, and droughts). Results of these extensive losses appear as degradation of wetland features such as ridge and slough and tree islands which impact ecology, biology, biodiversity, and health of these sensitive ecosystems. An example of such degradation is seen in the Everglades wetland in southern Florida where degradation is evidenced as loss of sloughs and their connectivity in areas exposed to changes in hydrology driven by water management practices. Understanding the mechanisms involved in ridge and slough landscape formation, stability, and maintenance is crucial in restoration efforts. Therefore comprehensive studies and investigations are needed to interpret the different interacting mechanisms.

Wetlands around the world exhibit various spatial patterning in the form of hummocks and hollows, and maze and patterning (Sakaguchi, 1980; Belyea and Lancaster, 2002). In low gradient wetlands, spatial patterns in vegetation distribution are found as formations 
parallel (longitudinal) or perpendicular to the flow, such as string patterns (Foster et al., 1983). These consist of regular densely vegetated bands (hummocks forming ridges); alternating with lower/wetter zones that are less vegetated (hollows forming sloughs). Examples of wetlands with longitudinal patterning include the ridge and slough landscape of the Florida Everglades (Ogden, 2005; Larsen et al., 2007), the Okavango Delta located in Botswana (Ellery et al., 2003; Gumbricht et al., 2004), the Llanos in Venezuela and Colombia (San Jose et al., 2001), the Brazilian Pantanal (Silva et al., 2000), and the Sian Ka'an coastal wetlands in the Yucatan peninsula of Mexico (Querejeta et al., 2007). In these wetlands, ridges with trees or herbaceous vegetation are scattered among open-water conduits, i.e., sloughs, aligned parallel to the regional flow direction.

On the basis of the previous studies, four mechanisms are found to contribute to wetland pattern formation and maintenance: 1) peat accumulation, 2) water ponding, 3) nutrient accumulation, and 4) sediment transport. Eppinga et al. (2009) combined the first three mechanisms to simulate the spatial interaction between vegetation, peat elevation, nutrient and hydrology in both flat ground and sloped peatland. Their model explicitly links spatial surface patterning to underlying patterns in nutrients and hydrology for different structuring mechanisms. By switching on/off each mechanism, they devise a tool which allows seeing how these mechanisms affects surface patterning and underlying patterns in nutrients and hydrology. Their results reveal that different combinations of structuring mechanisms lead to similar types of peatland surface patterning, but contrasting underlying patterns in nutrients and hydrology. This model 
not only generates hummock-hollow and maze patterns of vegetation distribution on flat ground but also produces linear patterns on peatland slopes that are parallel to each other and perpendicular to the slope direction. However, their model does not reproduce lateral growth of peatland because of the fixed extent for peatland area as one of its initial assumption. Also, the model does not include sediment transport as the possible mechanism contributing to lateral growth.

In a recent study, Watts et al. (2010) hypothesized that interactions between hydrologic conditions, plant composition, production and respiration create peat accretion at point scales while spatial interaction between patches create regular patterns at landscape scales. Using a simple model formulation, they were able to predict that 1) soil elevation is bimodal, 2) there is a positive autocorrelation at short distance and negative values at long distance, 3) strong anisotropy and self-organization, 4) there is loss of ridge and slough patterns as a result of hydrologic modification. Their results show that under bestconserved hydrologic conditions, which resemble the Everglades historic hydrology, ridge and slough landscape elements reflect multiple elevation equilibria generated by feedback among site vegetation (which affects primary production), soil elevation (which affects respiration), and local hydrology. They suggests that because soil elevation is independent of underlying geology (Lewis, 2005; Givnish et al., 2008), ridges and sloughs should be viewed as discrete self-organized ecosystem states that control local elevation (and thus hydrology), not simply as vegetation assemblages. 
Lago et al. (2010) simulated the interaction between water flow, sediment transport (erosion and deposition), vegetative litter production and decomposition, and dynamic soil accretion processes using a simple numerical model, and investigated whether these feedbacks could explain the observed landscape features and their long-term stability. Results of this model show a self-organizing soil depth variation and increasing pattern contrast (difference between the minimum and the maximum soil depths) over time, which indicates spatial and temporal evolution of landscape in the direction of regional flow. These results resemble ridge and slough features of the Everglades. Lago et al. (2010) also found that lateral growth of ridges and sloughs as the result of lateral vegetation growth by production, is a major factor controlling spatial and temporal pattern development by enhancing sediment deposition in ridge areas, and increasing sediment erosion in slough areas.

The Science Coordination Team (2003) hypothesized that sediment transport and redistribution from slough to ridges is the key mechanisms that controls initial formation and maintenance in ridge and slough. However, some may disagree with the above hypothesis because of specific characteristics and behavior of existing peat and suspended sediment in ridge and slough features over period of time. Nonetheless this complex mechanism and its effectiveness toward ridge and slough formation and stability has not been fully understood or developed nor has the effect of pulsed flow on sediment spatial distribution been studied. 
Larsen et al. (2009) developed a series of state-space diagram derived from a field validated numerical model to predict the required bed shear stress for sediment redistribution in different vegetation community. Their laboratory results indicate that increasing flow velocity by management decision alone cannot provide the necessary shear stress and a series of pulse loads are needed to maintain the sediment redistribution. Although their model can predict shear stress and sediment redistribution potential in different vegetation communities, it does not explore the effect of spatial distribution of suspended sediment particles on changes in bed morphology during a pulsed load condition.

Noe et al. (2009) also tested the sediment redistribution hypothesis by measuring the concentration and characteristics of suspended sediment and its associated nutrients in the flow paths of adjacent ridge and slough plant communities in the Everglades, Water Conservation Area 3 (WCA3). Their experimental findings indicate that spatial and temporal variations in suspended sediment are not related to water velocity because low flow velocity in WCA3 because of present-day managed Everglades does not create necessary sheer stress for sediment entrainment, which will lead to further degradation of ridge and slough geomorphology and vegetation in the future.

Larsen and Harvey (2010) studied the effect of vegetation and sediment transport feedbacks on landscape changes in the Everglades by a process-based numerical modeling. They hypothesized that emergent vegetation promotes sediment accumulation through differential peat accretion and sedimentation, which will increase emergent 
vegetation growth. Their model was developed following a cellular automata approximation on a steady state flow regime with a one-year of time step, and sediment transport for a long period of 2700 years. On the basis of a series of sensitivity tests, they describe that peat accretion and sediment transport are primary drivers of ridge and slough stability and maintenance. However, there are several uncertainties on their modeling approximations. As a consequence of the exceedingly large time step they use to allow long-term simulations, their model may not account for short-term events or an implemented conditional pulsed flow that could impact sediment transport, deposition/erosion patterns and further landscape evolution.

In a recent study, Min et al. (2010) explain spatial distribution of surface water flow in the Everglades ridge and slough landscape by developing a two dimensional spatially distributed flow dynamics model which was used in an area of $1.5 \mathrm{~km} \times 4 \mathrm{~km}$ located in WCA 3 where the most preserved ridge and slough exists. Results of their model simulation indicate significant seasonal difference in hydraulic resistance for ridge and slough suggesting more sediment transport during wet seasons. However, their model neither accounts for a pulsed condition nor simulates sediment transport.

Most of the previous modeling attempts to describe mechanisms involved in wetland patterning and ridge and slough formation and stability have focused on hydrology, nutrient, and vegetation biomass components depend on both physical and field data while not considering sediment transport and its influence on landscape patterning. Moreover, the impact of pulsed flow on spatial distribution of sediment distribution has 
not been considered in previous studies. Simulating sediment transport and erosion/deposition would contribute to better understand how sediment transport and spatial distribution of sediments might affect the ridge and slough landscape evolution, stability and maintenance throughout time.

In this dissertation, it is hypothesized that:

1. Sediment transport plays a significant role on ridge and slough landscape evolution and maintenance in wetlands.

2. Implementing pulsed flow conditions could improve sediment transport, which may directly be responsible for changes in bed elevation that lead to pattern formation.

Therefore, the present dissertation focuses on development, testing, and application of a numerical model that 1) quantifies water depth and velocity distribution through landscape patterns when a sudden pulsed flow occurs, 2) simulates spatial distribution of suspended sediment during the pulsed condition, and 3) estimates changes in bed elevation in a wetland with low topographic gradients, as a function of water flow and sediment transport. Results and insight gained from this research can provide an improved mechanistic understanding of how landscape patterns such as ridges and sloughs may have formed, developed, and affected by changing water management practices. 


\subsection{Objectives}

The present $\mathrm{PhD}$ dissertation focuses on the following objectives:

- Developing a two-dimensional hydrology model using FLO-2D

- Development of a physically based numerical model of sediment transport and bed erosion and deposition as an extension of the hydrology model

- Gather data (e.g. flow depth and velocity, suspended sediment concentration, bed elevation, etc.) from field and use these data to compare with simulated results.

- Perform a sensitivity analysis to understand how landscape morphology responds to variations in environmental conditions (e.g., flow velocity and depth, topography gradient, suspended sediment concentration, etc.).

\subsection{Dissertation Organization}

The rest of this dissertation is organized as follows: Chapter 2 (submitted to journal of Hydrologic Engineering) presents development of a two-dimensional hydrology model that describes spatiotemporal changes in flow velocity and depth during an implemented pulsed flow condition in study area which is located at the Loxahatchee Impoundment Landscape Assessment (LILA) located in Boynton Beach, Florida.

Chapter 3 (submitted to International Journal of Computational Methods and Experimental Measurements) describes the development of a solute transport model in two dimensions that is used to simulate the spatial distribution of a solute concentration during a conditional pulsed flow in the study area. The model is applied to a tracer test 
study conducted at the LILA study area. The flow field for solute transport is generated by the hydrology model described in Chapter 2 .

Chapter 4 (to be submitted to Journal of Ecohydrology) provides the details of how the transport model is used to develop a two-dimensional numerical model of sediment transport and bed elevation that explains the spatial and temporal variation in bed elevation when a conditional pulsed flow is implemented. The developed model is applied to the LILA study area to simulate the changes is bed morphology.

Finally, the dissertation concludes in Chapter 5 with a summary of the three main chapters and suggested future research paths in this area. 


\subsection{References}

Belyea, L. R., and Lancaster, J., 2002, Inferring landscape dynamics of bog pools from scaling relationships and spatial patterns: Journal of ecology, v. 90, no. 2, p. 223234.

Ellery, W. N., McCarthy, T. S., and Smith, N. D., 2003, Vegetation, hydrology, and sedimentation patterns on the major distributary system of the Okavango Fan, Botswana: Wetlands, v. 23, no. 2, p. 357-375.

Eppinga, M. B., de Ruiter, P. C., Wassen, M. J., and Rietkerk, M., 2009, Nutrients and hydrology indicate the driving mechanisms of peatland surface patterning: Am Nat, v. 173 , no. 6 , p. $803-818$.

Foster, D., King, G., Glaser, P., and Wright, H., 1983, Origin of string patterns in boreal peatlands.

Givnish, T. J., Volin, J. C., Owen, V. D., Volin, V. C., Muss, J. D., and Glaser, P. H., 2008, Vegetation differentiation in the patterned landscape of the central Everglades: importance of local and landscape drivers: Global Ecology and Biogeography, v. 17, no. 3, p. 384-402.

Gumbricht, T., McCarthy, J., and McCarthy, T., 2004, Channels, wetlands and islands in the Okavango Delta, Botswana, and their relation to hydrological and sedimentological processes: Earth Surface Processes and Landforms, v. 29, no. 1, p. 15-29.

Lago, M. E., Miralles-Wilhelm, F., Mahmoudi, M., and Engel, V., 2010, Numerical modeling of the effects of water flow, sediment transport and vegetation growth on the spatiotemporal patterning of the ridge and slough landscape of the Everglades wetland: Advances in Water Resources, v. 33, no. 10, p. 1268-1278.

Larsen, L. G., and Harvey, J. W., 2010, How vegetation and sediment transport feedbacks drive landscape change in the Everglades and wetlands worldwide: The American Naturalist, v. 176, no. 3, p. E66-E79.

Larsen, L. G., Harvey, J. W., and Crimaldi, J. P., 2007, A Delicate Balance: Ecohydrological Feedbacks Governing Landcape Morphology in a Lotic Peatland: Ecological Monographs, v. 77, no. 4, p. 591-614.

Larsen, L. G., Harvey, J. W., and Crimaldi, J. P., 2009, Predicting bed shear stress and its role in sediment dynamics and restoration potential of the Everglades and other vegetated flow systems: Ecological Engineering, v. 35, no. 12, p. 1773-1785. 
Lewis, C. G., 2005, Linkages among vegetative substrate quality, biomass production, and decomposition in maintaining Everglades ridge and slough vegetative communitiesMaster Thesis]: University of Florida.

Min, J.-H., Paudel, R., and Jawitz, J. W., 2010, Spatially distributed modeling of surface water flow dynamics in the Everglades ridge and slough landscape: Journal of Hydrology, v. 390, no. 1-2, p. 1-12.

Noe, G. B., Harvey, J. W., Schaffranek, R. W., and Larsen, L. G., 2009, Controls of Suspended Sediment Concentration, Nutrient Content, and Transport in a Subtropical Wetland: Wetlands, v. 30, no. 1, p. 39-54.

Ogden, J. C., 2005, Everglades ridge and slough conceptual ecological model: Wetlands, v. 25 , no. 4 , p. $810-820$.

Querejeta, J. I., Estrada-Medina, H., Allen, M. F., and Jiménez-Osornio, J. J., 2007, Water source partitioning among trees growing on shallow karst soils in a seasonally dry tropical climate: Oecologia, v. 152, no. 1, p. 26-36.

Sakaguchi, Y., 1980, On the genesis of banks and hollows in peat bogs: an explanation by a thatch line theory: Bulletin of the department of Geography University of Tokyo, v. 12, p. 35-58.

San Jose, J., Meirelles, M., Bracho, R., and Nikonova, N., 2001, A comparative analysis of the flooding and fire effects on the energy exchange in a wetland community (Morichal) of the Orinoco Llanos: Journal of Hydrology, v. 242, no. 3, p. 228254.

Science Coordination Team, S. F. E. R. W. G., 2003, The role of flow in the Everglades ridge and slough landscape: USGS.

Silva, M. d., Mauro, R., Mourao, G., and Coutinho, M., 2000, Distribuição e quantificação de classes de vegetação do Pantanal através de levantamento aéreo: Revista Brasileira de Botânica, v. 23, no. 2, p. 143-152.

Watts, D. L., Cohen, M. J., Heffernan, J. B., and Osborne, T. Z., 2010, Hydrologic Modification and the Loss of Self-organized Patterning in the Ridge-Slough Mosaic of the Everglades: Ecosystems, v. 13, no. 6, p. 813-827. 
CHAPTER 2: HIGH RESOLUTION TWO-DIMENSIONAL MODELING OF FLOW PULSE DISCHARGES INTO WETLANDS

\subsection{Abstract}

Wetland ecosystems are controlled by their hydrology. Recent experimental and numerical investigations have suggested that flow pulses are needed to preserve sediment redistribution in some wetlands. In this study, we investigate the effect of pulsed flow conditions on the hydrologic regime of low-gradient densely vegetated wetlands using a fine resolution, two-dimensional depth-averaged numerical flow model. The model was applied to simulate flow depth and velocity within the Loxahatchee Impoundment Landscape Assessment (LILA) wetland located in Boynton Beach, Florida. Two pulsed flow conditions with low pulse and high pulse flow magnitude were considered. The simulation results of low pulse flow conditions reveal the areas within deep sloughs where flow velocities and directions change continuously, creating enhanced mixing areas within the deep slough. These mixing areas may have the potential to affect processes such as sediment redistribution and nutrient transport. Simulation of high pulse flow magnitude however results in more uniform flow velocity inside deep slough. It also indicates that a pulse can only be detected when inflow discharge is at least $3.0 \mathrm{~m}^{3} / \mathrm{s}$. Lower inflow discharge values are too weak in magnitude to generate substantial changes in water surface elevation and velocity and they may not exhibit flow wave propagation into the study area. 


\subsection{Introduction}

Wetlands are heterogeneous ecosystems characterized by unique biodiversity, hydrology, spatial variability of vegetation types and densities, and landscape patterns (Bolster and Saiers, 2002). The Everglades in South Florida is one the largest subtropical wetlands in the world. Its landscape patterns range from hammocks-and-hollows to ridges and sloughs to tree islands. Because of rapid population growth and urbanization, and increase in flood control and agricultural land use in South Florida, degradation of natural landscape features such as ridges in areas exposed to changes in hydrology driven by water management practices has been observed.

Previous studies found that hydrology is one of the key factors controlling wetland landscape patterning (Swanson and Grigal, 1988; Rietkerk et al., 2004; Noe et al., 2007; Lago et al., 2010). Therefore, an improved understanding of wetland hydrology is key in determining conditions for landscape morphology sustainability. Larsen et al. (2009) showed that increase flow velocity by management decisions alone cannot provide the necessary hydrologic conditions to stabilize landscape patterning, and that induced pulsed flow loading is necessary. The effect of natural and induced pulsed flow conditions on wetland's hydrology received limited attention by previous studies.

The objective of the present study is to investigate the effect of induced pulsed flow conditions on the hydrology regime in wetlands. In our study, a two-dimensional vertically-averaged (FLO-2D) model formulation (Garcia and Kahawita, 1986; O'Brien et al., 1993) was adopted and applied to simulate the spatiotemporal variation of flow depth 
and velocity in a study area located within the Loxahatchee Impoundment Landscape Assessment (LILA) in Boynton Beach, Florida (Fig. 2.1).

The model development and numerical simulations provide an improved understanding of how wetland surficial (sheet) flow may respond to various inflow conditions and whether creating pulsed flow scenarios through water management can improve ridge and slough restoration. These modeling results can further be used to simulate transport of suspended sediments in the study area and investigate the effect of suspended sediment transport on spatial and temporal distribution of bed elevation in the areas dominated by landscape patterns such as ridge and slough of the Everglades.

\subsection{Background}

Hydrological models of wetland surface flow fall into two categories: they are either used as water inventory (budgeting) tools, such as in the case of ecological and regional ecosystem models, or used to simulate runoff and stream flow as input to hydrodynamic transport models for water quality applications (Hammer and Kadlec, 1986). A few highresolution, two-dimensional (2D areal) models have been developed to simulate surficial water flow in wetlands where flow depth and velocity are highly affected by dense vegetation coverage and low topographic gradients. Hammer and Kadlec (1986) developed a one-dimensional surface hydrology model that can be used to predict wetland water depth when short-term rainfall events occur. Their model was tested in a constructed wetland with coarse grids and estimated ground surface elevation. Their 
findings show that topography and ground surface gradients of the study area have significant influence on modeling results and predicting flow velocity and water depth. However, their findings only covered the comparison between simulated and measured results of water depth and elevation and no comparison was made on flow velocity.

The Receiving Water Quantity (RWQ) Model is part of the Storm Water Management Model (SWMM, EPA 1971) that was modified to describe the flow regime in Water Conservation Areas (WCAs) in South Florida when additional inflow under backpumping scenarios occurs (Lin and Shih, 1979). It combines Monte Carlo techniques with RWQ and uses the concept of dual elevation in a network of hypothetical channels. The model discretizes the study domain (WCAs) into nodes and triangular grids, and then generates time series of flow depth and velocity at any selected locations inside the study domain.

The South Florida Water Management Model (SFWMM) is a regional-scale hydrologic model developed specifically for South Florida in the early 1970s (MacVicar et al., 1984). It is derived from the diffusive wave approximation and Manning equation on two-by-two miles square grids that cover 7600 square miles of South Florida from Lake Okeechobee to Florida Bay. The SFWMM is coupled with a groundwater model that accounts for a two-dimensional single layer aquifer. The model is widely used to predict the long-term response of the Everglades system to changes in hydraulic structures, operational scenarios and management decisions. 
The Natural System Model (NSM) is a two dimensional model that was developed by the South Florida Water Management District. It simulates integrated surface water and groundwater hydrology and estimates surface flow for a hypothetical and more natural system of the Everglades National Park (ENP) and WCAs, with no hydraulic control structures (e.g., canals, levees, pumps, etc.) by using calibrated data and parameters from the SFWMM developed for the today's managed system in order to evaluate the efficacy of restoration plans.

The Hydrologic Simulation Engine (HSE) is a finite-volume model that was developed to simulate groundwater and overland flow in the Everglades national Park (Lal et al., 1998). The model solves the diffusion wave and Manning's equations for surface flow and Darcy's equation for groundwater flow. Bolster and Saiers (2002) suggest that the diffusion model is appropriate for describing sheet flow over vegetated surfaces. They developed a two-dimensional nonlinear diffusive model that relates flow velocity and water depth with a simplified power-law equation. Their model predicts large scales spatial and temporal changes in surface water levels and it was tested in Shark River, a portion of the Everglades that contains ridge and slough patterning.

The U.S. Geological Survey has developed Tides and Inflows in the Mangroves Ecotone (TIME) model to investigate the interaction between freshwater inflows and tidal forces in mangrove ecotone in south Florida (Schaffranek, 2001). This model is used to simulate flow and salinity through a coupled surface water/groundwater model in transition areas such as coastal zones. The model however, is uniquely developed to 
serve in coastal zone and it may not be applicable to wetlands that are located further inland away from tidal effects.

These previous hydrologic modeling studies focused on spatial scales ranging from large

areas $\left(\mathrm{a}\right.$ few $\mathrm{km}^{2}$ ) to regional; their framework requires numerical grid sizes larger than $300 \mathrm{~m}$ which limits their ability to be used for high resolution assessments in a smaller areas such as LILA. These models also require a large number of input parameters that may not be always feasible to obtain. To overcome these limitations, we have applied the FLO-2D model that is capable of modeling hydrology for detailed analyses where fine grid sizes are required (such as LILA). We use the results of this flow analysis to simulate sediment transport and bed elevation changes in the study area.

\subsection{Study Area}

Established in 2003, LILA is an area of 34 ha ( 80 acres) located at the Arthur R. Marshall Loxahatchee National Wildlife Refuge (LNWR), so-called Water Conservation Area 1 (WCA1), in Boynton Beach, Florida (Fig. 2.1). It is an enclosed area divided into four sub-sections called macrocosms M1 through M4 with dimension of $200 \mathrm{~m}$ by $400 \mathrm{~m}$ (Science Coordination Team, 2003).

Each macrocosm consists of one ridge, one deep slough, two tree islands located inside the deep slough, and one shallow slough build to resembles the ridge and slough and tree island landscape features of the Everglades (Fig. 2.2). LILA also refers to "living 
laboratory" of the Everglades and it is a model of the Everglades ecosystem that gives researchers the opportunity to apply and test their restoration techniques in a smaller and controlled area before applying it in the Everglades.

Culverts are installed at each inflow and outflow locations, which allows controlling stages and flows at each macrocosm. Flow through LILA macrocosms is generated by a $1.1 \mathrm{~m}$ diameter electric axial flow submersible pump and is controlled by $0.9 \mathrm{~m}$ gated culverts at the inflows (western end) and $0.9 \mathrm{~m}$ culverts with stop logs at the outflows (eastern end). Two of the macrocosms are constant flowing systems (M2 and M4) whereas the other two are non-flowing cells (M1 and M3). Water depth and velocity in each macrocosm can be controlled independently to mimic the Everglades flow system and also makes it possible to conduct pulsed flow studies. For the purpose of this study, the flowing cell, M2, was selected as the study area to conduct pulsed flow experiments (Fig. 2.2).

\subsection{Materials and Methods}

\subsubsection{Dye Study}

The South Florida Water Management District (SFWMD) has studied surface flow patterns in the M2 cell at LILA by applying a two-dimensional Finite Element Surface Water Modeling System (FESWMS) model to the study area. The model was originally developed for the US Department of Transport Federal Highway Administration (FHWA) to perform hydraulic analysis of highway structures such as crossings, bridges, 
culverts, etc. for flow modeling and simulation in roads and highways vicinities (Froehlich, 1989). The developed model was calibrated by flow data registered by ADVs installed inside macrocosm during the dye test performed in 2007. Their results however show that FESWMS can just roughly capture the flow velocity trend registered by Acoustic Doppler Velocimeter (ADV). The authors also mention that the difference between simulated flow velocity results and ADVs might have been a consequence of overestimating velocity by ADVs. In our study however, we developed and applied the FLO-2D model to the study area and compared the results with the 2007 dye test (Scinto et al., 2009).

A tracer study was conducted on October 3, 2007 at LILA macrocosms M1 and M2. In both macrocosms, Intracid Rhodamine WT fluorescent dye was used to assess water flow patterns (Scinto et al., 2009). Approximately 19 L (5 gallons) of Rhodamine WT was injected over 20 minutes from 9:30 am to 9:55 am into the M2 through the headwater inlet culvert at inflow location (Fig. 2.3). Aerial photos were taken roughly every hour to provide visual record of the dye transport during this eight hours study. Flow through the culvert was registered at $0.38 \mathrm{~m}^{3} / \mathrm{s}(6000 \mathrm{gpm})$. However, an average flow rate of 0.34 $\mathrm{m}^{3} / \mathrm{s}$ was registered by the inlet ADV. We reconstructed the inflow hydrograph (water discharge as a function of time) derived from inflow conditions as well as the outflow hydrograph, which was registered by ADV located at M2 outlet. The reconstructed hydrographs were used as inflow and outflow hydrographs in the FLO-2D simulation. Fig. 2.4 illustrates the hydrographs used to simulate the conditions during the dye study. 
A total of 8 areal photos were taken during the dye study (Scinto et al., 2009). These images were used to validate the hydrology model. We georeferenced and prepared the images in GIS (Fig. 2.5). Each image was taken at a specific time. Within each image, the distance between dye head locations and injection point were measured and then the local velocities were calculated at each time. The dye traveling distance was measured by finding the distance form injection point to the dye leading edge of each snapshot in both sides of the tree islands. Fig. 2.6 shows the estimated locations of dye leading edge during the tracer experiment. Four additional ADVs were installed inside M2 at north and south of each tree island to register flow velocity during this experiment (Fig. 2.6).

\subsubsection{FLO-2D Model Description}

The FLO-2D model is a quasi two-dimensional physically based flood routing model that simulates surface flow depth and velocity on a variety of land surfaces from floodplains to urban areas including the presence of hydraulic structures and their operation (O'Brien et al., 1993). The FLO-2D model discretizes a domain into uniform square grid cells and computes the discharge across eight flow directions (four compass and four diagonal) as shown in Fig. 2.7. It models the progress of a flow hydrograph through the topographic domain both as channel flow and overland flow. FLO-2D solves the depth-averaged shallow water equations using an explicit central finite difference (CFD) numerical scheme and calculates flow depth at each grid element and velocity for 8-directions on each grid edge using the following equations: 
$S_{f}=S_{0}-\frac{\partial h}{\partial x}-\frac{V}{g} \frac{\partial V}{\partial x}-\frac{1}{g} \frac{\partial V}{\partial t}+\frac{1}{g} \frac{\partial}{\partial x}\left(D_{x} \frac{\partial V}{\partial x}\right)$

$\frac{\partial h}{\partial t}+\sum_{i=1}^{8} \frac{\partial h V_{i}}{\partial x}=I$

where, $V$ is one-dimensional velocity for each flow direction, $h$ is the depth which assumed constant over the grid element, $S_{f}$ and $S_{0}$ are friction slope and bed slope respectively, $I$ is a function accounting for water sources and sinks, $g$ is the gravitational acceleration constant, and $D_{x}$ refers to diffusion coefficient.

The FLO-2D model is one of the few inundation models approved by the Federal Emergency Management Agency (FEMA) for Flood Insurance Studies and has been used worldwide in multiple applications ranging from volcanic debris flow inundation (Canuti et al., 2002) to dam breaks in river basins (Chen et al., 2004), assessing impact of extreme flow events on mountainous watersheds ( $\mathrm{Li}$ et al., 2005), flood delineation (Hosseinipour et al., 2012), and flooding events in alluvial fans (Hübl and Steinwendtner, 2001). The simplicity of the data requirements to set up a FLO-2D simulation made this model particularly suitable for the application sought in the present study. The digital elevation model, Manning's roughness coefficients and an inflow hydrograph are the only input data required to set up simulation. The present work appears to be the first application of FLO-2D to model free-surface wetland sheet flow. 


\subsubsection{Modeling Input}

\section{Digital Terrain Model (DTM)}

The first step to setup FLO-2D simulations is to define the computational domain starting from a Digital Terrain Model (DTM) and developing the grid system for the study area. In the present work, the area (M2) was first discretized using a $5 \mathrm{~m}$ by $5 \mathrm{~m}$ square grid elements (Fig. 2.3) and then original elevation data of LILA (referred to as-built) was used to create the FLO-2D DTM data set (Scinto et al., 2009; Aich et al., 2011). A cross section of the study area is shown in Fig. 2.3. These elevation data were processed in Geographic Information System (GIS) and converted into ASCII files containing x-y coordinates and elevation data for each point. The elevation data set was processed in FLO-2D's Grid Developer System (GDS) and was interpolated using the Inverse Distance Weighting method (Fig. 2.8). Light Detection and Ranging (LiDAR) data were also considered as initial elevation dataset for the study area. The LiDAR data was acquired in 2010 and were processed by GIS ArcMap software. As a result of the inaccuracy of LiDAR data, this dataset was disregarded in the present work.

\section{Pulsed Flow Conditions}

Pulsed flow events may occur as natural events or induced by management decisions. Both events can be characterized by five primary components: magnitude, frequency, duration, timing, and rate of change in flow from beginning to end (Committee, 2009). Wood (2011) used several tools such as GIS application, Routing Application for Parallel computatIon of Discharge (RAPID), and Hydrology-based Environmental Flow Regime (HEFR) to model a high pulse flow events. The Texas Commission on Environmental 
Quality Texas Commision on Environmental Quality (TCEQ) (2011) defines a high pulse flow event as a short-term, high flow event within the stream channel that occurs during or immediately after a storm event. Although, their work demonstrates results of pulsed flow condition, their conditions are strictly defined by a natural storm event with high flow magnitude and short duration rather than being determined by a managed pulsed flow condition. In another study, Karim et al. (2012) have used MIKE 21 to simulate the time history of inundation across a tropical floodplain during a pulse flow event. They used three different storm events on wetland to estimate the flood wave propagation.

In the present study, we focus on the two most important components of a pulse flow event: the magnitude and the duration of the pulse event. We refer to pulse flow magnitude as an increase of inflow discharge through the operational culvert gate at inflow location during specific period of time in which the inflow discharge remains high. The ADV records show an average daily flow discharge of $0.32 \mathrm{~m}^{3} / \mathrm{s}$ into $\mathrm{M} 2$ at inflow location. In the present study, the inflow discharge was increased up to $0.34 \mathrm{~m}^{3} / \mathrm{s}$ for duration of 8 hours. This condition indicates pulsed flow condition that may not be as strong as a pulsed flow scenario created by a naturally occurred extreme events or other pulsed condition that occurs in areas where flow discharge is high or topography is steep. Fig. 2.4 shows the hydrograph of inflow during the pulsed flow condition. The hydrograph was used as inflow and outflow hydrographs. The outflow hydrograph was also used at outflow location. This hydrograph was obtained from the ADVs located at outlet culverts within the M2 cell. The ADV was set to register flow rate every 15 minutes. This flow rate data was collected for pulsed flow conditions, which were 
generated on October 3, 2007. Hydrographs were modified and converted into text files as per FLO-2D requirements and then used as inflow/outflow hydrographs in FLO-2D.

\section{Manning's Roughness}

An aerial image of the study area for 2006 was obtained from the National Map Viewer site and it was used to specify M2 boundaries. The image was later digitized in GIS to create a vegetation map. Min et al. (2010) determined manning's value for ridge and slough of Water Conservation Area 3 (WCA3) to be 0.42 and 0.28 respectively in wet season, and increased to 0.81 and 0.41 in dry season. These values are considerably higher than Manning's values reported in classical Manning tables that are 0.15 for ridge, 0.025 for slough. This may be because of the fact that Manning's values reported in tables represent roughness of channels and rivers while Min et al. (2010) estimated Manning's coefficient in open water body wetland with sheet flow. We used Min et al. (2010) manning's value of dry season as initial manning's value because the original image of the area obtained from National Map Viewer was taken in dry season. We assigned initial Manning's value of 0.3 , and 0.04 to patchy vegetation, and tree islands respectively. Fig. 2.9 illustrates the distribution of Manning's n values in LILA-M2.

\subsubsection{Model Setup}

The computational domain boundary was set around levees surrounding the M2 macrocosm. The domain was then discretized using $5 \mathrm{~m}$ by $5 \mathrm{~m}$ square grid elements (Fig. 2.3). As-built elevation data (Fig. 2.8) were imposed into the domain and 
interpolated. A no-flow boundary condition was imposed on all sides of the domain. Inflow and outflow elements were identified at the inflow and outflow culverts locations. To improve flow conditions at inflow and outflow boundaries, the reconstructed inflow/outflow hydrographs of the dye test were assigned to both inflow and outflow elements. It is assumed that the area was initially flooded with constant water elevation that corresponds to depths up to $0.5 \mathrm{~m}$. The FLO-2D simulation was initiated with report time intervals of one hour and continued for total of 30 hours including 6 hours warm up with flow of $0.32 \mathrm{~m}^{3} / \mathrm{s}, 8$ hours high flow pulse of $0.34 \mathrm{~m}^{3} / \mathrm{s}$, and then 6 hours of normal $0.32 \mathrm{~m}^{3} / \mathrm{s}$ flow.

\subsubsection{Model Calibration}

We used the October 3, 2007 inlet hydrograph and Manning's value of 2006 vegetation coverage to simulate the dye test hydrologic conditions assuming that vegetation coverage had not changed significantly; therefore Manning's values for 2006 can be used for 2007. The model calibration was performed by modifying Manning's values until the simulated velocity was matched the ADV observations at the outlet. These observed velocities were used to calibrate vegetation roughness in the model. Table 2.1 shows the original and modified value of Manning's coefficient. 


\subsection{Results}

\subsubsection{Model Application 1: Dye Study Flow Condition}

We applied the model to the dye study flow conditions in the study area. Fig. 2.10 illustrates simulation results of water surface elevation before, 5, 15, and 30 mins after inflow culvert was opened and water flowed into the study area in full capacity. No significant changes in water surface elevation is being detected in these series of results except some minor local changes $(2-3 \mathrm{~mm})$ along western side close to the inflow location. This may be the result of the low pulse flow magnitude. As it is shown in the inflow hydrograph (Fig. 2.4), the discharge has increased from $0.32 \mathrm{~m}^{3} / \mathrm{s}$ to $0.34 \mathrm{~m}^{3} / \mathrm{s}$, which roughly translates into $6 \%$ increase in inflow discharge and pulse magnitude of approximately $0.02 \mathrm{~m}^{3} / \mathrm{s}$. Fig. 2.11 shows the results of simulated water surface elevation and velocity vectors after $1,3,5$, and 7 hrs. Changes in water surface elevation are observed $1 \mathrm{hr}$ after change in inflow conditions (Fig. 2.11a) along western side near inflow location and they continue to progress into both deep and shallow sloughs as the time passes within the next 6 hrs (Fig. 2.11b, c, and d). However, these changes are very small and only up to $1.00 \mathrm{~cm}$ in deep and shallow sloughs and dissipate quickly afterward. Some in situ water depth measurements inside deep slough where ADV 1 was installed (Fig. 2.6) also confirmed that water level only changed by $1.00 \mathrm{~cm}$. Because of the pulsed flow is low magnitude, the pulse has only propagated up to the eastern tree island and it has dissipated faster than a pulsed flow condition with higher magnitude may show (Fig. 2.12). Fig. 2.11 (e through h) also illustrates simulated velocity vectors over time. This image indicates that velocity does not change during the dye experiment. 
It is mainly result of the fact that increase in inflow discharge is too small to affect velocity inside the study area. Therefore the velocity vectors remained almost constant during the experiment. These results also show that velocities are more uniform toward downstream inside the shallow slough, while deep slough experiences areas between tree islands and downstream, where the flow direction varies constantly. This non-uniformity in flow velocity regime creates enhanced mixing areas within the deep sloughs that may affect nutrient and solute transport inside the study area (Fig. 2.11).

\subsubsection{Model Application 2: High Intensity Pulsed Flow Condition}

In order to understand the model behavior when a pulsed condition is implemented, we applied the model to various pulsed flow conditions scenarios with inflow discharges magnitude as high as $1.5 \mathrm{~m}^{3} / \mathrm{s}$ and $3.0 \mathrm{~m}^{3} / \mathrm{s}$ over one hour duration with total simulation time of 4 hours. These amounts of discharges are 5 and 10 times higher than daily discharge into M2 under operational procedure. The results show that the pulse behavior only when inflow discharge is at least $3.0 \mathrm{~m}^{3} / \mathrm{s}$. Lower inflow discharge values are too weak in magnitude to generate substantial changes in water surface elevation and velocity and they may not exhibit flow wave propagation into the study area. The results of water surface elevations and velocities of a high pulse value of $3.0 \mathrm{~m}^{3} / \mathrm{s}$ are presented in Fig. 2.12 and Fig. 2.13 respectively. These series of images show how water surface elevation increases as the water flows downstream and out of the macrocosm. These results also reveal that water depth is increasing on top of ridge faster than inside the slough. 


\subsection{Discussion}

Our result of calibration for Manning's value for ridge and slough (Table 2.2) indicate that there are significant differences between modified Manning's values from model and initial value from Min et al. (2010). Initial $\mathrm{n}$ values for ridge and slough were set to be 0.81 and 0.41 respectively while the calibrated values are 0.1 and 0.02 . It appears that modified $\mathrm{n}$ results are closer to the values reported in classical Manning coefficient table ( 0.05 for highly vegetated area and 0.025 for water body with low dense vegetation). This may be the result of the fact that the macrocosms in LILA actually act as open channels rather than open water body in wetlands. The surrounded levees create boundaries that are similar to the bank of streams, and therefore Manning's coefficients are closer to the values reported for open channel table.

For the purpose of the comparison between simulation results and observation from each areal image, velocity was calculated by dividing the distance between the injection point and the dye leading edge in the areal image. These images approximate a uniform flow velocity of $0.02 \mathrm{~m} / \mathrm{s}$ during the pulse condition. Table 2.2 presents a comparison between observed and simulated velocity results and Fig. 2.6 shows approximate locations of dye leading edge at each areal photo every hour. Total of 19 points (locations) were marked from areal photos. Average velocities (distance from the injection over time) at locations 1,2 , and 3 are $0.03 \mathrm{~m} / \mathrm{s}, 0.03 \mathrm{~m} / \mathrm{s}$ and $0.02 \mathrm{~m} / \mathrm{s}$, while simulated velocities are $0.02 \mathrm{~m} / \mathrm{s}$,

$0.03 \mathrm{~m} / \mathrm{s}$, and $0.02 \mathrm{~m} / \mathrm{s}$ respectively. Locations $4,5,6$, and 7 experience average velocity of $0.02 \mathrm{~m} / \mathrm{s}$ and simulated velocity of $0.015 \mathrm{~m} / \mathrm{s}$. Simulated results are in agreement with dye results for points $8,10,11$, and 14, but are lower than observations for points 9 and 
$13(0.01 \mathrm{~m} / \mathrm{s})$ and higher for point $12(0.02 \mathrm{~m} / \mathrm{s})$. Results at $244 \mathrm{~min}$ through $422 \mathrm{~min}$ indicate faster flow in the shallow slough while images show that the dye flow in the shallow slough is much slower than what simulation has predicted. This may be because of accuracy of elevation data inside the shallow slough. The overall results show very good agreement between observed data of dye study and simulated results (Table 2.2).

Fig. 2.14 illustrates simulated results of water depth over time in a few locations inside the study area. These graphs show that the water depth increases by about $1.0 \mathrm{~cm}$ during the pulse and then decreased to the original depth after flow discharge reached to operational flow (non-pulse) conditions. However, because depth was not measured during the tracer experiment, there are no data to compare with the simulated depth.

The non-uniformity in flow direction within the deep slough creates zones of high mixing capacity (Fig. 2.11e-h). These zones are bound to affect transport mechanisms within deep sloughs and cause in delay in transporting solutes or particles toward downstream. These mixing zones were confirmed by in situ flow measurements, which was conducted during tracer test using a hand held flow tracker (Scinto et al., 2009). Visual comparison between simulated velocity results under high-pulsed flow condition (Fig. 2.13) and dye study flow (low-pulsed flow) condition (Fig. 2.11) may conclude that these distinct areas exist because of the low flow velocity in under dye study flow conditions. As inflow discharge increases, water flows faster and more uniform inside the deep slough toward downstream. Further numerical modeling and field investigations are necessary to evaluate these zones existence and the hydrologic conditions which they may exist. 
There are also limitations to the present modeling attempt. The FLO-2D model is input data sensitive and requires following certain detailed procedure to prepare input data such as elevation, flow hydrograph, and Manning's value, which may lengthen the initial modeling set up if not followed carefully. It also has limited visualization capability. FLO-2D reports final results as text files, which requires using other software and programs to visualize. It should be noted that in study, we did not consider the effect of floating mat of periphyton in Manning's calibration. As result of mobility of these floating mats with flow, it may not be possible to assign spatially fixed roughness value to the areas where they cover the surface of slough. Leonard et al. (2006) have shown that floating plants and periphyton affect velocity magnitude and the shape of vertical profiles, especially in slough where they are most abundant. The presence of these periphyton mats on the surface of water inside slough may also affect the dispersion and diffusion, which have not been considered. Lack of enough flow velocity and water depth data during the tracer study, and limited areal images of dye transport are another limited factors in the present study.

The flow model developed in the present investigation will be used to develop a twodimensional solute transport model in low topographic gradient wetlands with dense vegetation coverage. Such a transport model can then be further extended to simulate bed elevation changes in wetlands as a result of sediment transport and redistribution, and whether these changes may have an influence on the stability and maintenance of wetland landscape features such as tree islands and ridge and slough during pulsed flow events that may be implemented through water management practices. 


\subsection{Conclusion}

The purpose of the present study was to develop a high-resolution hydrologic model in FLO-2D and evaluate whether the model could simulate the effect of pulsed flow conditions on sheet flow in low gradient wetlands with high vegetation density. We presented the results of a two different pulsed flow conditions: low inflow discharge with magnitude of $0.34 \mathrm{~m}^{3} / \mathrm{s}$ and duration of $8.0 \mathrm{hrs}$ which represents hydrologic condition during a dye study conducted on October 2007, and high inflow discharge with magnitude of $3.0 \mathrm{~m}^{3} / \mathrm{s}$ and duration of $1.0 \mathrm{hr}$. The results reveal that low-pulsed flow condition produces flow velocity values that are low $(0.02 \mathrm{~m} / \mathrm{s})$ and vary in direction and do not follow the east-west flow direction, creating areas of mixing inside deep slough. Under high-pulsed flow, simulated flow velocity values are high $(0.1 \mathrm{~m} / \mathrm{s})$ but they are uniform indicating east-to-west flow direction toward downstream inside deep slough. The high spatial resolution of this modeling effort may also be another reason to reveal mixing zones inside deep slough where flow direction varies. This may affect transport of sediments and nutrients and cause accumulation of substances within these areas. Further investigations are needed to support the existence of these "mixing zones" and whether they may significantly alter transport mechanisms.

The present modeling investigation indicates that the proposed model is capable of estimating flow depth and velocity in wetlands with realistic accuracy. The hydrologic model was developed using FLO-2D, a vertically-averaged numerical model for surface water flow. This model was calibrated using flow depth and velocity measurements obtained during a field test with generated pulsed flow condition. The calibrated model 
was used to simulate water flow in an experimental wetland system (LILA) where a dye study was conducted. Simulated values of water velocity were found to compare favorably with those derived from dye test observations. This study also provides a platform for further application of FLO-2D to simulate flow velocity and water depth in regional areas such as WCAs and the Everglades. 


\subsection{References}

Aich, S., Dreschel, T., Cline, E., and Sklar, F., 2011, The Development of a Geographic Information System(GIS) to Document Research in an Everglades Physical Model: Journal of Environmental Science and Engineering, v. 5, no. 3, p. 289302.

Bolster, C. H., and Saiers, J. E., 2002, Development and evaluation of a mathematical model for surface-water flow within the Shark River Slough of the Florida Everglades: Journal of Hydrology, v. 259, no. 1-4, p. 221-235.

Canuti, P., Casagli, N., Catani, F., and Falorni, G., 2002, Modeling of the Guagua Pichincha volcano (Ecuador) lahars: Physics and Chemistry of the Earth, Parts A/B/C, v. 27, no. 36, p. 1587-1599.

Chen, C.-Y., Chen, T.-C., Yu, F.-C., and Hung, F.-Y., 2004, A landslide dam breach induced debris flow - a case study on downstream hazard areas delineation: Environmental Geology, v. 47, no. 1, p. 91-101.

Committee, S. A., 2009, Use of hydrologic data in the development of instream flow recommendations for the environmental flows allocation process and the Hydrology-Based Environmental Flow Regime (HEFR) Methodology: Report\# SAC-2009-Ol-Revl.

Froehlich, D. C., 1989, Finitr Element Surface-Water Modeling System: TowDimensional Flow in a Horizontal Plane. User's Manual.

Garcia, R., and Kahawita, R. A., 1986, Numerical solution of the St. Venant equations with the MacCormack finite-difference scheme: International Journal for Numerical Methods in Fluids, v. 6, no. 5, p. 259-274.

Hammer, D., and Kadlec, R., 1986, A model for wetland surface water dynamics: Water Resources Research, v. 22, no. 13, p. 1951-1958.

Hosseinipour, E. Z., Vargas, S., O'Brien, K., and Kasraie, H., 2-D Fine Grid Hydrodynamic Modeling for More Accurate Floodplain Mapping in Southern California, in Proceedings World Environmental and Water Resources Congress 2012@sCrossing Boundaries2012, ASCE, p. 1096-1107.

Hübl, J., and Steinwendtner, H., 2001, Two-dimensional simulation of two viscous debris flows in Austria: Physics and Chemistry of the Earth, Part C: Solar, Terrestrial \& Planetary Science, v. 26, no. 9, p. 639-644.

Karim, F., Kinsey - Henderson, A., Wallace, J., Arthington, A. H., and Pearson, R. G., 2012, Modelling wetland connectivity during overbank flooding in a tropical 
floodplain in north Queensland, Australia: Hydrological Processes, v. 26, no. 18, p. $2710-2723$.

Lago, M. E., Miralles-Wilhelm, F., Mahmoudi, M., and Engel, V., 2010, Numerical modeling of the effects of water flow, sediment transport and vegetation growth on the spatiotemporal patterning of the ridge and slough landscape of the Everglades wetland: Advances in Water Resources, v. 33, no. 10, p. 1268-1278.

Lal, A. W., Belnap, M., and Van Zee, R., Simulation of overland and groundwater flow in the Everglades National Park, in Proceedings Proc., Int. Water Resour. Engrg. Conf., ASCE, Reston, VA1998, p. 610-615.

Larsen, L. G., Harvey, J. W., Noe, G. B., and Crimaldi, J. P., 2009, Predicting organic floc transport dynamics in shallow aquatic ecosystems: Insights from the field, the laboratory, and numerical modeling: Water Resources Research, v. 45, no. 1, p. n/a-n/a.

Leonard, L., Croft, A., Childers, D., Mitchell-Bruker, S., Solo-Gabriele, H., and Ross, M., 2006, Characteristics of surface-water flows in the ridge and slough landscape of Everglades National Park: implications for particulate transport: Hydrobiologia, v. 569, no. 1, p. 5-22.

Li, M.-H., Yang, M.-J., Soong, R., and Huang, H.-L., 2005, Simulating typhoon floods with gauge data and mesoscale-modeled rainfall in a mountainous watershed: Journal of Hydrometeorology, v. 6, no. 3, p. 306-323.

Lin, S. T., and Shih, S. F., 1979, Modified Water Quantity Receiving Model for Florida Conservation Areas: JAWRA Journal of the American Water Resources Association, v. 15, no. 1, p. 155-166.

MacVicar, T. K., Vanlent, T., and Castro, A., 1984, South Florida water management model documentation report, Resource Planning Department, South Florida Water Management District.

Min, J.-H., Paudel, R., and Jawitz, J. W., 2010, Spatially distributed modeling of surface water flow dynamics in the Everglades ridge and slough landscape: Journal of Hydrology, v. 390, no. 1-2, p. 1-12.

Noe, G. B., Harvey, J. W., and Saiers, J. E., 2007, Characterization of suspended particles in Everglades wetlands: Limnology and Oceanography, v. 52, no. 3, p. 1166.

O'Brien, J. S., Julien, P. Y., and Fullerton, W. T., 1993, Two-dimensional water flood and mudflow simulation: Journal of hydraulic engineering, v. 119, no. 2, p. 244-261.

Rietkerk, M., Dekker, S., Wassen, M., Verkroost, A., and Bierkens, M., 2004, A putative mechanism for bog patterning: The American Naturalist, v. 163, no. 5, p. 699708. 
Schaffranek, R. W., 2001, The Tides and Inflows in the Mangroves of the Everglades (TIME): interdisciplinary project of the South Florida Ecosystem Program, US Geological Survey.

Science Coordination Team, S. F. E. R. W. G., 2003, The role of flow in the Everglades ridge and slough landscape: USGS.

Scinto, L., Price, R., and Ross, M., 2009, LILA (Loxahatchee Impoundment Landscape Assessment) Tree Island, Ridge, Slough Studies and Site Management. May 1, 2005 to September 4, 2009, Final Report submitted to SFWMD, Aug 17, 2009, $11 \mathrm{pp}$

Swanson, D. K., and Grigal, D. F., 1988, A simulation model of mire patterning: Oikos, p. 309-314.

Texas Commision on Environmental Quality (TCEQ), 2011, Chapter 298, Environmental Flow Standard for Surface Water.

Wood, A., 2011, Characterization of High Pulse Flows at Ungaged Locations for the Purpose of Applying Environmental Flow Standards: University of Texas, Austin. 


\subsection{Tables}

Table 2.1: Calibrated vegetation roughness coefficient

\begin{tabular}{|c|c|c|}
\hline Land Cover & Original $\mathrm{n}$ values & Modified $\mathrm{n}$ values \\
\hline Ridge & 0.81 & 0.1 \\
\hline Slough & 0.41 & 0.02 \\
\hline Patchy Vegetation & 0.3 & 0.02 \\
\hline Tree Islands & 0.04 & 0.04 \\
\hline
\end{tabular}

Table 2.2: Comparison between observed velocity from dye images and simulated with FLO-2D

\begin{tabular}{|c|c|c|c|c|}
\hline Locations & $\begin{array}{l}\text { Distance from Inflow } \\
(\mathrm{m})\end{array}$ & $\begin{array}{l}\text { Time } \\
(\mathrm{min})\end{array}$ & $\begin{array}{c}\text { Velocity } \\
\text { Observed }(\mathrm{m} / \mathrm{s})\end{array}$ & $\begin{array}{c}\text { Velocity } \\
\text { Simulated }(\mathrm{m} / \mathrm{s})\end{array}$ \\
\hline 1 & 48 & \multirow{3}{*}{25} & 0.03 & 0.02 \\
\hline 2 & 25 & & 0.02 & 0.03 \\
\hline 3 & 26 & & 0.03 & 0.02 \\
\hline 4 & 105 & \multirow{4}{*}{71} & 0.02 & 0.02 \\
\hline 5 & 120 & & 0.02 & 0.01 \\
\hline 6 & 65 & & 0.02 & 0.01 \\
\hline 7 & 60 & & 0.02 & 0.01 \\
\hline 8 & 150 & \multirow{5}{*}{128} & 0.02 & 0.02 \\
\hline 9 & 105 & & 0.02 & 0.01 \\
\hline 10 & 130 & & 0.02 & 0.02 \\
\hline 11 & 70 & & 0.01 & 0.01 \\
\hline 12 & 75 & & 0.01 & 0.02 \\
\hline 13 & 220 & \multirow{2}{*}{182} & 0.02 & 0.02 \\
\hline 14 & 225 & & 0.02 & 0.02 \\
\hline 15 & 330 & \multirow{2}{*}{244} & 0.02 & 0.01 \\
\hline 16 & 270 & & 0.02 & 0.01 \\
\hline 17 & 147 & 313 & 0.01 & 0.02 \\
\hline 18 & 382 & 360 & 0.02 & 0.02 \\
\hline 19 & 167 & 422 & 0.01 & 0.04 \\
\hline
\end{tabular}




\subsection{Figures}

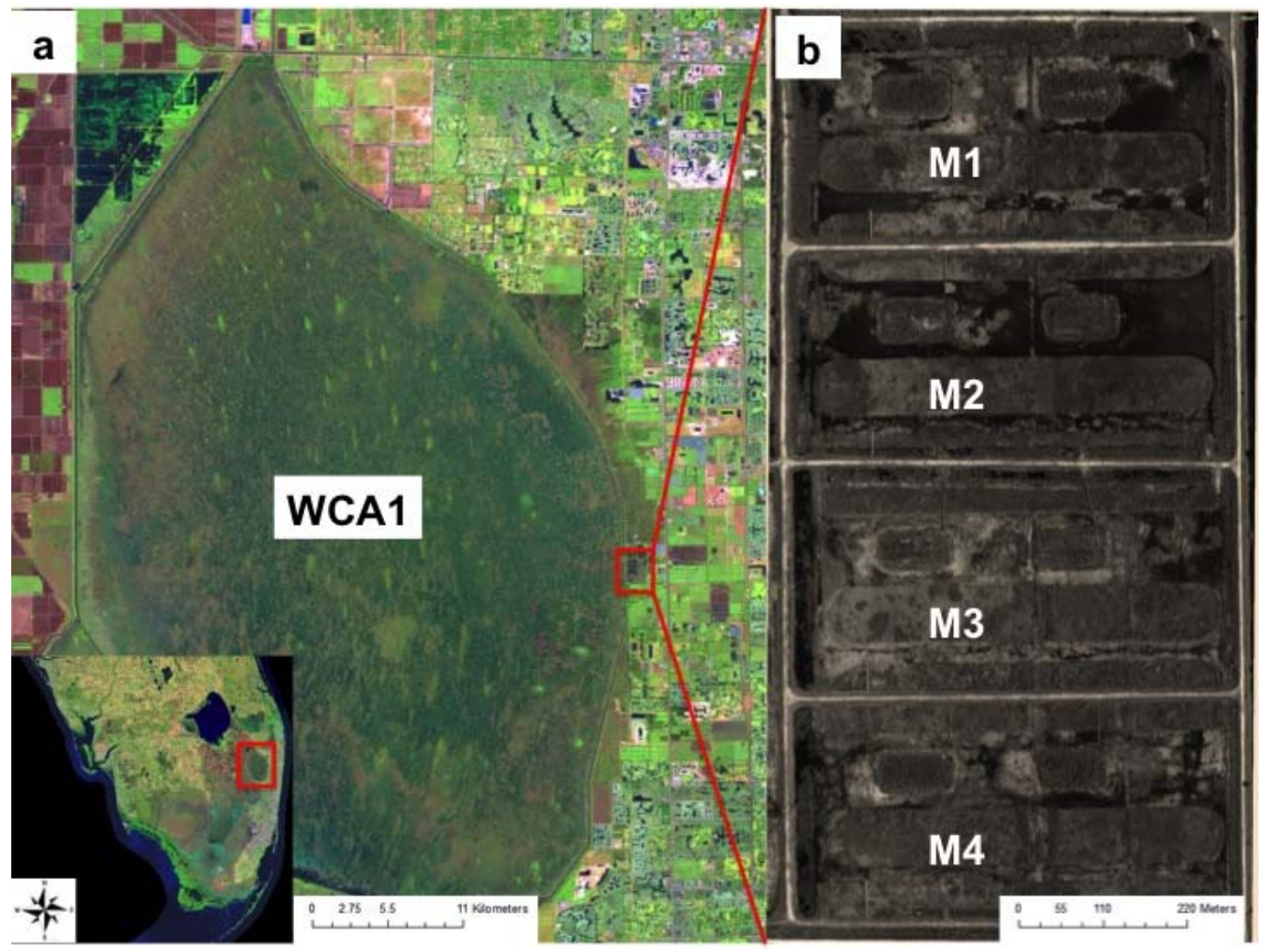

Fig. 2.1: (a) LILA location at the eastern boundary of WCA-1. The location with respect to southern Florida is shown in the insert. (b) Air plot showing the four macrocosms of LILA 


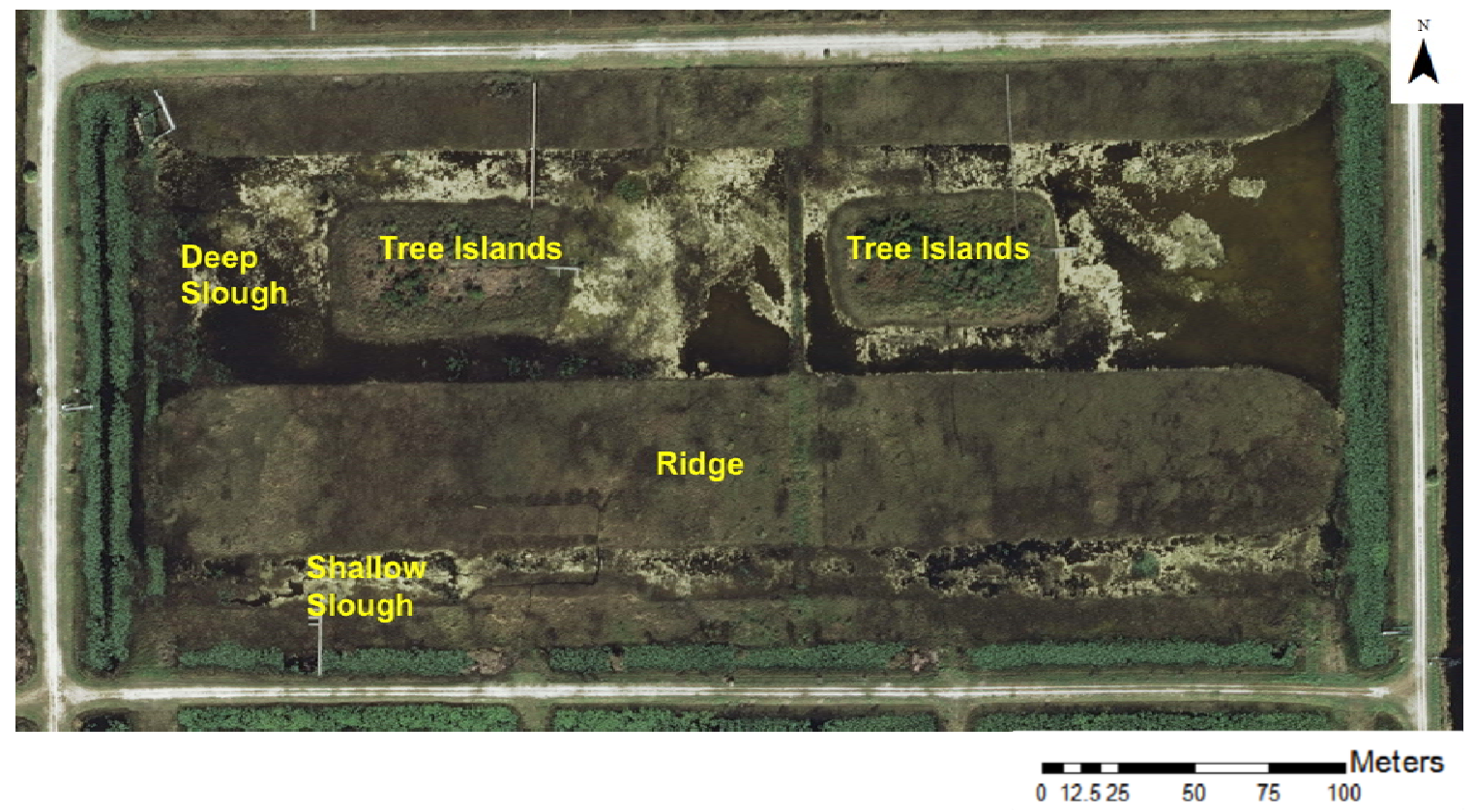

Fig. 2.2: landscape features in LILA-M2 

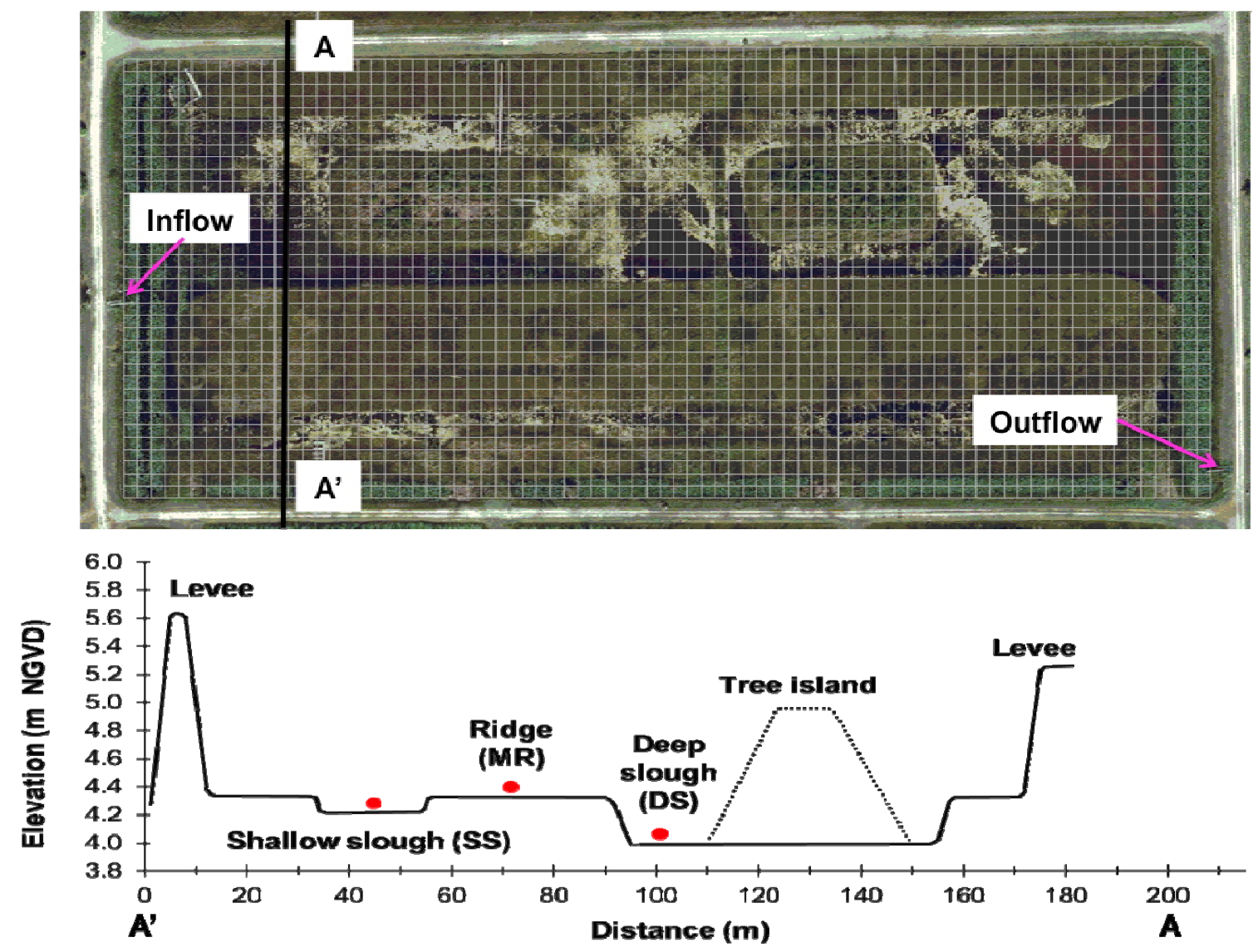

Fig. 2.3: Air photo showing macrocosm 2 (M2), grid system, cross section, and inflow/outflow locations. 


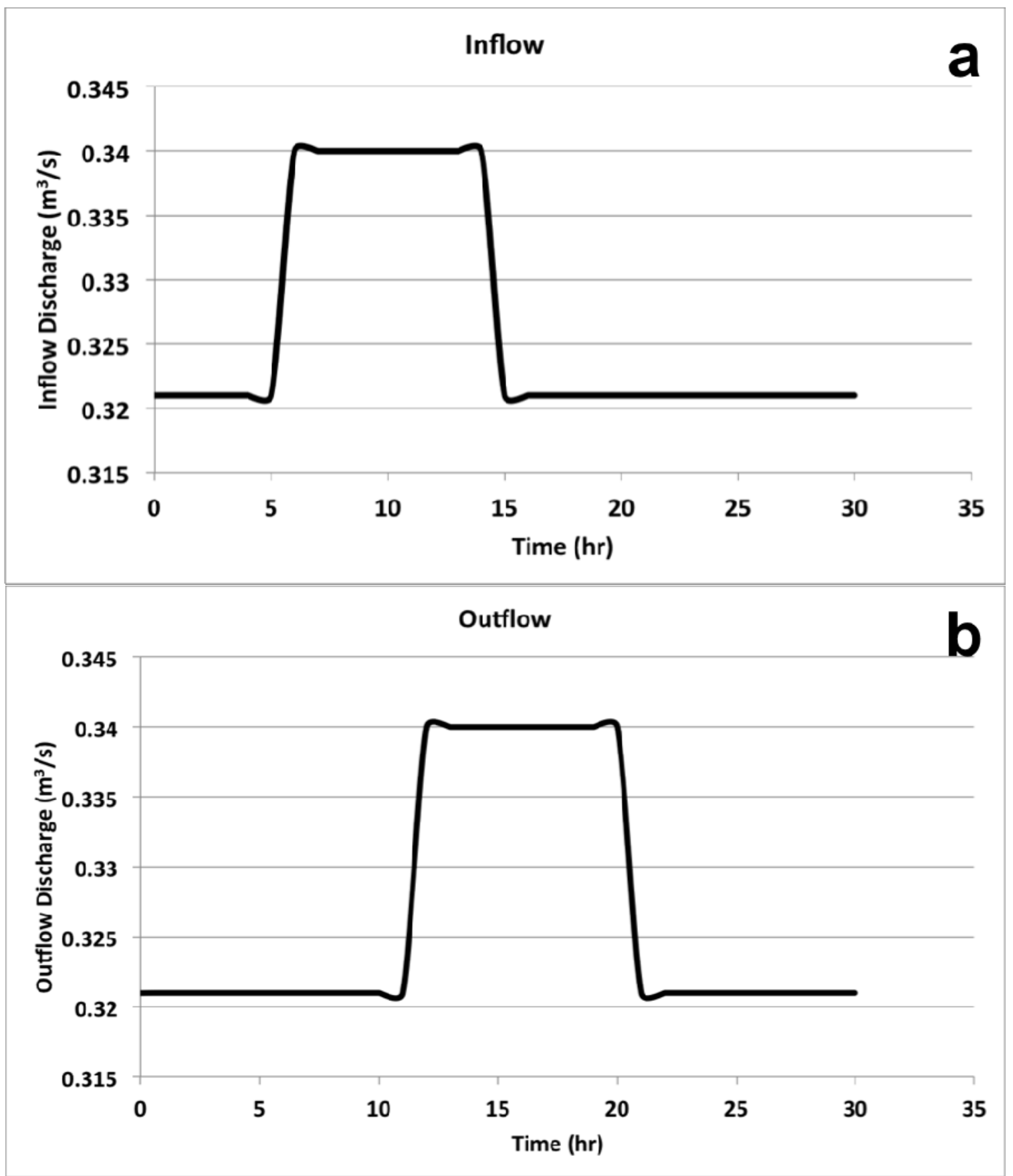

Fig. 2.4: M2 inflow (a) and outflow (b) hydrograph 


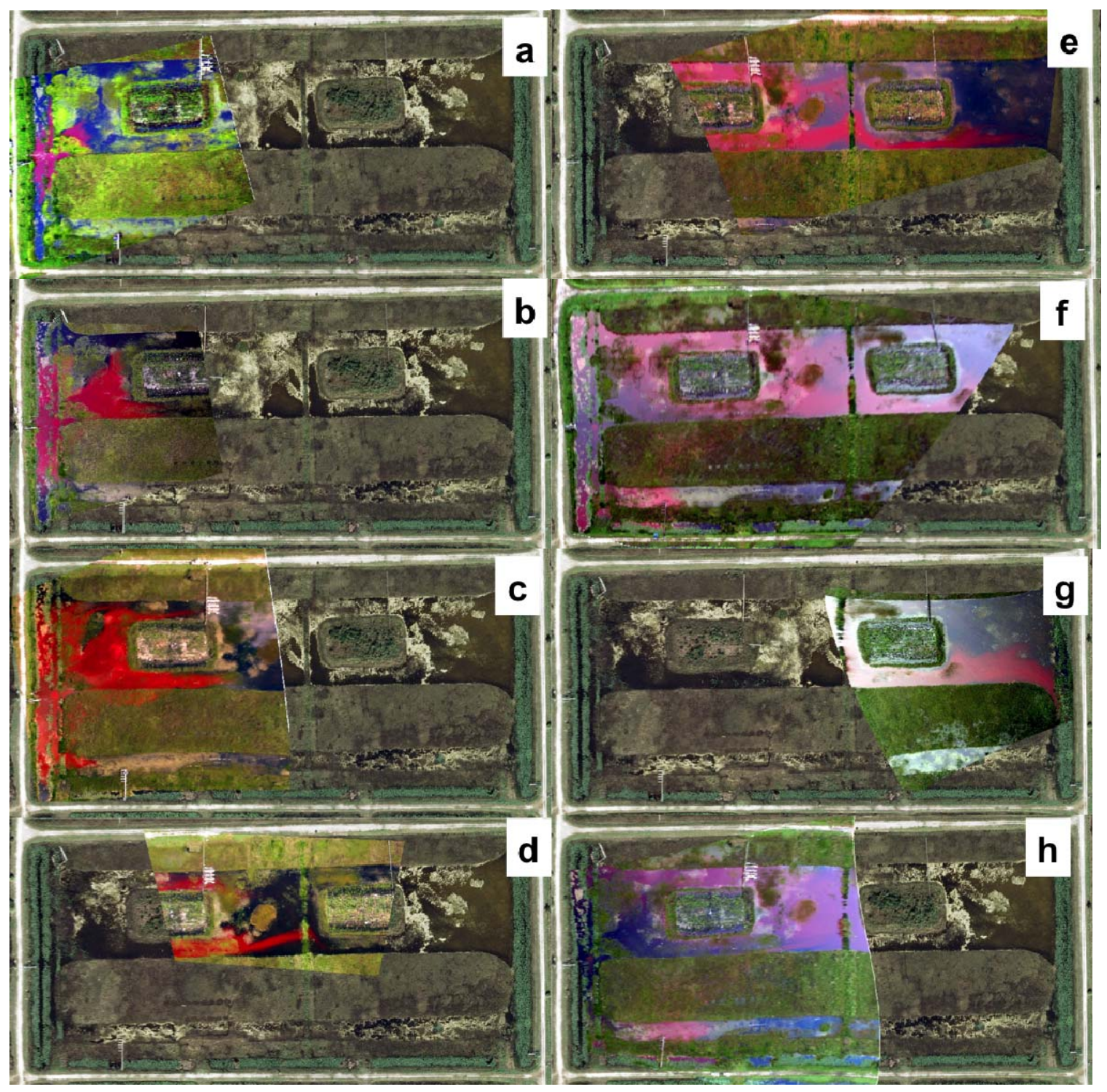

Fig. 2.5: Areal images of dye study overlaid on areal image of the study area: (a) 25 mins,

(b) $1 \mathrm{hr}$, (c), 2 hrs, (d) $3 \mathrm{hrs,} \mathrm{(e),} 4$ hrs, (f) 5 hrs, (g) $6 \mathrm{hrs,} \mathrm{(h)} 7 \mathrm{hrs}$. White lines in (a),

(c), and (h) are the result of the overlaying dye images in Arc Map 


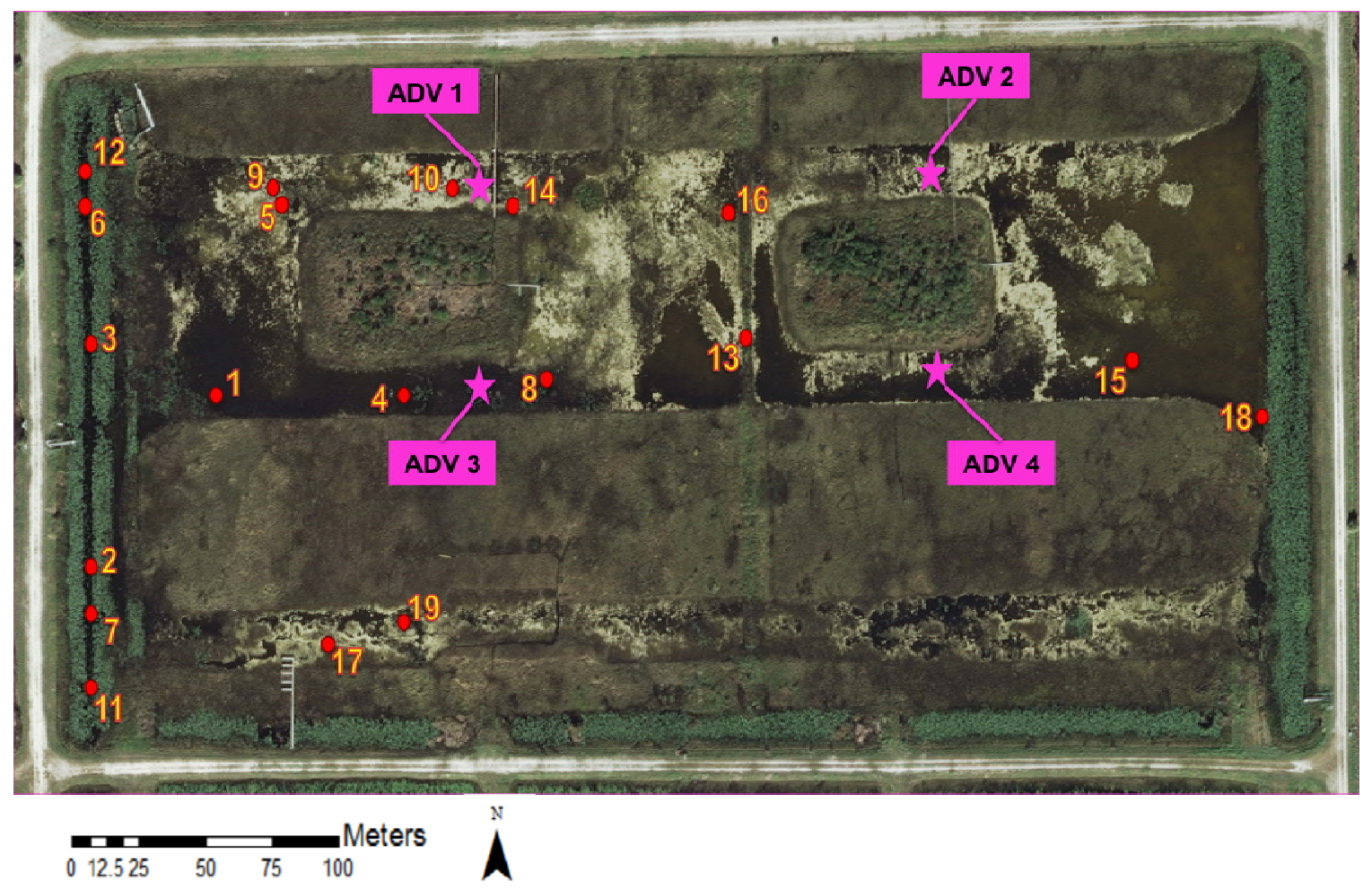

Fig. 2.6: Approximate location of projected dye head from hourly areal photos and ADVs location. Red dots represent dye head. 


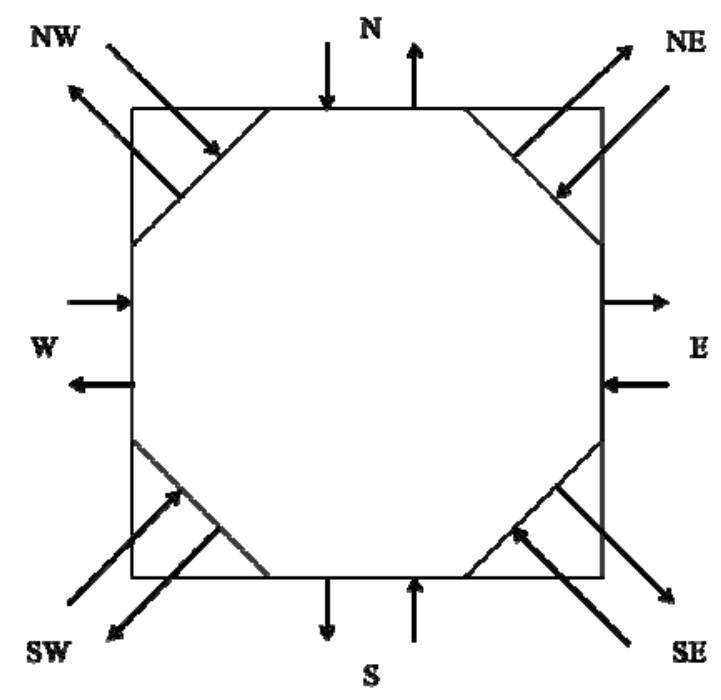

Fig. 2.7: FLO-2D discharge directions at eleme

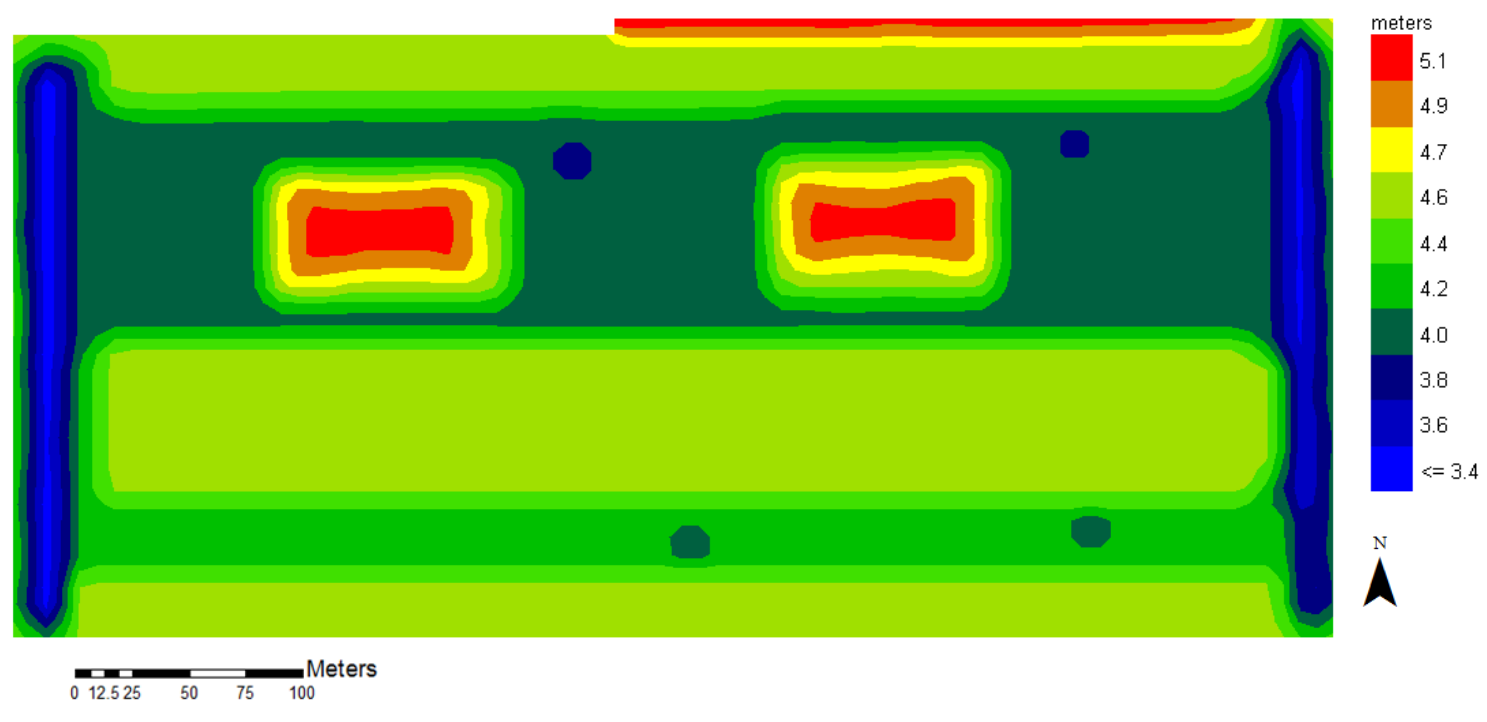

Fig. 2.8: M2 ground elevation contours 

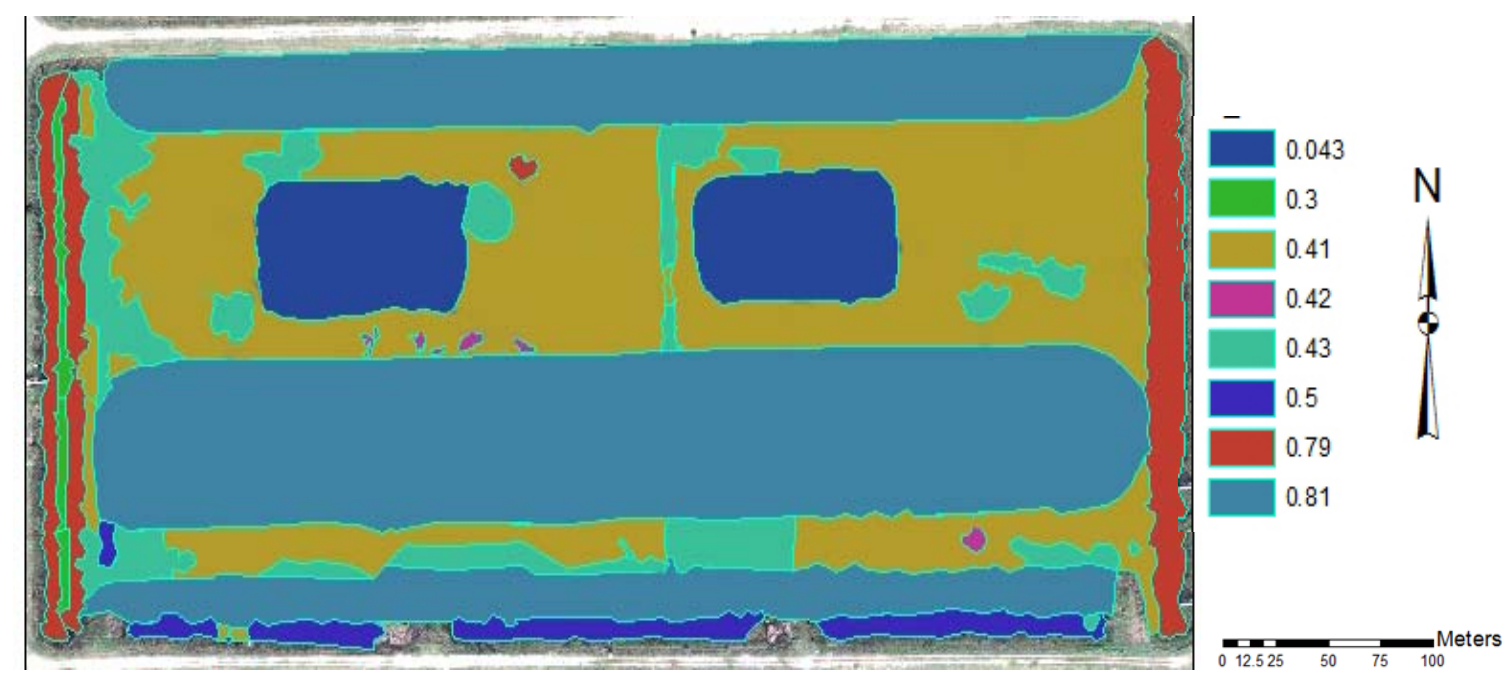

Fig. 2.9: M2 Manning's roughness coefficient distribution driven from vegetation map

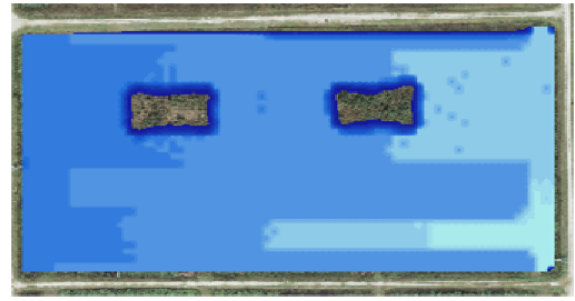

(a)

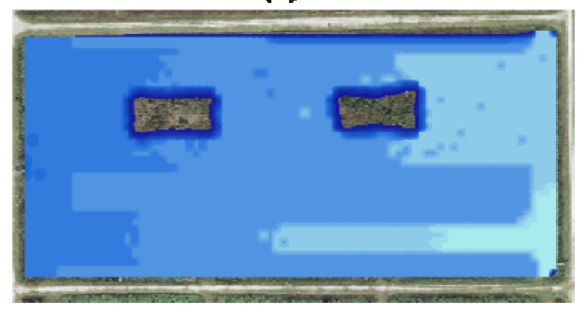

(b)

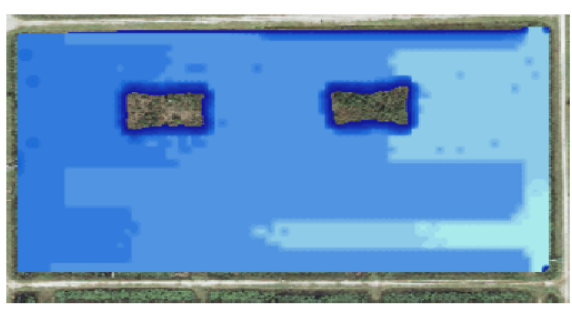

(c)

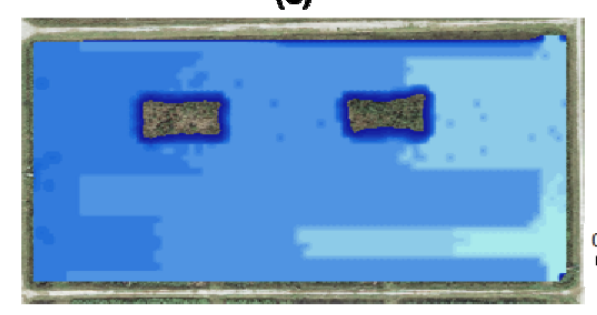

(d)
Water Surface Elevation (m)

$\square^{4.50-1.502}$

$4.502-4503$
$4.503-4.504$

$4.504-4.506$

$4.506-4.511$

$4.511-4.528$

$4.528-4.582$

$4.582-4.753$

$4.753-5.3$

$\stackrel{\Lambda}{N}^{N}$

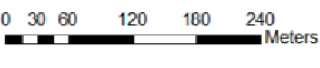

Fig. 2.10: Simulation results of water surface elevation for dye experiment at: (a) before pulse and dye release, (b) 5 mins after opening culvert, (c) 12 mins after pulse, (d) 30 mins after pulse. No change in water surface elevation is detected at the area near to inflow discharge. 

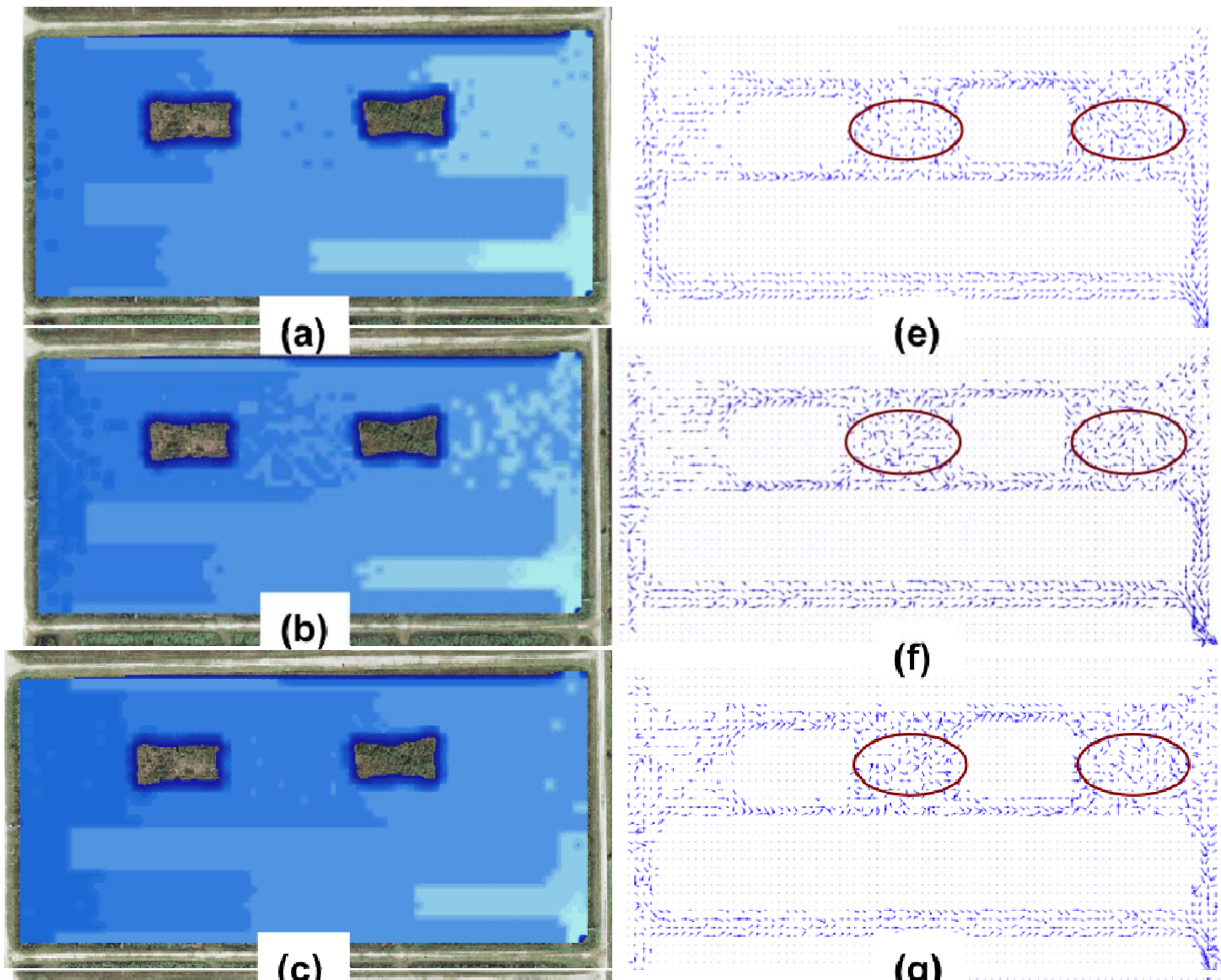

\section{(f)}

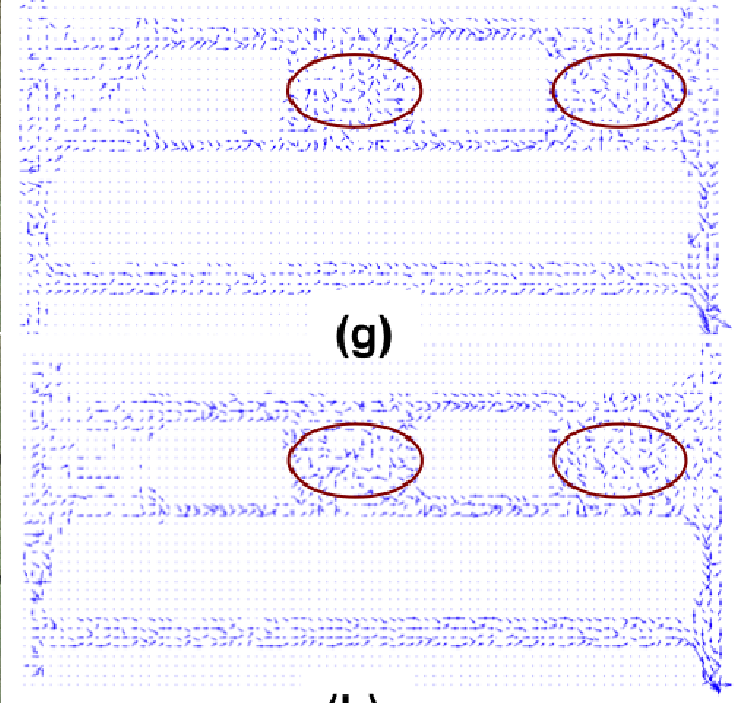

(d)

(h)

Water Surface Elevation $(\mathrm{m})$
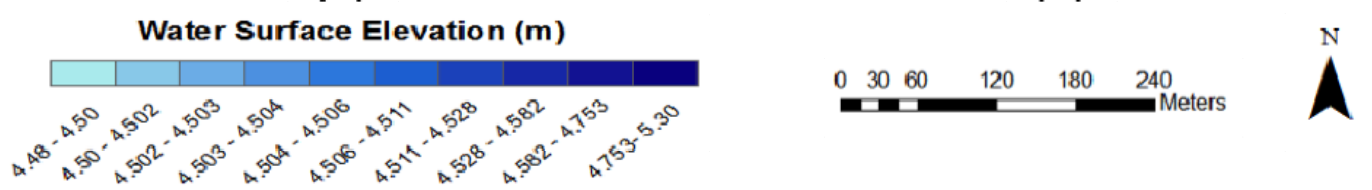

Fig. 2.11: Dye study hydrology simulation results. Left column represents water surface elevation after (a) $1 \mathrm{hr}$, (b) $3 \mathrm{hrs}$, (c) $5 \mathrm{hrs,} \mathrm{(d)} 7 \mathrm{hrs}$, and right column illustrates velocity vectors after (e) $1 \mathrm{hr}$, (f) $3 \mathrm{hrs,} \mathrm{(g)} 5 \mathrm{hrs}$, (h) $7 \mathrm{hrs}$. Red circles indicate the mixing zones within the deep slough 


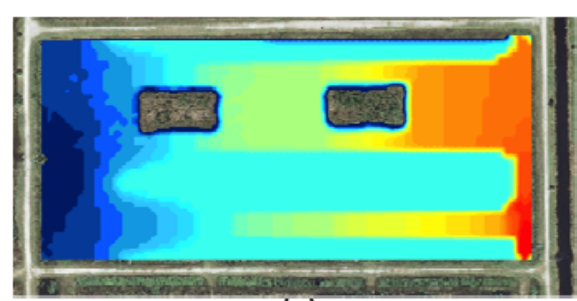

(a)

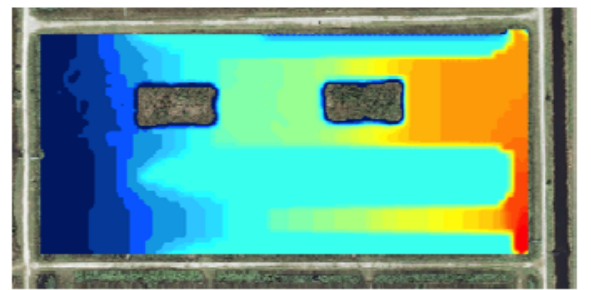

(b)

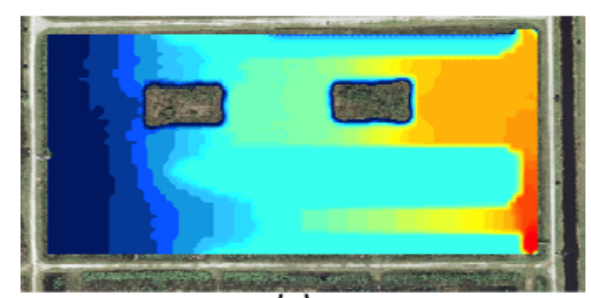

(c)

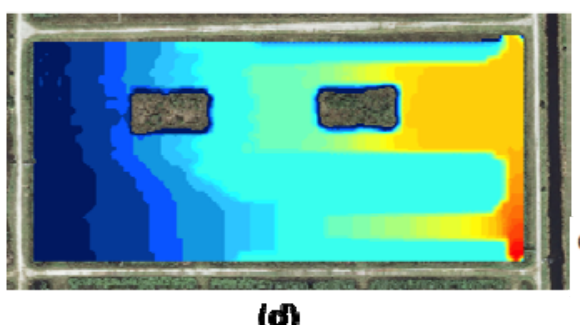

(d)
Water Surface Elevation

(m)

4.05- 4.21

$4.21-4.31$

$4.31-4.40$

$440 \quad 448$

$448-453$

\. $4.53-4.61$

$4.61-4.71$

प 1/1- 482

$482-49 ?$

$4.92-5.03$

^

\begin{tabular}{lll}
$0 \quad 25$ & $50 \quad 100 \quad 150 \quad 200$ \\
\hline
\end{tabular}

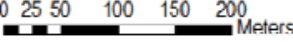

Fig. 2.12: Increase in depth of water when 1-hour pulsed flow discharge of $3 \mathrm{~m}^{3} / \mathrm{s}$ is applied at inflow culvert. Each image shows water flows after (a) 2 mins, (b) 10 mins, (c) 15 mins, and (d) 30 mins of pulse implementation 


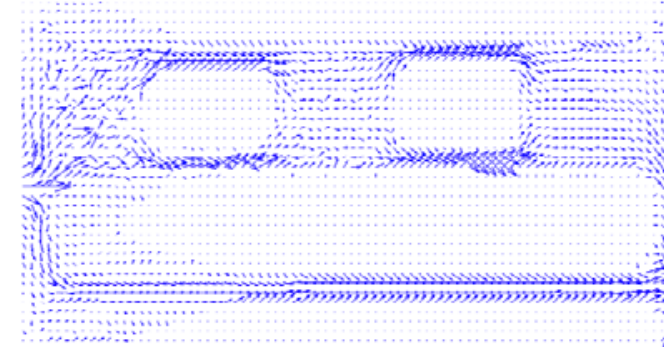

(a)

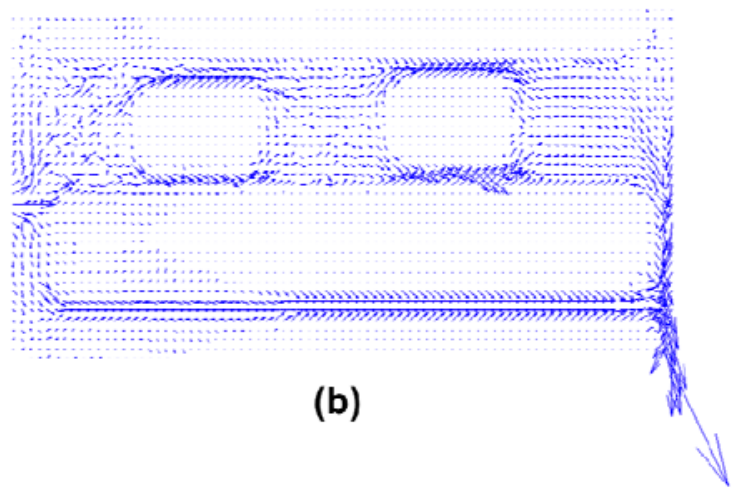

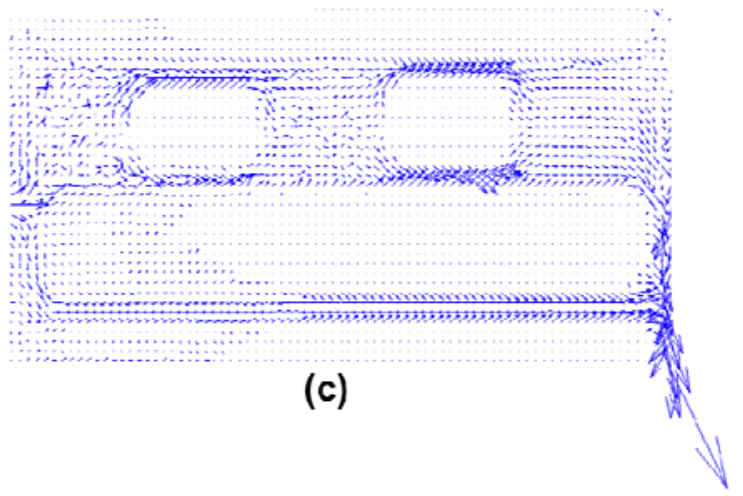

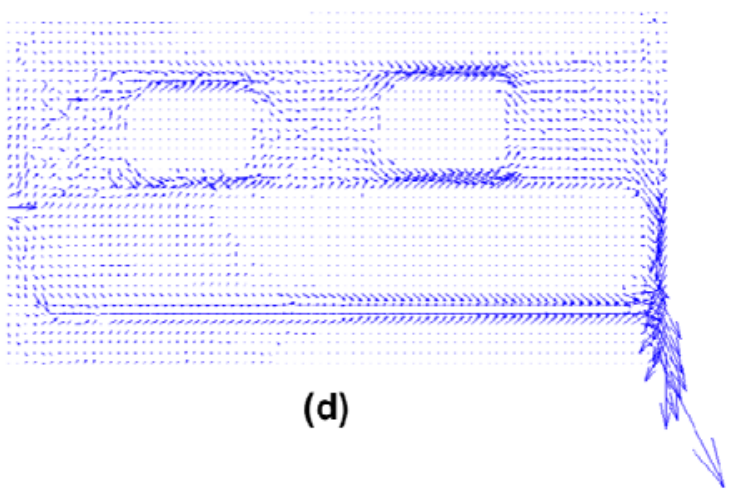

Fig. 2.13: Velocity vector when 1-hr pulse condition with $3.0 \mathrm{~m}^{3} / \mathrm{s}$ discharge magnitude is applied after (a) 2 mins, (b) 10 mins, (c) 15 mins, and (d) 30 mins. 


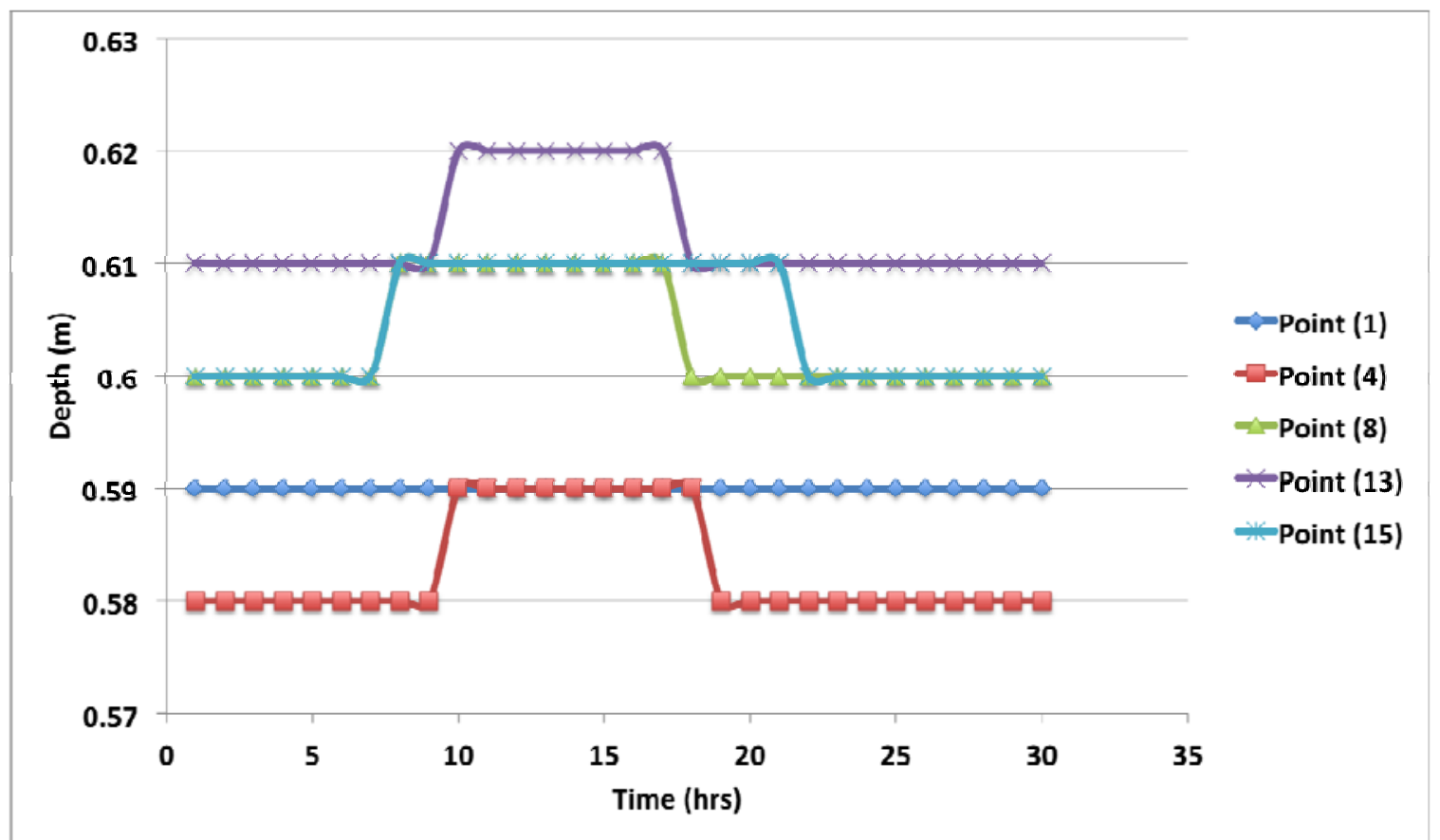

Fig. 2.14: Depth results from FLO-2D at locations 1, 4, 8, 13, and 15 (Fig. 2.6). It shows slight increase of $1.0 \mathrm{~cm}$ in water depth at these locations. 


\section{CHAPTER 3: NUMERICAL MODELING OF SOLUTE TRANSPORT IN WETLANDS: QUALITATIVE APPROACH TO A TRACER TEST AT THE LOXAHATCHEE IMPOUNDMENT LANDSCAPE ASSESSMENT (LILA) SITE}

\subsection{Abstract}

A two-dimensional numerical model of the advection-dispersion equation has been developed and applied to simulate solute transport in wetlands with high vegetation density and low topographic gradient. The model was used to simulate transport of a nonreactive dissolved dye under pulsed flow conditions and was applied to a tracer test at the Loxahatchee Impoundment Landscape Assessment (LILA) wetland site, located in Boynton Beach, Florida. The dissolved plume transport simulated results were compared with aerial images taken during the tracer test. Visual comparison between numerical results and the images indicate that the model is in a good agreement with observed dye movement, and that the model is capable of simulating the solute transport. The simulation results also support the existence of areas within the domain where the mixing processes happen. These areas may cause that nutrients and suspended particles have longer residence time in the system. The developed model can be further used to simulate erosion and deposition processes, which may cause change in bed elevation and morphology in area where ground data collection is difficult. 


\subsection{Introduction}

Transport of nutrient, sediments and other biogeochemically active solutes, is one of the key mechanisms in wetland ecosystem and functioning (Harvey et al., 2005; Larsen et al., 2007; Larsen and Harvey, 2010a). Whether referring to nutrients, suspended particles, or other constituents, transport plays an important role in wetland ecosystems such as the Everglades in South Florida where water flows under a low topographic gradient, high vegetated conditions through heterogeneous landscapes such as tree islands and ridge and slough. Wetlands also rely on transport process to remove suspended sediments and excess nutrients components such as nitrogen and phosphorus (Kadlec and Hammer, 1982).

The Science Coordination Team (2003) hypothesized that sediment transport is one of the main factors controlling ridge and slough landscape stability. Larsen and Harvey (2010a) postulated that sediment transport and redistribution from sloughs with lower elevation toward ridges with higher elevation is the key to maintaining and preserving the ridge and slough landscape pattern in their native state. They also have shown that sediment transport does not occur at the present-day managed Everglades ecosystem. Furthermore, they argue that increasing in flow velocity alone may not result in sediment entrainment in downstream; therefore, pulsed flow is necessary to increase the bed shear stress and redistribute sediments. However, none of these researches have pointed out how particles would be redistributed when a pulsed flow condition is implemented. 
The focus of this study is simulating the distribution of any solute, nutrient or suspended particle using a physical based numerical model of advection-dispersion equation under a sudden pulsed flow condition. The results will help to understand how solutes may entrain or redistribute when conditional pulsed flow is applied.

\subsection{Background}

Study of solute transport in wetlands can be challenging, particularly when it involves data collection and sampling. Physical based models, on the other hand, can be very useful and cost effective tools for analyzing transport processes and help quantify their variables and parameters (Bencala, 1983; Runkel, 1998; Garcia-Martinez et al., 1999; Velleux et al., 2008; Lago et al., 2010; Larsen and Harvey, 2011). Several investigations have focused on physical based numerical modeling of transport in wetlands.

The One-Dimensional Transport with Inflow and Storage (OTIS) model was developed by Runkel (1998) built on the concept of transient storage, a temporary pocket of water that contains solute and becomes stagnant relative to the fast moving mid channel flow (Bencala, 1983). This model was mainly developed to explain water flow in streams and rivers. López and García (1998) used a turbulence $k-\varepsilon$ closure scheme to model steady state suspended sediment transport in flow through vegetation. Their model explains the effect of vegetation drag force on reducing the entrainment of sediment into suspension from channel bed. However, the model does not include the temporal variations in the transport mechanisms. 
With a two-equation turbulence model based on the $k-\varepsilon$ scheme, López and García (1998) determined the mean flow velocity of open channel through vegetation and estimating suspended sediment concentration, which were used to estimate suspended sediment capacity under various flow and vegetation conditions. Their model can only explain the effect of vegetation density and flow of suspended sediment capacity under constant (non-transient) conditions and may not be applicable when conditions such as pulsed flow occurs naturally or implemented through water management practices.

Harvey et al. (2005) developed a one-dimensional transport model to explain a tracer test that was performed at the Everglades National Park. They simulated tracer concentration by adjusting the average velocity, cross-sectional area and the longitudinal dispersion coefficient through a statistical optimization method. Their method explained the concept of storage zone process and how that may affect biogeochemical reactions and water quality in these areas. However, their model does not quantify two-dimensional (aerial) distribution of tracers in open water.

Transport modeling through advection-dispersion with a source and sink formulation has been used vastly to explain various transport processes such as nutrient, contaminants, and suspended particles. For instance, Garcia-Martinez et al. (1999) present a twodimensional finite element model to simulate suspended sediment transport in coastal regions and predict the bed evolution near coastal structures such as channels, docks, and marinas. 
By combining CASC2D (CASCade) and WASP/IPX (Water Quality Analysis Simulation Program/In-Place Pollutant Export), Velleux et al. (2008) developed a Two-Dimensional Runoff Erosion, and Export (TREX) model to simulate chemical fate and transport at the watershed scale. Surface hydrology and sediment transport are simulated by CASC2D, and chemical transport and fate were simulated by WASP/IPX. This model was used to simulate event-based hydrology, sediment transport, chemical transport, fate processes, and assess potential remediation efforts in areas exposed to mining wastewater. However, this model is not applicable to wetland areas such as the Everglades where vegetation plays significant role in hydrology and transport mechanisms.

Transport in wetlands with low hydraulic gradient such as the Everglades involves both nutrient transport, which is one factor that limits vegetation growth, and transport of organic suspended particles (floc) that significantly impact fluxes of organic carbon (Larsen et al., 2009). Therefore, comprehensive experimental and modeling efforts are required to understand the effects of transport in wetland ecosystems. Through a cellularautomata approximation, Larsen and Harvey (2010b) present a numerical model to describe the effect of suspended particle transport along with their previous formulation of "differential peat accretion" (Larsen et al., 2007) on changes in bed elevation in the model domain. They simulated advective-dispersive transport equation over a ten-year period while assuming steady flow conditions over a one-year time step.

In the present investigation, we develop a two-dimensional numerical model to simulate solute transport during a flow perturbation experiment (conditional pulsed flow) in 
wetlands with low topographic gradient and that consist of geomorphic features such as ridge and slough and tree islands, typical of the Everglades landscape. We use this model to simulate a tracer test using Rhodamine dye conducted in the study area and to quantify the effects of changing flow conditions on suspended particle transport. The results of the developed model provide better understanding of transport processes in wetlands with these characteristics and how solute or suspended particles may entrain, transport or deposit in these systems. These results can be used to simulate changes in wetland geomorphology (i.e., bed elevation) in response to changing flow conditions that arise naturally or through water management practices; the latter are predominant in the Everglades.

\subsection{Study Area}

Our study area is located in the Loxahatchee Impoundment Landscape Assessment (LILA) in Boynton Beach, Florida. LILA is referred to as a "living laboratory" model of the Everglades ecosystem that gives researchers the opportunity to apply and test their restoration techniques in a smaller and controlled area before applying in the Everglades. LILA includes an enclosed area of 34 ha (80 acres) at Arthur R. Marshall Loxahatchee National Wildlife Refuge (LNWR), also known as Water Conservation Area 1 (WCA1) as shown in Fig. 3.1. The area is divided into four macrocosms of $200 \mathrm{~m}$ by $400 \mathrm{~m}$ (M1 through M4). Each macrocosm consists of one ridge, one deep slough, two tree islands inside deep slough, and one shallow slough (Fig. 3.2). This assemblage is a replica of 
ridge and slough and tree island landscape feature of the greater Everglades (Scinto et al., 2009; Sullivan et al., 2010; Sullivan et al., 2012).

Water flows into each macrocosm through an inflow culvert at the eastern end and discharges from an outflow culvert at western end. An axial flow submersible pump generates flow through LILA macrocosms. Macrocosms 1 and 3 are non-flowing cells while macrocosms 2 and 4 are constant flowing cells. For the purpose of this study, the flowing cell, M2, was selected as the study area to conduct pulse flow experiments.

\subsection{Materials and Methods}

\subsubsection{Tracer Study}

On October 3, 2007, a tracer study was conducted at LILA to assess water flow patterning in LILA macrocosms and the M2 cell was subjected to an Intracid Rhodamine WT fluorescent dye experiment (Scinto et al., 2009). Density of the dye is reported on Material Safety Data Sheet (MSDS) to be about $1.13 \mathrm{~g} / \mathrm{cm}^{3}$. Approximately, 19.01 (5 Gallons) dye was injected into the cell over 20 minutes from 9:30 am to 9:55 am into the M2 inlet culvert at the inflow location (Fig. 3.2). Dye was injected with a concentration of $59.4 \mathrm{mg} / \mathrm{L}$ at the inflow location. A pulsed flow with a magnitude of $0.34 \mathrm{~m}^{3} / \mathrm{s}$ and a duration of 8 hours was applied at the inflow location where the dye was released. Mahmoudi et al. (2014) developed a two-dimensional flow model and simulated the flow depth and velocity during the pulsed flow implementation. A series of hourly aerial photos were taken to provide a visual record of the dye's path and time of travel over the 
course of the eight-hour study (Scinto et al., 2009). These images were georeferenced in chapter 2 in Arc Map and later used as visual comparison.

\subsubsection{Model Development}

Transport phenomena in fluids takes place through three mechanisms: advection, dispersion, and diffusion. Advection is responsible for carrying solutes, along with the flow at a rate that is proportional to the local flow velocity. Dispersion combines the effects of diffusion and the spatially variable velocity and is responsible for spreading solutes away from the expected path of advection alone. Solutes such as suspended particles are dispersed in both parallel (longitudinal) and perpendicular (transversal) to flow direction. Generally, longitudinal dispersion is greater than transverse dispersion (Zheng and Bennett, 1995; Delgado, 2007). Diffusion is driven by concentration gradients (Fick's Law) and occurs even in the absence of fluid motion.

The two-dimensional depth-averaged solute transport equation (advection-dispersion) can be generally written as follows:

$$
\frac{\partial(h C)}{\partial t}+\left[v_{x} \frac{\partial(h C)}{\partial x}+v_{y} \frac{\partial(h C)}{\partial y}\right]-\left[D_{x x}\left(\frac{\partial^{2}(h C)}{\partial x^{2}}\right)+D_{y y}\left(\frac{\partial^{2}(h C)}{\partial y^{2}}\right)\right]=\gamma
$$

where, $C$ is particle concentration, $h$ is flow depth, $\gamma$ represents source/sink, $v_{x}$ and $v_{y}$ are flow velocity in x, y directions, $D_{x x}$ and $D_{y y}$ are dispersion (includes diffusion) coefficient in $\mathrm{x}, \mathrm{y}$ directions. 
The above equation can be solved numerically using one of several numerical schemes. In this work, we have developed a numerical modeling code that uses an upwinding scheme to solve the equation (Spalding, 1972; Heinrich et al., 1977). The twodimensional upwinding discretization is used for rectangular elements with $\Delta x$ and $\Delta y$ dimensions (Fig. 3.3). Concentrations are calculated at element centers at each time step $(\Delta t)$.

In the present work, the area (M2) was first discretized using a $5 \mathrm{~m}$ by $5 \mathrm{~m}$ square grid elements $(\Delta x$ and $\Delta y)$ as it is shown in Fig. 3.4. Each element consists of initial concentration $\left(C_{0}\right)$, velocity components in $\mathrm{x}$ and y directions $\left(v_{x}\right.$ and $\left.v_{y}\right)$, water depth $(h)$, and final concentration $(C)$. The dye initial concentration at each element throughout M2 was zero. Velocity components and flow depth were simulated using FLO-2D model in chapter 2. The dye was injected at the inflow location into the study area when a conditional pulsed flow was implemented.

A two-dimensional numerical model of solute transport was developed and applied to the dye study in LILA. The transport model simulations result in the spatiotemporal distribution of dye concentrations over the study area during the implementation of a pulsed flow condition. Several images of dye spatial distribution were generated using Arc Map 10.1 software over the period of 8 hrs. Each image depicts the dye distribution at the same time that aerial images were taken. These images were visually compared to aerial images of the dye in order to verify the developed transport model application. 


\subsubsection{Model Setup}

We set up the transport model for the study area with square grid elements of $5 \mathrm{~m}$ by $5 \mathrm{~m}$. We assumed that all elements inside the study area (Fig. 3.4) have a constant initial concentration equal to zero $\left(C_{0}=0.0\right)$. Neumann boundary conditions of constant flux at the edges of the domain are applied; therefore, elements at the boundaries had the same concentration as the neighboring element. A pulse concentration of $59.4 \mathrm{mg} / \mathrm{L}\left(C_{0}=59.4\right.$ $\mathrm{mg} / \mathrm{L}$ ) was applied at the inflow element over 20 minutes. The total simulation time was $8 \mathrm{hrs}$, which represents the entire dye study timeframe. We used the FLO-2D model (O'Brien et al., 1993) to simulate the two-dimensional water flow velocity and depth over the study area chapter 2 . Spatiotemporal distributions of water flow (i.e., velocities $v_{x}(i, j)$ and $v_{y}(i, j)$, and depth $\left(h_{i, j}\right)$ model were used as input in the transport model. For the stability of the model, time step of 10 seconds $(\Delta t=10 \mathrm{~s})$ was selected to calculate concentration at each element. The Peclet number $(P e)$ was also used to determine initial diffusion coefficient value in the model. By definition, Peclet number $(\mathrm{Pe})$ refers to ratio between advection and diffusion in transport and can be written as:

$P e=\frac{\text { Advection }}{\text { Dispersion }}=\frac{u L}{D}$

where, $u$ is flow velocity, $L$ is the distance, and $D$ is dispersion coefficient. In the modeling effort, we impose a numerical constraint on the Peclet number for model accuracy and stability and estimated the initial dispersion coefficient as follow:

$P e=\frac{v_{x} \Delta x}{D_{L}}<2.0$

With an average water flow velocity of $v_{x}=0.02 \mathrm{~m} / \mathrm{s}$, and $\Delta x=5.0 \mathrm{~m}$, a longitudinal dispersion coefficient $\left(D_{L}\right)$ higher than $0.05 \mathrm{~m}^{2} / \mathrm{s}$ must be considered. The simulation 
started with $D_{L}=0.1 \mathrm{~m}^{2} / \mathrm{s}$ and $D_{T}=D_{L} / 2$. Similarly, we assigned a constant molecular diffusion coefficient $\left(D_{x}\right.$ and $\left.D_{y}\right)$ of $0.1 \mathrm{~m}^{2} / \mathrm{s}$ to areas within the slough, where flow velocities are almost zero and solute transport is diffusion dominated. To check the sensitivity of the transport model to changes in dispersion coefficients, additional simulations were performed with higher $\left(D_{L}=0.5 \mathrm{~m}^{2} / \mathrm{s}\right)$ values of longitudinal dispersion coefficient. Lower values of dispersion coefficient were not considered as a result of the Peclet number condition (3.3).

\subsection{Results}

The simulations of the dye experiment are presented visually and evaluated by comparing them to the observed dye results as detected by the air photos taken during the experiment (Fig. 3.5 through Fig. 3.12). Each figure is a snapshot that includes two images: observed aerial image (a) and simulated image (b). These results correspond to a longitudinal dispersion $\left(D_{L}\right)$ of $0.1 \mathrm{~m}^{2} / \mathrm{s}$. The results of transport simulation with higher dispersion coefficient revealed that the model was not sensitive to increase in dispersion coefficient.

Fig. 3.5 shows the simulation and aerial images of the dye 25 minutes after the injection time. The image indicates that the transport model has reasonably reproduced the observed dye movement in the study area. After one hour in Fig. 3.6, the simulated image shows that the dye has been transported into the shallow slough (2) faster than shown by aerial images. While the deep slough simulation replicates aerial results of dye 
movement at the upstream (1), it shows slower transport in southern part of deep slough (3).

Two hours after the dye injection, (Fig. 3.7) both aerial and simulated images show that the dye has been transported into the northern part of the deep slough (1) with very similar patterns. However, the model results have deviated from the observed dye image in the southern part of the deep slough (3). Transport in the shallow slough (2) is faster in model results than in the observed dye image.

Fig. 3.8 displays the dye behavior after three hours. Although the aerial image only covers the study area, it indicates that the stream of dye in the southern deep slough (3) has reached behind the densely vegetated area in mid section of the study area while model results stay behind the observed dye movement in those zones (3). However, simulated results exhibit similar movement in northern deep slough (1) and fast movement in the shallow slough (2).

Model results between 4 and 7 hours after injection show partial replication of dye behavior in the study area (Fig. 3.9 through Fig. 3.12). Model results replicate the dye behavior in the northern part of the deep slough (1) in Fig. 3.9 but underestimate the rate of dye transport in the southern part of the deep slough (3). The simulated results also display almost equal rates of transport between the two east and west tree islands (4). Because of the partial aerial photos of the area, no observed image was taken of the shallow slough until 5 hours after injection as shown in Fig. 3.10. In this figure, 
movement of the dye inside the shallow slough (2) is similar in both aerial and simulated images. The image also indicates reasonably close dye transport behavior in both aerial and simulated through spreading canal at the inflow location (5).

The aerial photo in Fig. 3.11 (upper image) indicates that dye exiting the deep slough at point (3) and entering eastern spreading canal (5) moving toward outflow location, while simulated results (lower image) show dye outflow through the shallow slough rather than the deep slough.

The simulated image in Fig. 3.12 however is in good agreement with the aerial photo of the dye after 7 hours of injection. This model results show good visual agreement with the observed dye movement in the upstream deep slough at the northwest corner of the study area, in the northern deep slough (1) and in the mixing zone (4) in the mid section between west and east tree islands while it fails to capture the dye transport downstream of deep slough. The simulated image also indicates that dye would exit the study area faster through the shallow slough rather than through the deep slough.

\subsection{Discussion}

In general, visual inspection of the model results indicates that they are in good agreement with aerial images in the northern part of the deep slough, and inside the eastern spreading canal. However, the simulated results fail to produce similar dye behavior in areas farther away from the injection point, and downstream. The results of a 
previous model simulation (chapter 2) indicate that some of these areas have experienced almost no flow velocity. This may be a reasonable explanation for the model failure to simulate the observed dye distribution shown in areal photos. Despite of previous studies in the Everglades (Saiers et al., 2003; Harvey et al., 2005; Huang et al., 2008) arguing that the transport is dominated by advection, Delgado (2007) explains that at low flow velocity (near zero), transport is dominated by diffusion and dispersion rather than advection in areas where velocity is almost zero. That may result in very low Peclet number $(\mathrm{Pe}=0.8)$ as Dierberg et al. (2005) has documented in their work. In the present study, average velocity is about $0.02 \mathrm{~m} / \mathrm{s}$ resulting in Peclet number close to 2 with more advection dominating flow.

Transport is also highly affected by vegetation coverage. Flooded areas with dense vegetation coverage, particularly inside the slough, may experience very small or no velocity resulting in relatively small rates of transport by either advection or dispersion. However, aerial images show that despite no flow conditions, the dye still moves; which can be evidence of a diffusion-dominant transport process rather than dispersionadvection in those areas.

The simulated images also indicate areas where mixing occurs (chapter 2). Complex flow patterns inside the study area create mixing zones where the flow direction is not uniform but changes constantly during the pulsed flow conditions. This anomaly will create mixing zones within deep sloughs, between tree islands and downstream of the deep slough (chapter 2) causing the dye to stay longer and disperse more uniformly in 
those areas as it is shown at (4) in Fig. 3.12. These areas particularly experience dispersion and diffusion rather than advective transport, which causes delay in dye transport towards the outflow. The simulated results also show that the model is not sensitive to increasing longitudinal and transversal dispersion, as results were very similar with higher values of $\mathrm{D}_{\mathrm{L}}$ and $\mathrm{D}_{\mathrm{T}}$.

To quantify the dye concentration, water samples were taken at different locations inside the study area during the course of the dye study. However, we disregarded these data because of inconsistencies between reported data from different sources at the injection point. Consequently, no reliable concentration data were available for calibrating the dispersion coefficients. We thus used the observed aerial images showing the extent of the dye dispersion into the wetland and calibrated the model based on visual examination and comparison.

Results from the hydrologic flow model indicate that some areas within the deep and shallow sloughs may experience low to almost no flow velocity for a very short time during a pulsed flow condition. These areas experience some transport by diffusion rather than dispersion. Uncertainties in diffusion, longitudinal and transversal dispersion coefficients estimates are another factor that can produce results that may not be in agreement with available experimental or field measurements. 


\subsection{Conclusion}

The current study presents the development and application of a numerical transport model to simulate the spatiotemporal distribution of solute concentration in wetlands with low topographic gradients and high vegetation density. The transport model is derived from the two-dimensional vertically averaged advection-dispersion equation, which was solved numerically using a finite difference scheme with upwinding. The model application is based on visual comparison of simulated and observed aerial images taken during a tracer test conducted on October 3, 2007. The results indicate that the developed model was simulated well most of the dye tracer plume movement in the study area throughout the eight hours duration of the dye test. Our sensitivity analysis indicated that transport is highly affected by hydrologic conditions such as velocity and depth, which

are directly controlled by topography and vegetation coverage. Uncertainties in these factors may result in deviation from observed values.

In general, the results show that the developed model is able to simulate transport mechanism in wetlands and can be used as a tool to simulate transport for substances such as nutrients and suspended particles. In addition, the results from this model can be further used to simulate erosion and deposition processes in wetlands and how they may affect in bed elevation and morphology in wetlands with high vegetation density and low topographic gradient where experimental study is difficult. 


\subsection{References}

Bencala, K. E., 1983, Simulation of solute transport in a mountain pool - and - riffle stream with a kinetic mass transfer model for sorption: Water Resources Research, v. 19, no. 3, p. 732-738.

Delgado, J., 2007, Longitudinal and transverse dispersion in porous media: Chemical Engineering Research and Design, v. 85, no. 9, p. 1245-1252.

Dierberg, F. E., Juston, J. J., DeBusk, T. A., Pietro, K., and Gu, B., 2005, Relationship between hydraulic efficiency and phosphorus removal in a submerged aquatic vegetation-dominated treatment wetland: Ecological Engineering, v. 25, no. 1, p. 9-23.

Garcia-Martinez, R., Saavedra, I. C., De Power, B. F., Valera, E., and Villoria, C., 1999, A two-dimensional computational model to simulate suspended sediment transport and bed changes: Journal of Hydraulic Research, v. 37, no. 3, p. 327344.

Harvey, J. W., Saiers, J. E., and Newlin, J. T., 2005, Solute transport and storage mechanisms in wetlands of the Everglades, south Florida: Water Resources Research, v. 41, no. 5, p. n/a-n/a.

Heinrich, J., Huyakorn, P., Zienkiewicz, O., and Mitchell, A., 1977, An 'upwind' finite element scheme for two - dimensional convective transport equation: International Journal for Numerical Methods in Engineering, v. 11, no. 1, p. 131143.

Huang, Y. H., Saiers, J. E., Harvey, J. W., Noe, G. B., and Mylon, S., 2008, Advection, dispersion, and filtration of fine particles within emergent vegetation of the Florida Everglades: Water Resources Research, v. 44, no. 4, p. 13.

Kadlec, R. H., and Hammer, D. E., 1982, Pollutant transport in wetlands. Marshes, bogs, or other types of wetland prove to be excellent receivers for the disposition of treated wastewaters containing small amounts of dissolved nitrogen and phosphorus: Environmental Progress, v. 1, no. 3, p. 206-211.

Lago, M. E., Miralles-Wilhelm, F., Mahmoudi, M., and Engel, V., 2010, Numerical modeling of the effects of water flow, sediment transport and vegetation growth on the spatiotemporal patterning of the ridge and slough landscape of the Everglades wetland: Advances in Water Resources, v. 33, no. 10, p. 1268-1278.

Larsen, L. G., and Harvey, J. W., 2010a, How vegetation and sediment transport feedbacks drive landscape change in the Everglades and wetlands worldwide: The American Naturalist, v. 176, no. 3, p. E66-E79. 
Larsen, L. G., and Harvey, J. W., 2010b, How vegetation and sediment transport feedbacks drive landscape change in the everglades and wetlands worldwide: Am Nat, v. 176, no. 3, p. E66-79.

Larsen, L. G., and Harvey, J. W., 2011, Modeling of hydroecological feedbacks predicts distinct classes of landscape pattern, process, and restoration potential in shallow aquatic ecosystems: Geomorphology, v. 126, no. 3-4, p. 279-296.

Larsen, L. G., Harvey, J. W., and Crimaldi, J. P., 2007, A Delicate Balance: Ecohydrological Feedbacks Governing Landscape Morphology in a Lotic Peatland: Ecological Monographs, v. 77, no. 4, p. 591-614.

Larsen, L. G., Harvey, J. W., and Crimaldi, J. P., 2009, Morphologic and transport properties of natural organic floc: Water Resources Research, v. 45, no. 1, p. n/an/a.

López, F., and García, M., 1998, open-channel flow through simulated vegetation: Suspended sediment transport modeling: Water Resources Research, v. 34, no. 9, p. 2341-2352.

Mahmoudi, M., Garcia-Martinez, R., Miralles-Wilhelm, F., and Wdowinski, S., 2014, High Resolution Two-Dimensional Modeling of Flow Pulses Discharge into Wetlands: Hydrologic Engineering.

O'Brien, J. S., Julien, P. Y., and Fullerton, W. T., 1993, Two-dimensional water flood and mudflow simulation: Journal of hydraulic engineering, v. 119, no. 2, p. 244-261.

Runkel, R. L., 1998, One-dimensional transport with inflow and storage (OTIS): A solute transport model for streams and rivers, US Department of the Interior, US Geological Survey.

Saiers, J. E., Harvey, J. W., and Mylon, S. E., 2003, Surface - water transport of suspended matter through wetland vegetation of the Florida everglades: Geophysical Research Letters, v. 30, no. 19.

Science Coordination Team, S. F. E. R. W. G., 2003, The role of flow in the Everglades ridge and slough landscape: USGS.

Scinto, L., Price, R., and Ross, M., 2009, LILA (Loxahatchee Impoundment Landscape Assessment) Tree Island, Ridge, Slough Studies and Site Management. May 1, 2005 to September 4, 2009, Final Report submitted to SFWMD, Aug 17, 2009, $11 \mathrm{pp}$

Spalding, D., 1972, A novel finite difference formulation for differential expressions involving both first and second derivatives: International Journal for Numerical Methods in Engineering, v. 4, no. 4, p. 551-559. 
Sullivan, P. L., Price, R. M., Miralles-Wilhelm, F., Ross, M. S., Scinto, L. J., Dreschel, T. W., Sklar, F. H., and Cline, E., 2012, The role of recharge and evapotranspiration as hydraulic drivers of ion concentrations in shallow groundwater on Everglades tree islands, Florida (USA): Hydrological Processes, p. n/a-n/a.

Sullivan, P. L., Price, R. M., Ross, M. S., Scinto, L. J., Stoffella, S. L., Cline, E., Dreschel, T. W., and Sklar, F. H., 2010, Hydrologic processes on tree islands in the Everglades (Florida, USA): tracking the effects of tree establishment and growth: Hydrogeology Journal, v. 19, no. 2, p. 367-378.

Velleux, M. L., England Jr, J. F., and Julien, P. Y., 2008, TREX: Spatially distributed model to assess watershed contaminant transport and fate: Science of the Total Environment, v. 404, no. 1, p. 113-128.

Zheng, C., and Bennett, G. D., 1995, Applied contaminant transport modeling: theory and practice, Van Nostrand Reinhold New York. 


\subsection{Figures}

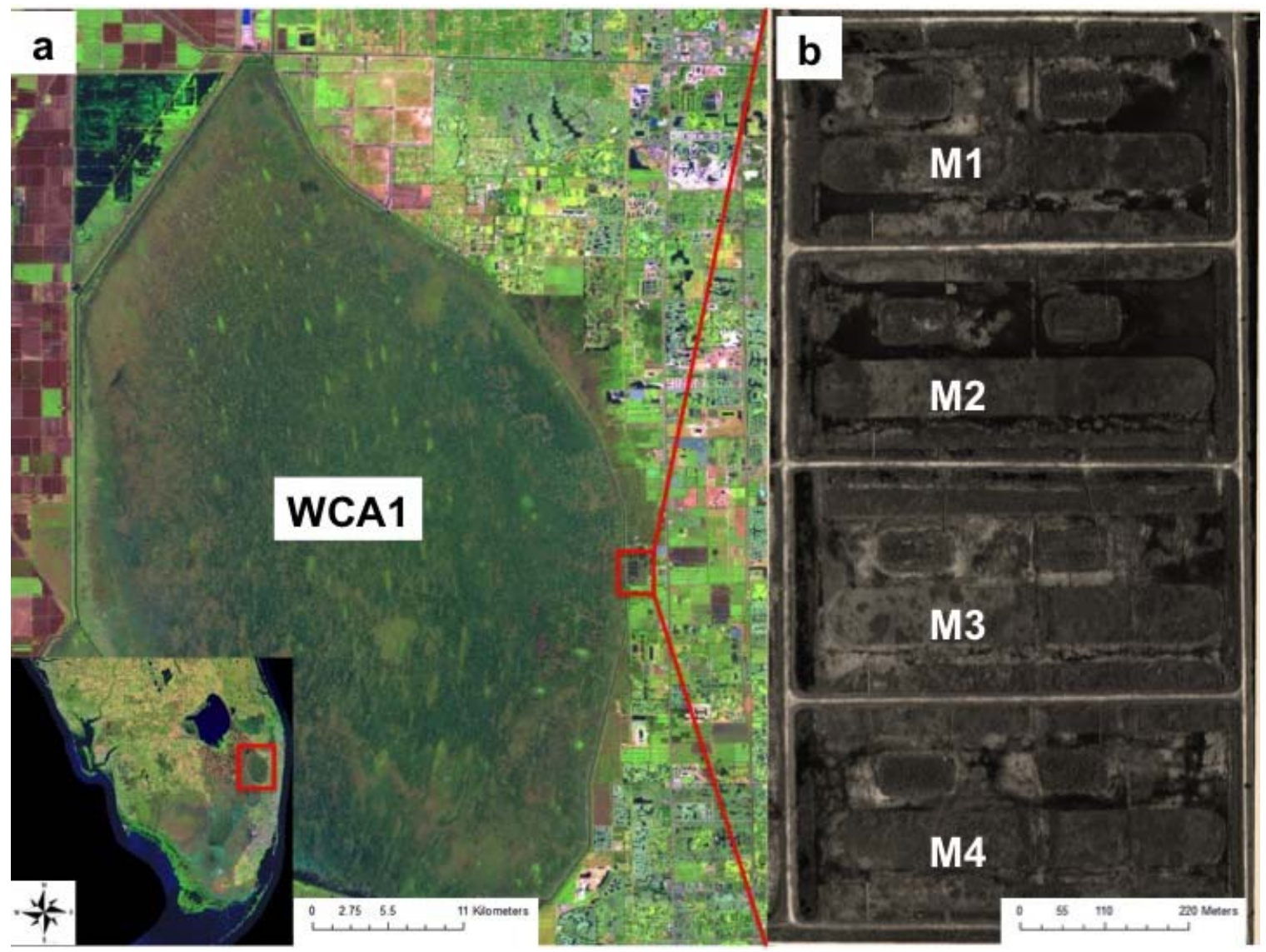

Fig. 3.1: (a) LILA location at the eastern boundary of WCA-1. The location with respect to southern Florida is shown in the insert. (b) Air plot showing the four macrocosms of LILA 


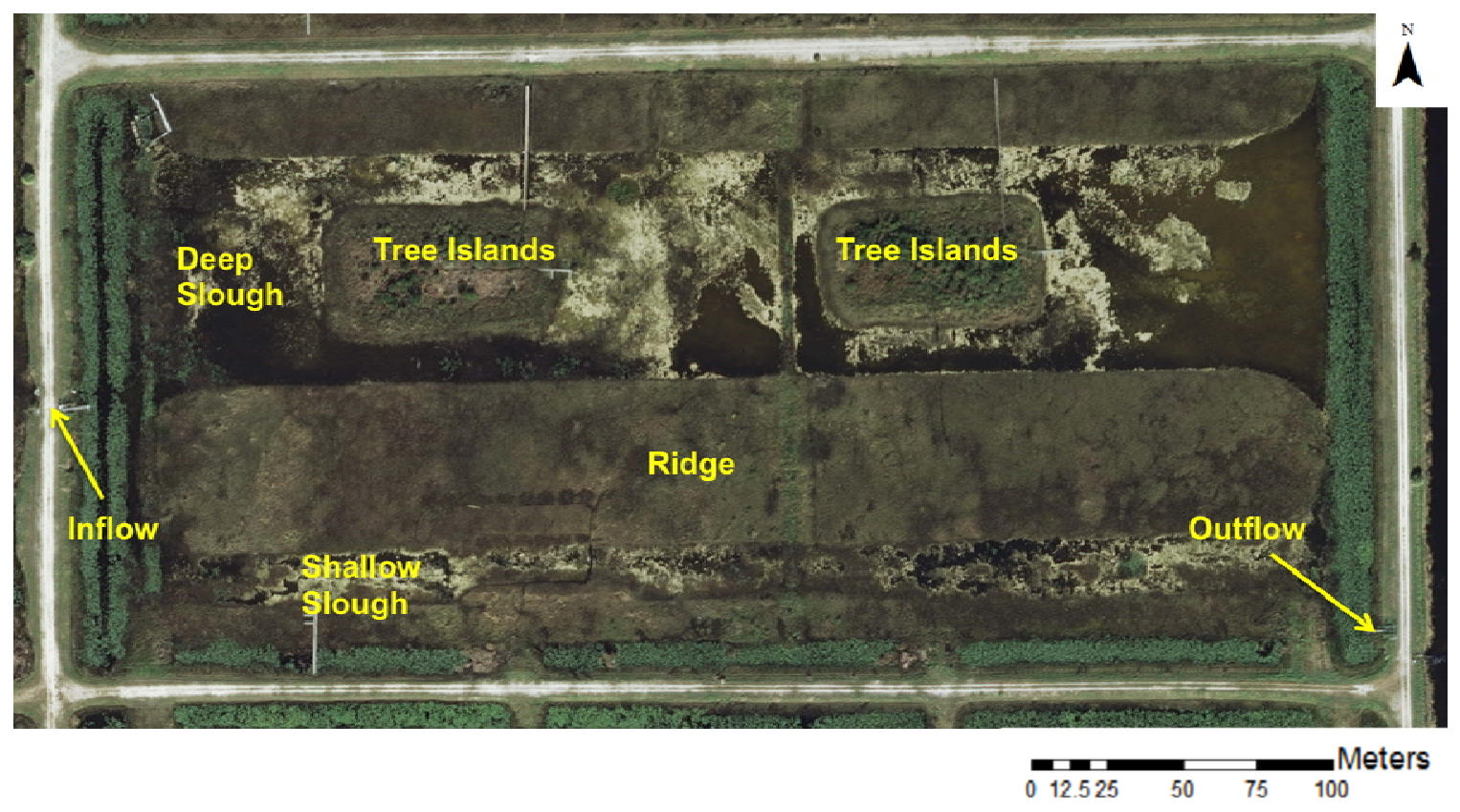

Fig. 3.2: Air photo of M2 in LILA site, showing the main landscape features 


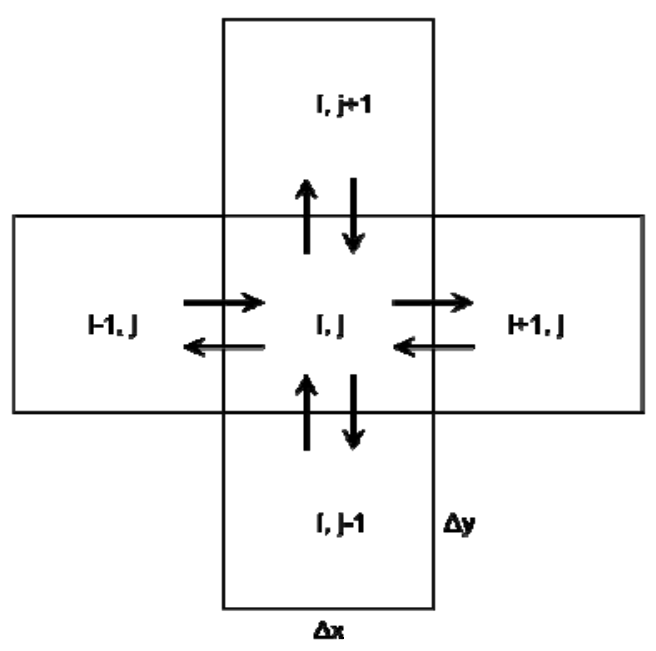

Fig. 3.3: Finite Difference Upwinding discretization. Flow can enter or exit an element in both horizontal and vertical dimension. Elements are rectangular with length and width of $\Delta \mathrm{x}$ and $\Delta \mathrm{y}$ respectively. 


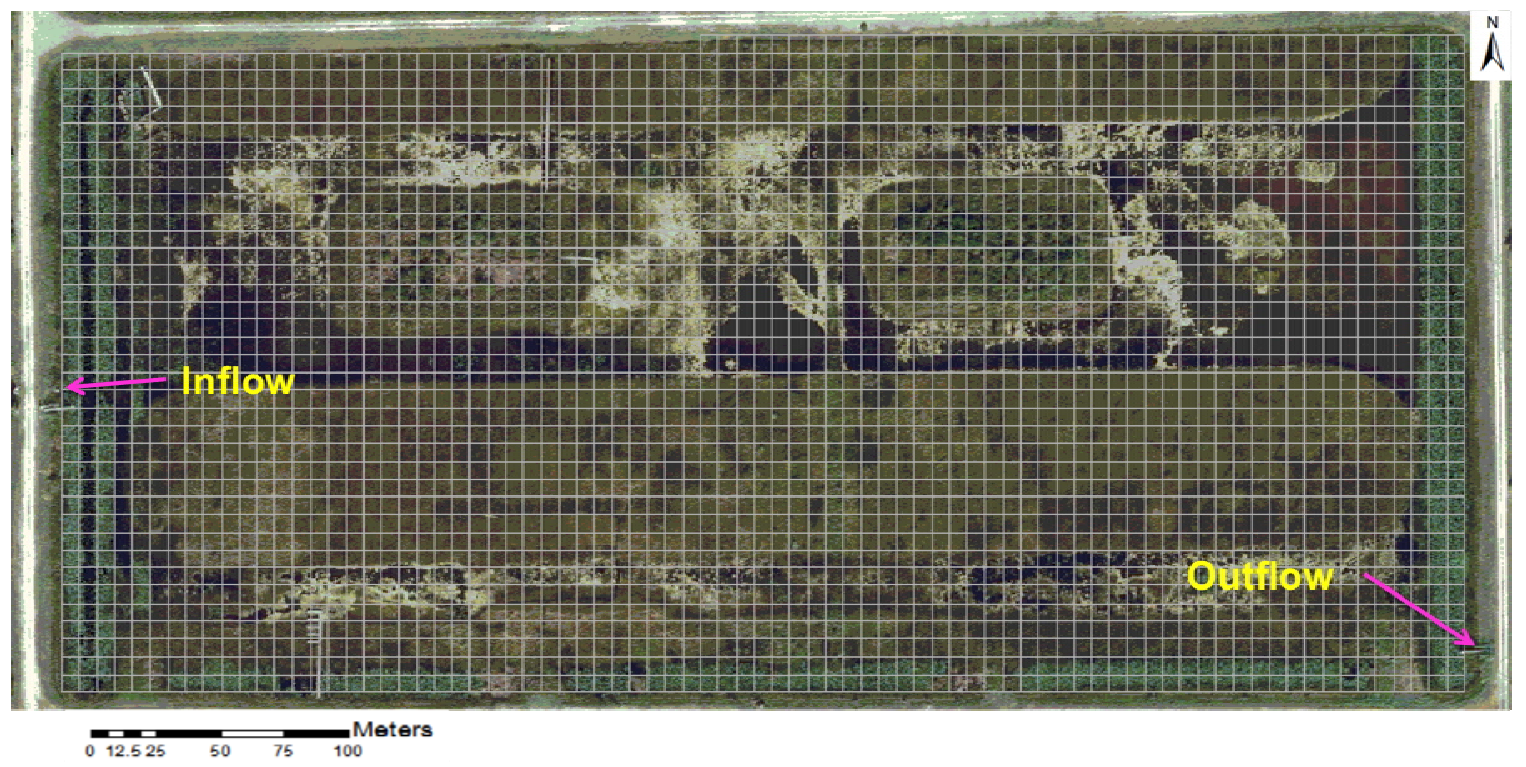

Fig. 3.4: Air photo showing macrocosm 2 (M2), grid system, and inflow/outflow locations 

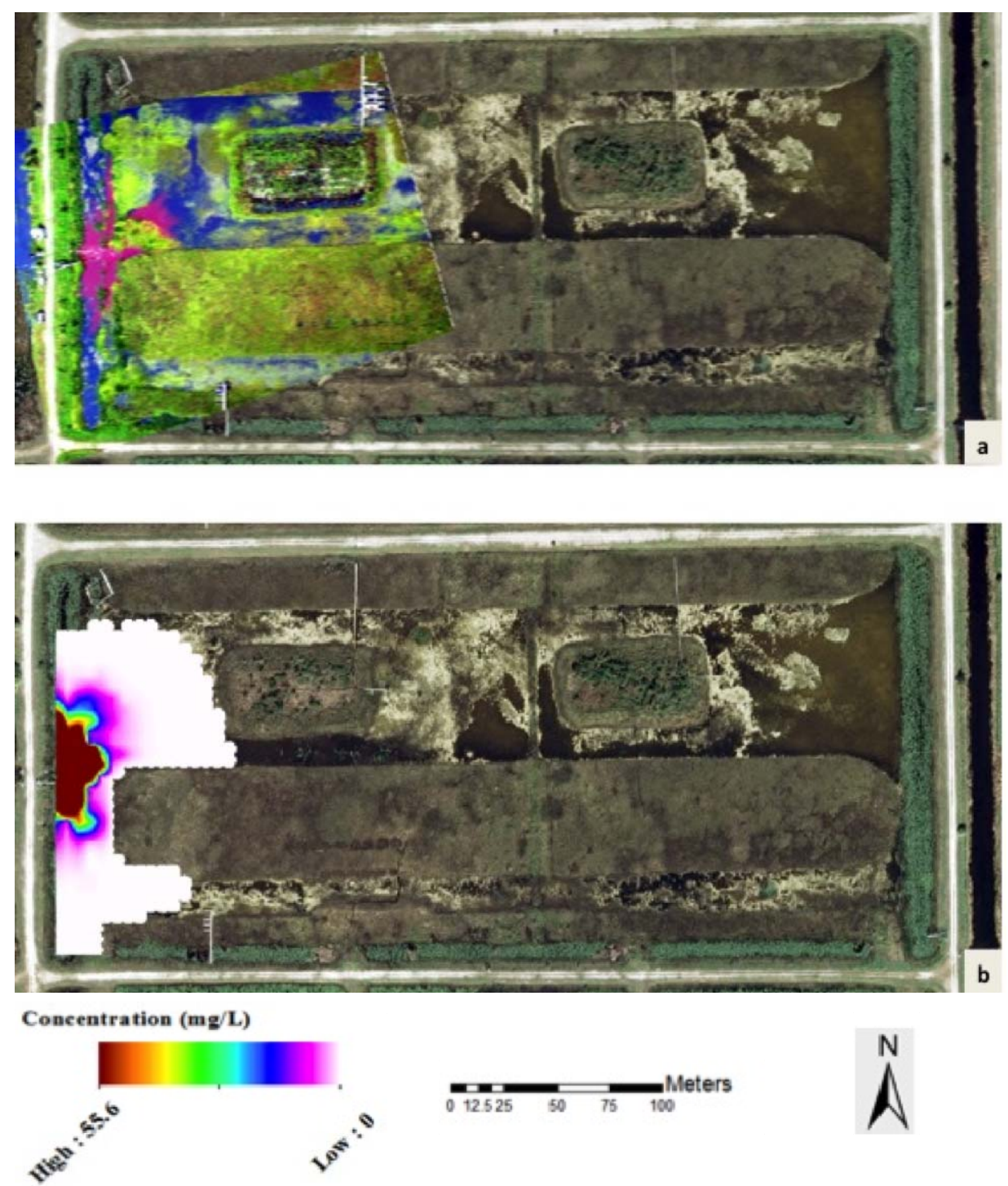

Fig. 3.5: Areal photo of M2 showing the observed (a) and simulated (b) of the dye transport 25 minutes after dye injection 


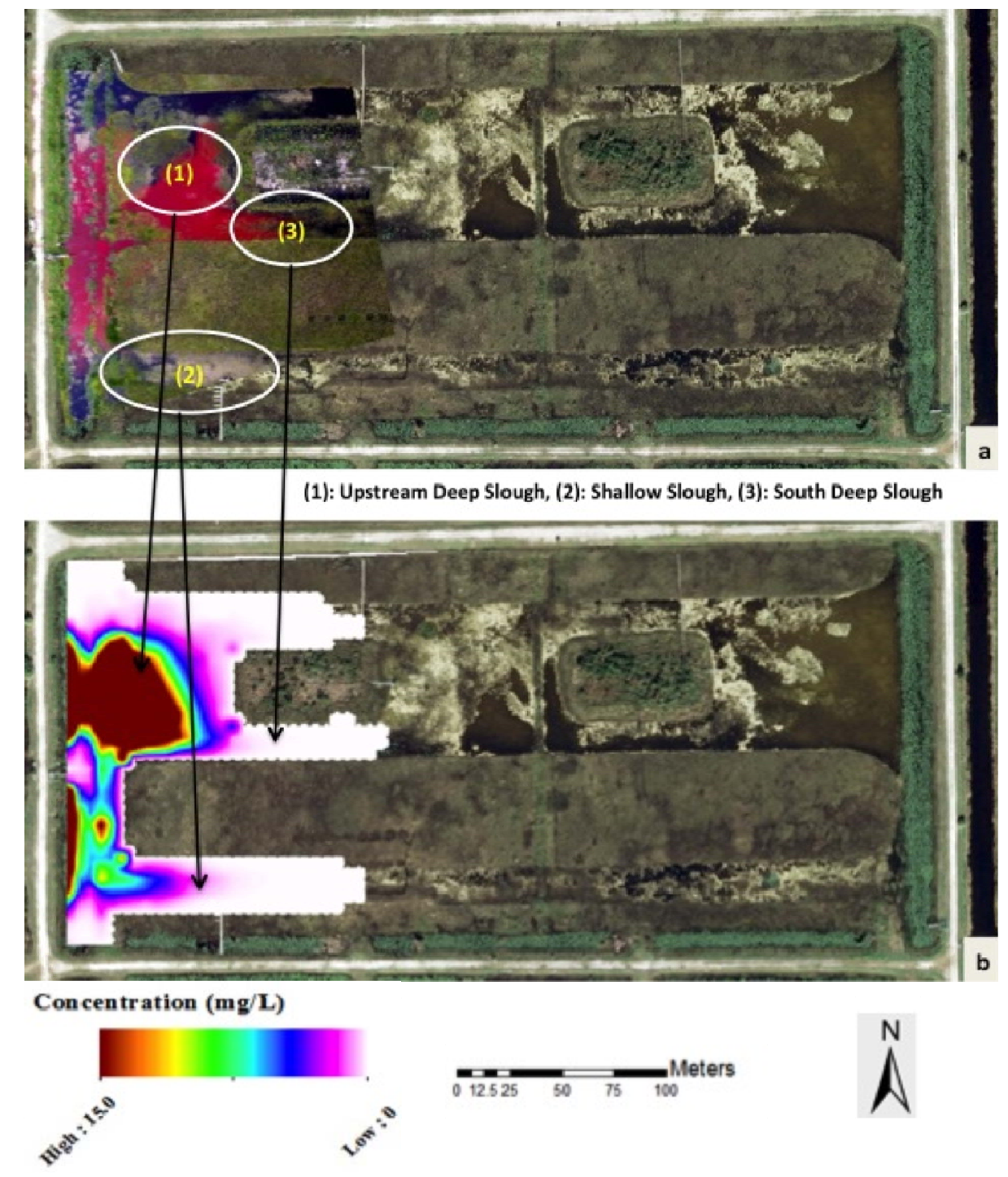

Fig. 3.6: Dye transport, one hour after injection, a) areal photo, b) simulated results 


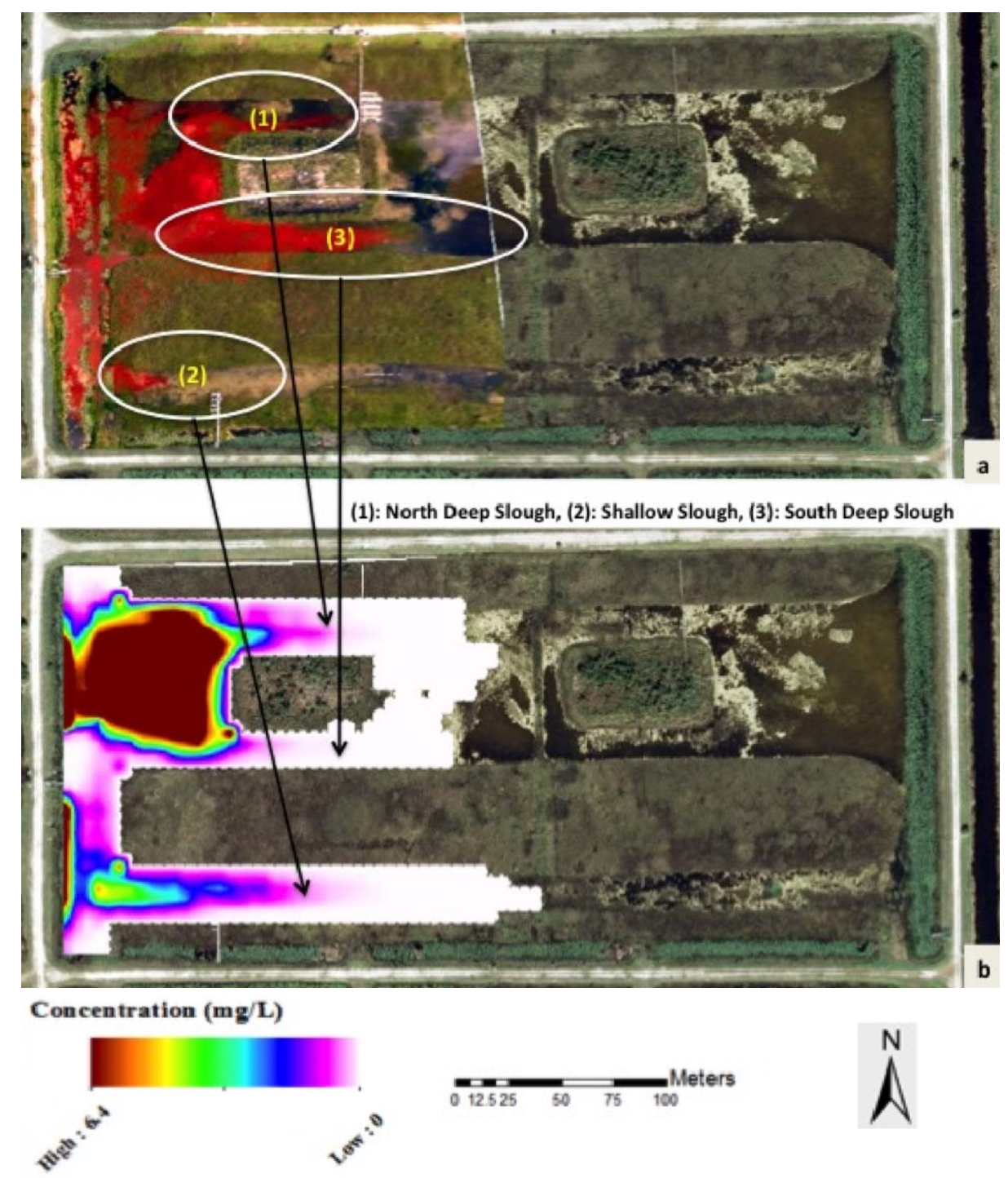

Fig. 3.7: Dye transport, 2 hours after injection, a) areal photo, b) simulated results 


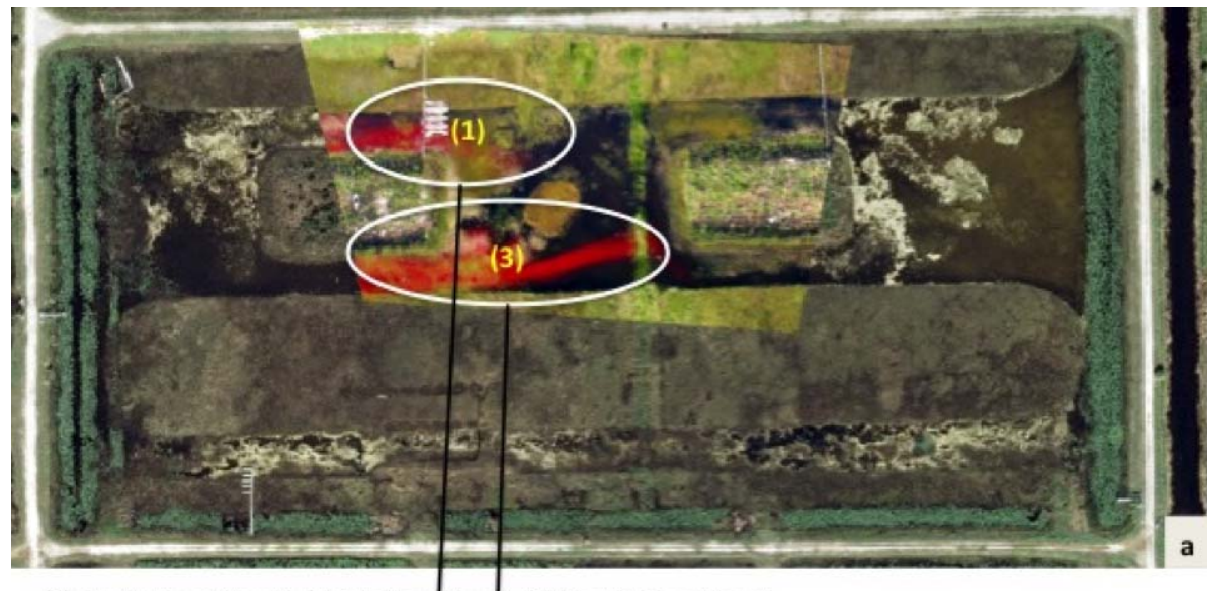

(1): North Deep Slough, (2): Shallow slough, (3): South Deep Slough

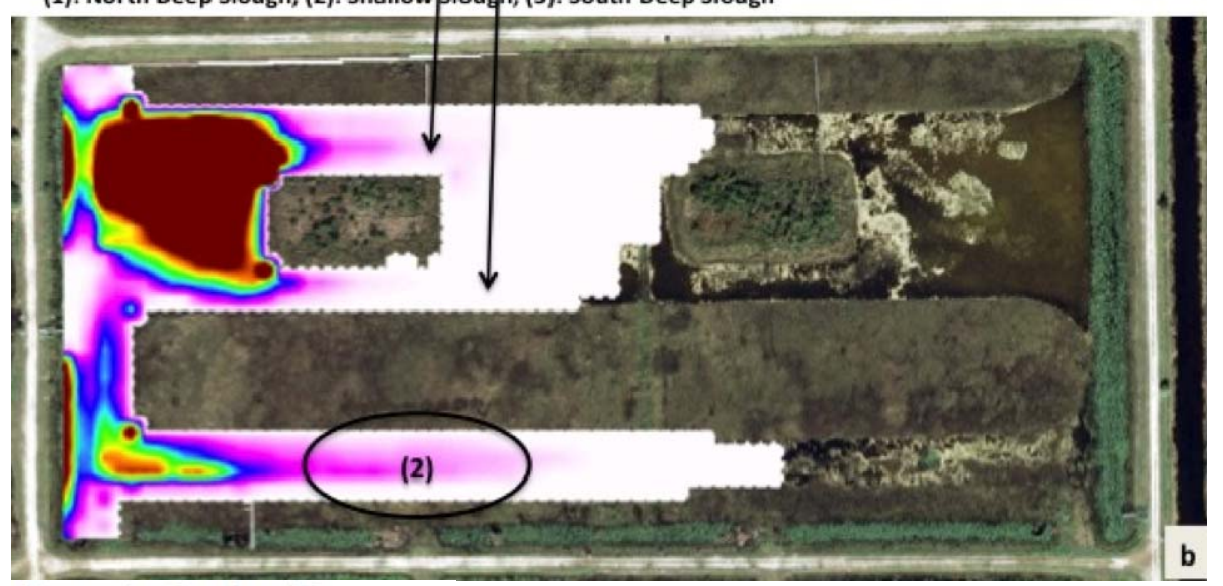

Concentration $(\mathrm{mg} / \mathrm{L})$

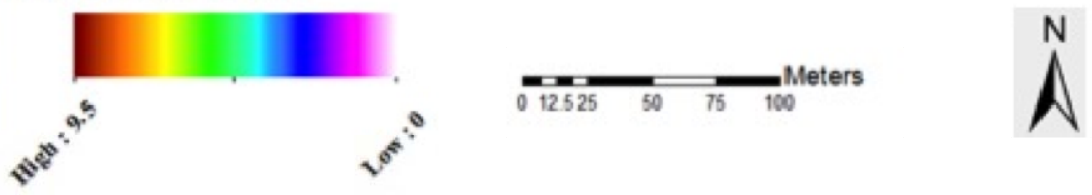

Fig. 3.8: Dye transport, 3 hours after injection 


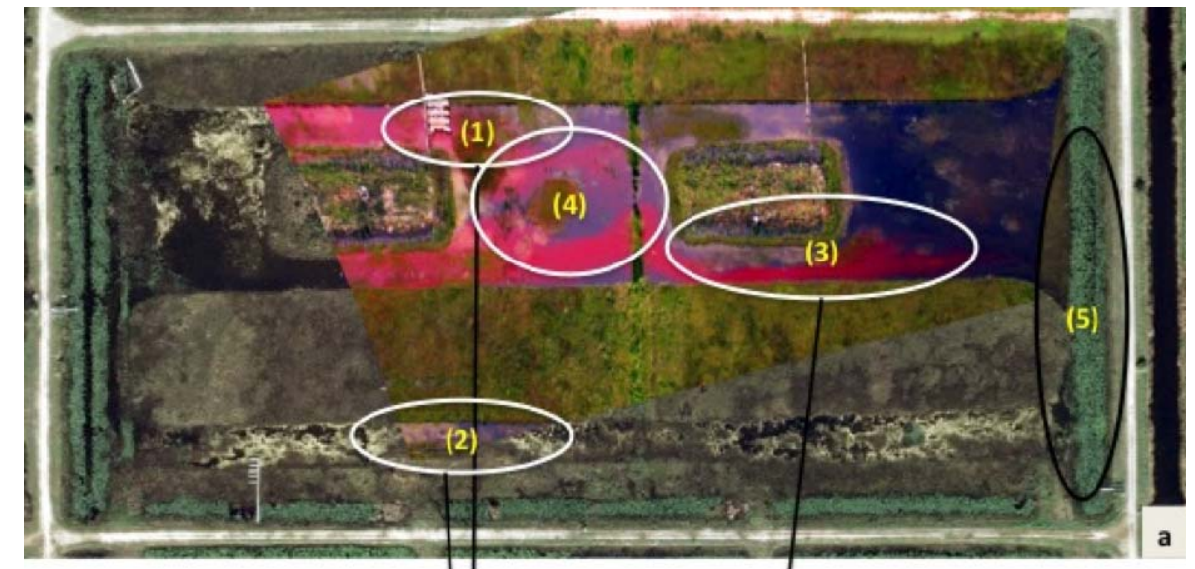

(1): North Deep Slough, (2): Shallow SIфugh, (3): South Deep Slough, (4): Midway, (5): Spreading Canals
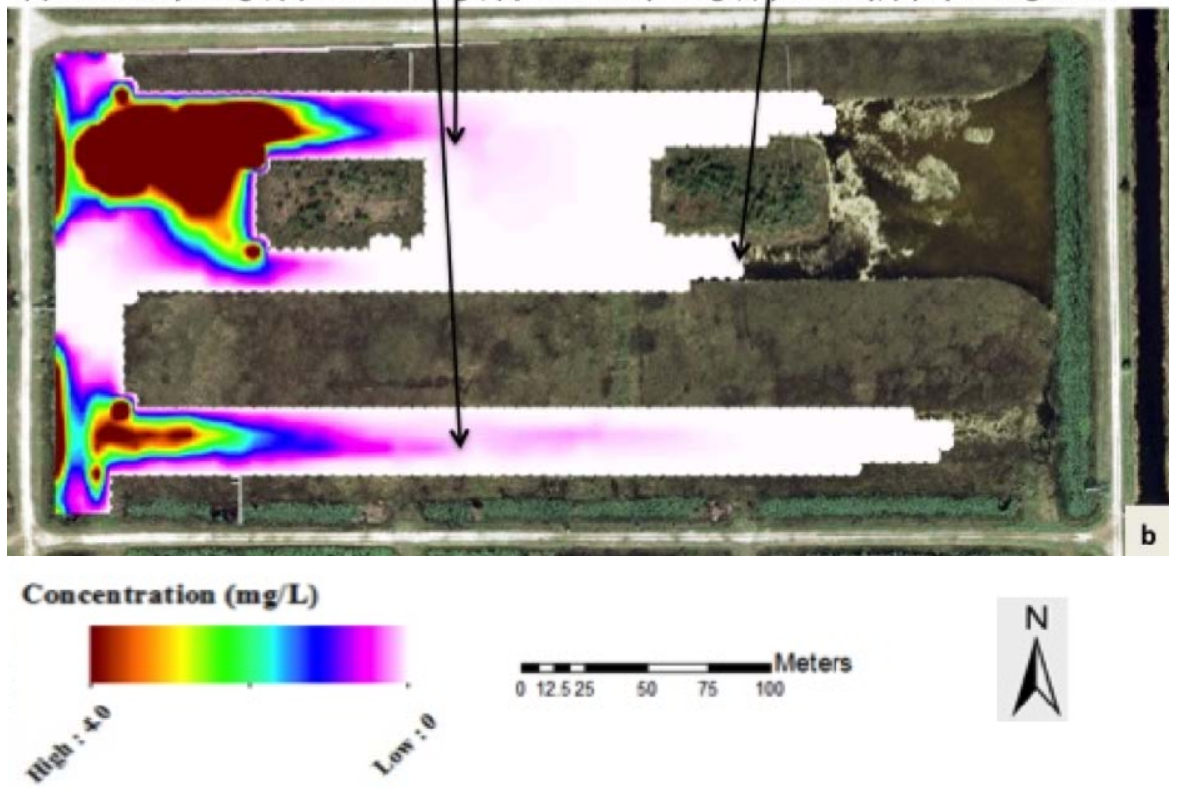

$N$

Fig. 3.9: Dye transport, 4 hours after injection 


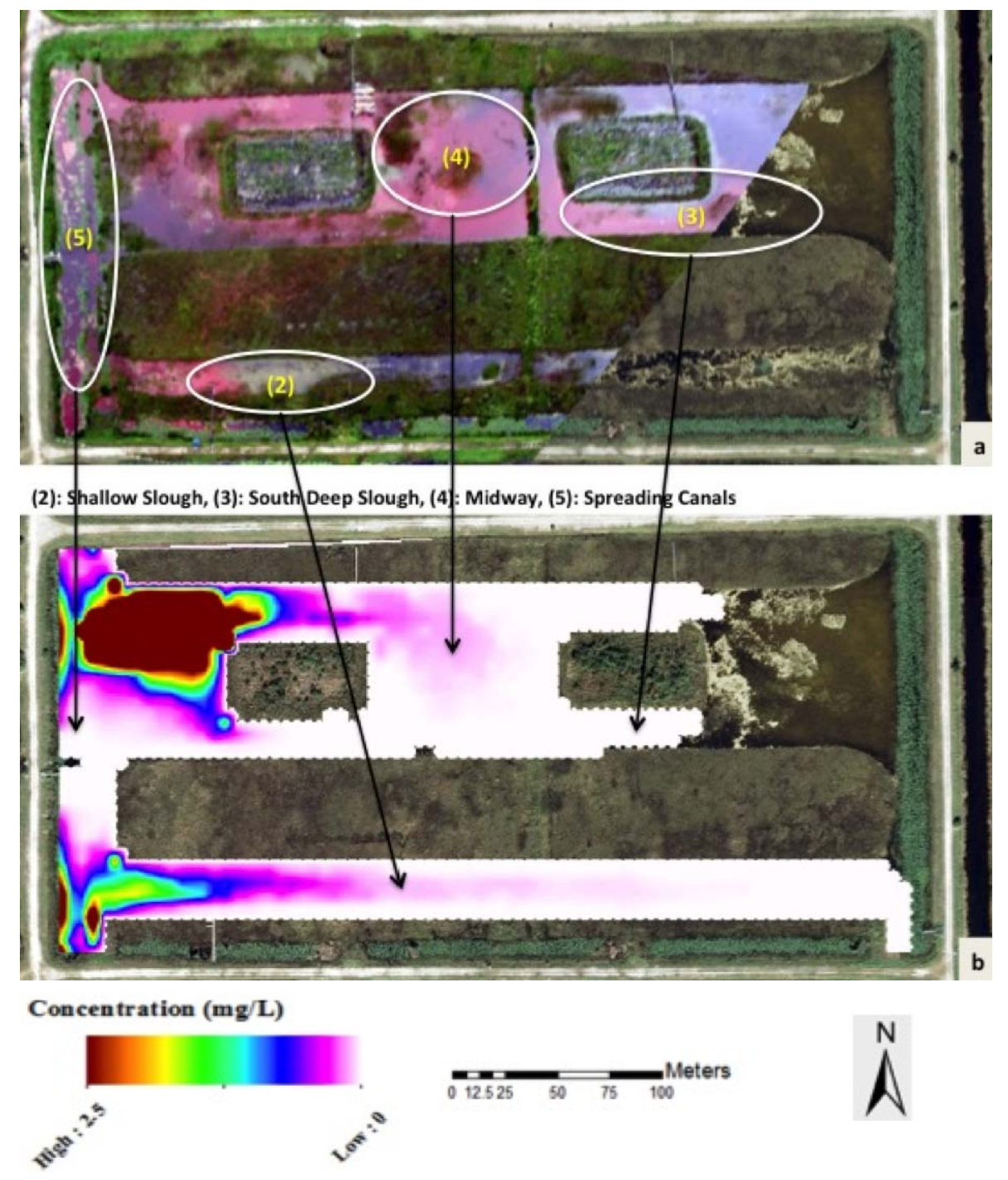

Fig. 3.10: Dye transport, 5 hours after injection 


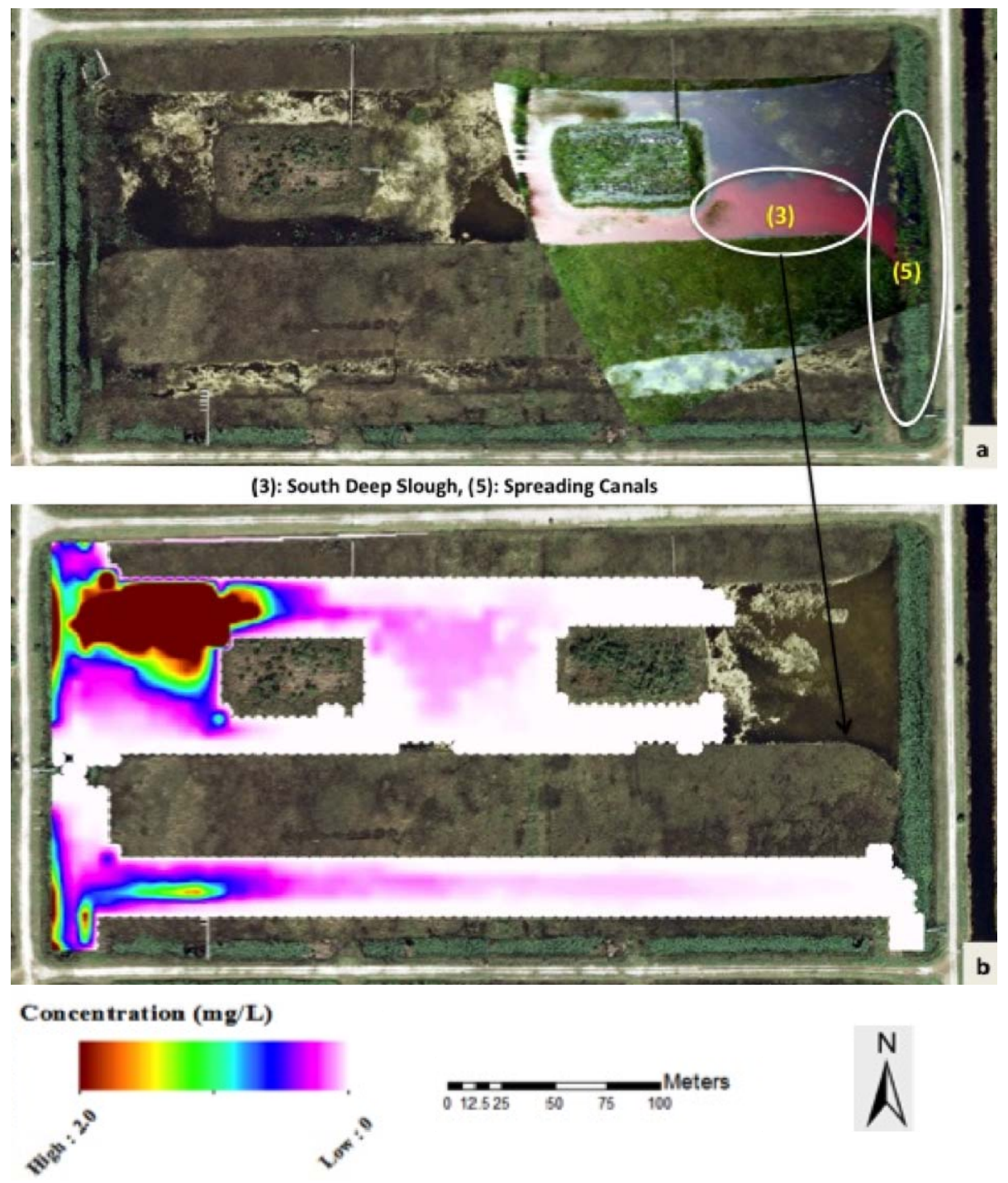

Fig. 3.11: Dye transport, 6 hours after injection 


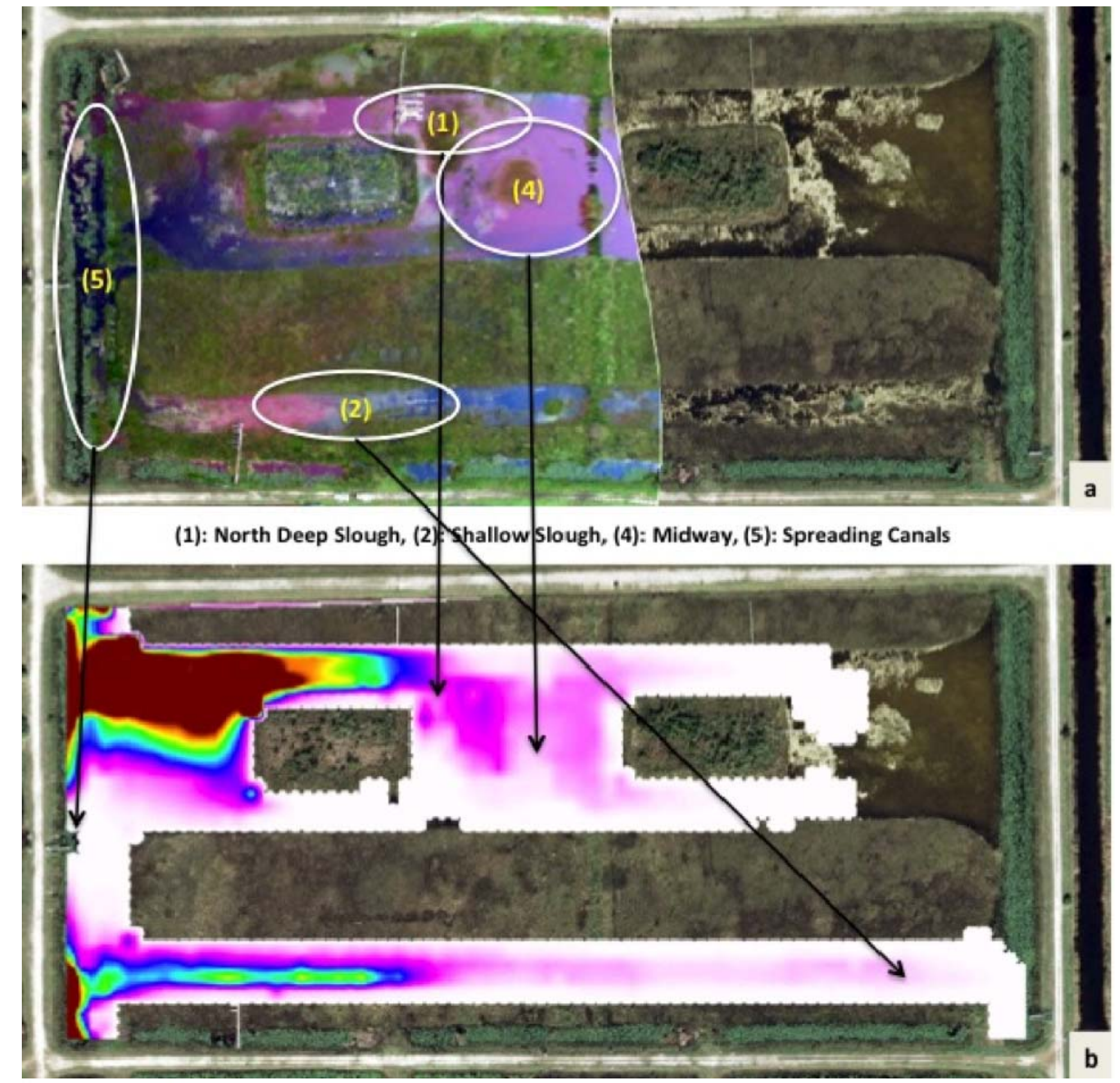

Concentration $(\mathrm{g} / \mathrm{L})$

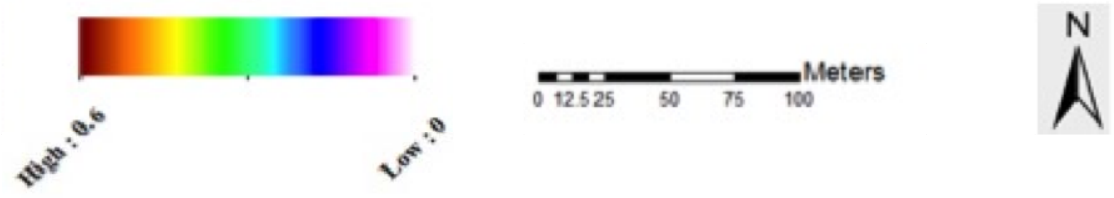

Fig. 3.12: Dye transport, 7 hours after injection 
CHAPTER 4: NUMERICAL MODELING OF SEDIMENT TRANSPORT IMPACTS ON SPATIOTEMPORAL VARIATION OF BED MORPHOLOGY IN WETLANDS: CASE STUDY IN THE LOXAHATCHEE IMPOUNDMENT LANDSCAPE ASSESSMENT (LILA) SITE

\subsection{Abstract}

Two-dimensional numerical models of suspended sediment transport and bed elevation have been developed to explain the spatiotemporal distribution of the suspended particles and how it dictates the bed elevation changes in wetlands with high vegetation density and low topographic gradient during a conditional pulsed flow. These models are tested for a pulsed flow condition and applied to the study in Loxahatchee Impoundment Landscape Assessment (LILA), which is located in Boynton Beach, Florida. The results of bed simulation have shown very small magnitude of change in bed elevation inside the deep slough and no changes on the ridge portion of the study area, when a conditional pulsed flow is applied. Sensitivity analyses indicate that the bed elevation may changes when either proportionality factor or resuspension rate is increased or decreased significantly. However, the sediment transport model did not produce stable results when a vegetation filtration factor is added to the source/sink equations. These findings may suggest that implementing pulsed flow conditions did not increase suspended sediment concentration, which results in insignificant changes in bed morphology of a ridge and slough landscape. Therefore sediment transport may not play an important role in wetland bed morphology and ridge and slough stability. 


\subsection{Introduction}

Wetlands typically exhibit various spatial landscape patterning such as "hammocks and hollows" (Sakaguchi, 1980; Lindsay et al., 1985; Belyea and Lancaster, 2002), "maze and string" (Foster et al., 1983; Rietkerk et al., 2004), "ridge and slough", and "tree islands" (Ogden, 2005; Larsen et al., 2007). The latter two are predominant landscape patterns found in the Everglades wetland, a subtropical fresh water wetland that is located in south Florida. The Everglades extends from Orlando and Kissimmee River in northern Florida to Florida Bay in the south (Fig. 4.1). The ridge and slough lanscape (Fig. 4.2) is an organized spatial pattern with vegetation oriented parallel to the flow direction and consisting of elevated elongated topographic features (ridges) largely vegetated by dense sawgrass (Cladium jamaicense) adjacent to free-flowing open water channels with less dense vegetation (sloughs). Historically, sloughs in the Everglades are $60-90 \mathrm{~cm}$ deeper than ridges (Fig. 4.3) and may stay flooded year around (Wright, 1912; Baldwin and Hawker, 1915). Present day surveys show that the difference of between ridge and slough elevation has reduced to $20-45 \mathrm{~cm}$ (Science Coordination Team, 2003).

Recent human activities such as compartmentalization and water management measurements have resulted in the loss of the ridge and slough landscape. The Science Coordination Team (2003) has defined the loss of ridge and slough landscape as flattening of the topography and loss of a directional vegetation patterning occurring over decades or more. Therefore, restoration plans have to be made on a time frame less than decade. They also hypothesized that sediment transport is one of the mechanisms responsible for topographically flattening of the ridge and slough landscape. However, 
few studies have focused on the effect of sediment transport on wetland bed morphology; yet, the importance of this process in developing and maintaining the ridge and slough landscape in the Everglades is not well understood.

Sediment transport is recognized as one of the factors that determine bed evolution in channels, rivers, estuaries and coastlines. Sediment transport is also important in maintenance and functioning of hydraulic structures. Laboratory experiments and in-situ data collection of sediment transport are generally costly, time consuming, and sometimes impossible in areas with limited accessibility. Therefore, mathematical models are often used to estimate sediment transport and bed evolution, and to support management and decision making in this kind of environmental setting.

Several investigations have been carried out to explain the effect of sediment transport on bed morphology. Lin et al. (1983) used a one-dimensional model to simulate morphological changes in estuaries and coastal regions where high concentration of sediments are carried by unsteady tidal flow. The authors argued that because sediments are so fine grain, suspension becomes the predominant mode of sediment transport in these areas. Although this formulation may be able to evaluate the spatial and temporal variations of sediment concentration in coastal areas, it is not suitable for wetlands with high vegetation density and low flow velocity. Their works was extended by GarciaMartinez et al. (1999) who developed a relatively simple, two-dimensional finite element mathematical model to simulate suspended sediment transport in coastal regions and 
predict the bed evolution near coastal structures (e.g., channels, docks, marinas, etc.) but the model has been applied to wetlands with high vegetation density.

Guo and Jin (1999) have developed a one-dimensional mathematical model to calculate bed changes in alluvial channels with suspended sediment. They solved the suspended sediment concentration equation by introducing sediment carrying capacity and control volume formulation and compared their results with the Hydraulic Engineering Center (HEC-6) model simulation and data obtained from laboratory flume experiments. Their model shows a good agreement with the HEC-6 model and laboratory flumes results. However, their model is only applicable for alluvial riverbed evolution where flow velocities and suspended sediment concentrations are high.

Larsen et al. (2007) postulated that the redistribution of suspended sediment from slough to ridge is a key factor in stability of ridge and slough landscape in the Everglades wetland. However, the effect of sediment redistribution on changes in bed elevation is not considered in their investigation. (Noe et al., 2007) tested the hypothesis by measuring suspended sediment concentration in adjacent ridge and slough in the Everglades, and found that under present-day managed Everglades, redistribution of suspended sediment does not occur. However, they did not measure bed variation that may have occurred in the vicinity of ridge and slough of the Everglades. Lago et al. (2010) investigated the importance of sediment transport in ridge and slough formation by using a numerical model of water flow, sediment transport, vegetation dynamics and 
differential soil accretion; however, their model did not investigate the variations in bed elevation that may occur as a result of sediment transport.

Ridge and Slough Cellular Automata Landscape (RASCAL) is a 3-D quasi cellular automata model developed by Larsen and Harvey (2011) that couples hydrology, bed shear stress, sediment transport, and vegetation dynamics and simulates landscape patterning in wetlands. Their model simulates bed shear stress and shows how landscape patterns such as ridge and slough may develop over millennia, but did not simulate shortterm changes in bed elevation under pulsed flow conditions.

Wu et al. (2005) simulated flow, sediment transport, and bed topography in rivers with both submerged and emergent rigid vegetation using a two-dimensional numerical model. Their model explains the effect of submerged vegetation or channel curvature on flow and sediment transport in streams and rivers where flow velocity is high and bed load is significant. Their model calculates flow velocity using vegetation drag and bed shear forces. Their model may explain sediment transport and bed elevation variations within rivers and streams where velocity is high, but it is not capable of simulating such variations in ridge and slough features of wetlands, with high vegetation density and low flow velocity.

The effect of sediment transport and bed variation on ridge and slough stability and maintenance are very complex and not fully understood. Previous studies (Noe et al., 2007; Larsen et al., 2009b; Larsen et al., 2009c; Larsen and Harvey, 2010b; Larsen and 
Harvey, 2011) have shown that sediment transport does not occur at the present-day managed Everglades ecosystem, and increases in flow velocity alone may not result in sediment entrainment towards downstream. While hypothesized that pulsed flow conditions are necessary to increase the bed shear stress and redistribute sediments, none of these investigations have focused on quantifying how sediment would be redistributed when a pulsed flow condition is implemented.

The objective of the present study is to develop a two-dimensional physical-based numerical model of bed elevation for wetlands with low topographic gradient, consisting of features such as ridge and slough and tree islands. We hypothesize that sediment transport plays a significant role on ridge and slough landscape evolution and maintenance in wetlands, focused on bed variations in highly vegetated, ridge and slough system when a pulsed flow condition implemented. We propose a two-dimensional erosion-deposition model that can be used to simulate bed elevation during a perturbation experiment (conditional pulsed flow). Results and insight gained from the proposed model can provide an improved understanding of the extent to which sediment transport generates changes in bed morphology and whether landscape patterns such as ridges and sloughs are affected by changing in water management practices that affect sediment transport.

This investigation may contribute to support the hypothesis presented in Larsen and Harvey (2010a) on the role of sediment transport in the ridge and slough pattern formation. The primary focus of our study was to understand the effect of erosion and 
deposition processes on generating the ridge and slough pattern than developing a "predictive" modeling tool that could be used to make management decisions.

\subsection{Study Area}

Our study area is located in the Loxahatchee Impoundment Landscape Assessment (LILA). It refers to as "living laboratory" model of the Everglades ecosystem that gives researchers the opportunity to apply and test their restoration techniques in a smaller and controlled area before applying in the Everglades. The LILA includes an enclosed area of 34 ha (80 acres) at the Arthur R. Marshall Loxahatchee National Wildlife Refuge (LNWR), also known as Water Conservation Area 1 (WCA1), Boynton Beach, Florida (Fig. 4.4). The area is divided into four macrocosms of $200 \mathrm{~m}$ by $400 \mathrm{~m}$ (M1 through M4). Each macrocosm consists of one ridge, one deep slough, two tree islands inside the deep slough, and one shallow slough (Fig. 4.5). This assemblage is a replica of the ridge and slough and tree island landscape features of the greater Everglades.

Culverts are installed at each inflow and outflow locations, which allows controlling stages and flows at each macrocosm. Flow through LILA macrocosms is generated by a $1.1 \mathrm{~m}$ diameter electric axial flow submersible pump and is controlled by $0.9 \mathrm{~m}$ gated culverts at the inflows (western end) and $0.9 \mathrm{~m}$ culverts with stop logs at the outflows (eastern end). Two of the macrocosms are constant flowing systems (M2 and M4) whereas the other two are non-flowing (M1 and M3). Water depth and velocity in each macrocosm can be controlled independently to mimic the Everglades flow system and 
also makes it possible to conduct pulsed flow studies. For the purpose of our study, the flowing cell, M2, was selected as the study area to conduct pulsed flow experiments (Fig. 4.5).

\subsection{Materials and Methods}

\subsubsection{Numerical Model Development}

The numerical model developed for this investigation consists of two parts: suspended sediment transport and bed elevation variations. Suspended sediment transport modeling involves simulation of advection, dispersion, erosion and deposition processes. Suspended particles are transported because of advection and dispersion processes. Both processes are dependent on flow velocity and the local concentration gradient. Erosion depends on sediment characteristics (such as cohesive or non-cohesive properties) and how it can be separated from the bed and carried by flow. When the bottom shear stress is insufficient (less than critical shear stress) to entrain sediment particles in the flow, then, deposition processes begins. Deposition depends on the critical shear stress, concentration of suspended sediment, settling velocity and depth of water. Sediment transport is usually divided into bed load and suspended load. Bed load occurs when sediments move, role, jump, or slip only at the bottom layer whereas suspended load occurs when sediment particles are moved into the water column, and away from the bottom layer through advection and dispersion mechanisms. When sediment particles are large, bed load is the dominant contributor, and when sediment particles are fine and loose, suspended load is the dominant contributor to the sediment transport processes. In 
wetlands with low flow velocity and subtle topographic gradient, such as the Everglades, where the bottom is covered with loose flocculent detrital organic matter (floc), sediment transport is dominated by suspended load.

The two-dimensional sediment transport equation can be generalized by depth-averaging the advection-dispersion equation as follows:

$$
\frac{\partial(h C)}{\partial t}+\left[v_{x} \frac{\partial(h C)}{\partial x}+v_{y} \frac{\partial(h C)}{\partial y}\right]-\left[D_{x x}\left(\frac{\partial^{2}(h C)}{\partial x^{2}}\right)+D_{x y}\left(\frac{\partial^{2}(h C)}{\partial y^{2}}\right)\right]=\gamma
$$

Where, $C$ is particle concentration $\left(\mathrm{ML}^{-3}\right), h$ is water flow depth $(\mathrm{L}), \gamma$ refers to source/sink $\left(\mathrm{ML}^{-2} \mathrm{~T}^{-1}\right), v_{x}, v_{y}$ are water flow velocity vector components in $\mathrm{x}, \mathrm{y}$ directions $\left(\mathrm{LT}^{-1}\right)$, and $D_{x x}, D_{y y}$ are dispersion coefficients in $\mathrm{x}, \mathrm{y}$ directions $\left(\mathrm{L}^{2} \mathrm{~T}^{-1}\right)$ and define as:

$$
\begin{aligned}
& D_{x x}=D_{L}\left(\frac{v_{x}^{2}}{v}\right)+D_{T}\left(\frac{v_{y}^{2}}{v}\right) \\
& D_{y y}=D_{T}\left(\frac{v_{x}^{2}}{v}\right)+D_{L}\left(\frac{v_{y}^{2}}{v}\right)
\end{aligned}
$$

Following Lago et al. (2010), source/sink terms are as result of erosion and deposition in this equation and are defined as follows:

$\gamma=\varepsilon_{\text {ero }}-\varepsilon_{\text {dep }}$

$\varepsilon_{\text {ero }}=\varepsilon_{\text {res }}+F\left(\frac{v}{v_{s}}\right)^{2}$

$\varepsilon_{\text {dep }}=v_{s} C+\Phi$

Where, $\varepsilon_{\text {ero }}$, $\varepsilon_{d e p}$, and $\varepsilon_{\text {res }}$ are referred to rates of erosion, deposition, and resuspension $\left(\mathrm{ML}^{-2} \mathrm{~T}^{-1}\right)$ respectively, $v_{s}$ and $v$ are setting velocity of sediment particles and the flow 
velocity (magnitude of the flow velocity vector) $\left(\mathrm{LT}^{-1}\right), C$ is local sediment concentration $\left(\mathrm{ML}^{-3}\right), F$ is proportionality parameter controlling increasing erosion with water velocity (Leonard et al., 2006; Lago et al., 2010), and $\Phi$ is vegetation entrapment rate (filtration) depending on vegetation type and density (Huang et al., 2008).

The relationship between the proportionality factor and erosion rate can be linearly illustrated (Fig. 4.6). In the model formulation, the erosion rate is assumed to be proportional to the bottom shear stress, and the bottom shear stress is assumed to be proportional to flow velocity squared following Manning's equation. Maximum deposition rates occur when the flow velocity is zero; this also means no erosion occurs when velocity is zero. As flow velocity increases, the rate of deposition decreases while rate of erosion increases until a point where both deposition and erosion rates are equal. Further increases in flow velocity will erode the bottom while no deposition will occur.

Sediment particles can be suspended and transported by flowing surface water. Suspended particles can be deposited (settling), filtered by vegetation or become eroded and resuspended in higher flow velocity. The resuspension rate $\left(\varepsilon_{r e s}\right)$ in equation (5) takes into account processes (other than erosion) that contribute to resuspension of the particles. In the Everglades, rewetting of dry areas with a lower bulk density than water (Davis, 1994), gas production in the peat layer, wind-generated waves, and animal activity are examples of processes causing particle resuspension in the water column. 
Change in bed elevation is expressed in a mass balance equation for soil depending on erosion and deposition of sediment particles:

$(1-\theta) \frac{\partial z_{b}}{\partial t}+\frac{1}{\rho} \frac{\partial(h C)}{\partial t}+\frac{\partial q_{x}}{\partial x}+\frac{\partial q_{y}}{\partial y}=0$

where, $\theta$ is soil porosity, $z_{b}$ is bed elevation (L), $\rho$ is soil bulk density $\left(\mathrm{ML}^{-3}\right)$, and $q_{x}$ and $q_{y}$ are total sediment transport fluxes in the $\mathrm{x}$ and $\mathrm{y}$ directions and are define as:

$q_{x}=\frac{h C v_{x}}{\rho}$ and $q_{y}=\frac{h C v_{y}}{\rho}$

Equations (3.1) - (7) can be solved using a numerical upwinding scheme (chapter 2). It is assumed that all elements have initial suspended sediment concentration of $C_{0}$ and initial elevation of $z_{b b}$. Neumann boundary conditions of constant flux and constant elevation at the edges of the domain are applied. No flow conditions are assigned to all boundaries except for the "inflow" and "outflow" cells located on east and west boundaries.

FORTRAN codes have been developed to generate time series of suspended sediment concentration and bed elevation variations in both one and two dimensions. The 1-D model is used to test the bed elevation model performance and behavior. The 2-D model is applied over the study area to explain how bed morphology would change during a pulsed flow condition.

The developed model was used to simulate the spatiotemporal changes in ridge and slough bed morphology through sediment deposition and erosion driven by the water 
flow fields. The resulting bed elevation and topography was used to explore the hypothesis of whether sediment transport plays an important role in ridge and slough landscape formation, maintenance and stability. Sensitivity analysis tested the model output to different input parameters, and was used to create different scenarios that could resemble prehistoric flow and depth conditions.

\subsubsection{Pulsed Flow in LILA}

The developed model of erosion and deposition was applied to a conditional pulsed flow discharge (Fig. 4.7) that was implemented during a dye study conducted on October 2007 in the study area (Scinto et al., 2009). The pulsed flow had a magnitude of $0.34 \mathrm{~m}^{3} / \mathrm{s}$ and duration of 8 hours and it was applied at the inflow location. This task was done by simply closing the inflow discharge into the study area and allowing water to accumulate behind the inflow culvert at least 24 hours prior to the testing. Chapter 2 explains the development of a two-dimensional flow model and simulation the flow depth and velocity during the pulsed flow experiment. On the day of this experiment, water samples were collected at several locations inside the study area in order to quantify the suspended particles initial concentration, and then water was released into the macrocosm by opening the inflow culvert to the maximum capacity. Inflow discharge was registered by Acoustic Doppler Velocimeter (ADV) to be as high as $0.34 \mathrm{~m}^{3} / \mathrm{s}$ for approximately 8 hours. According to the ADV installed at the inflow location of M2, the operational daily flow discharge into M2 is about $0.32 \mathrm{~m}^{3} / \mathrm{s}$. The inflow culvert was only able to generate maximum flow discharge of $0.34 \mathrm{~m}^{3} / \mathrm{s}$. Therefore, the maximum possible increase in 
inflow discharge that could be achieved was $0.02 \mathrm{~m}^{3} / \mathrm{s}$; this increased the flow velocity up to $0.03 \mathrm{~m} / \mathrm{s}$. Water samples were taken from several locations inside the deep slough and ridge using Van Dorn sediment trap device before releasing the water through the culvert. Samples then delivered to the lab and then vacuum filtered through a $0.45 \mu \mathrm{m}$ filter paper. Samples were dried at $80{ }^{\circ} \mathrm{C}$ for 2 hours. The residue was weighted using microbalance (Mettler-Toledo) with $10^{-4} \mathrm{~g}$ accuracy. The average initial concentration of $2.2 \mathrm{mg} / \mathrm{L}$ was measured in the water column before the pulsed flow started. The measured concentration is higher than the suspended particle concentration of $0.94 \mathrm{mg} / \mathrm{L}$, reported by Noe et al. (2007) in the Everglades ridge and slough. Therefore, $2.2 \mathrm{mg} / \mathrm{L}$ was used as the initial concentration in our simulation.

\subsubsection{Numerical Model Setup}

In this work, the study area (M2) was first discretized using rectangular grid elements of $5 \mathrm{~m}$ by $5 \mathrm{~m}(\Delta x$ and $\Delta y)$ as shown in Fig. 4.8. Each element consisted of initial suspended particle concentration $\left(C_{0}\right)$, initial bed elevation $\left(z_{b 0}\right)$, flow velocity components in $\mathrm{x}$ and y directions $\left(v_{x}\right.$ and $\left.v_{y}\right)$, water depth $(h)$, and final elevation $\left(z_{\mathrm{b}}\right)$.

The simulation of bed elevation consisted of three steps. The first step was to simulate spatial and temporal variation of flow depth and velocity in the study area. A two dimensional FLO-2D (O'Brien et al., 1993) model was set up to simulate flow depth and velocity during a pulsed condition inflow discharge in the study domain (chapter 2). The second step was to simulate suspended sediment concentration in the study area when the 
pulsed flow condition was applied. The results of the flow simulation was used to model suspended sediment transport during the pulsed flow condition. We developed a twodimensional transport model to simulate spatial and temporal distribution of solute concentration in the study area (chapter 3). We applied this model to simulate changes in suspended sediment concentration over the study area when a pulsed flow condition is applied.

The main source and sink of suspended particles are erosion and deposition, respectively. Particles may erode as a result of flow velocity and become entrained in the water column and transported further downstream or deposit later on. Suspended particles may leave the water body as a result of settling process or filtration through vegetation. At each time step and for each individual element, the model calculated suspended sediment concentration as a result of simulated erosion and deposition.

An initial concentration of $2.2 \mathrm{mg} / \mathrm{L}$ was imposed at each element. Water flows into the study area with the same suspended particle concentration as the initial inflow location. We assumed that the proportionality factor $(F)$, resuspension rate $\left(\varepsilon_{\text {res }}\right)$, and vegetation filtration $(\Phi)$ were all time independent and uniform over the entire study area during the pulsed flow condition. Lago et al. (2010) estimated a proportionality factor of $1.504 \times$ $10^{-10} \mathrm{~kg} / \mathrm{m}^{2} \mathrm{~s}$ and a resuspension rate of $2.0 \times 10^{-11} \mathrm{~kg} / \mathrm{m}^{2} \mathrm{~s}$; these values were used in this modeling work. We assumed that vegetation filtration may not affect the results of because the concentration of suspended sediments at the site is too small to be filtered 
through vegetation and system and therefore practically no filtration occurs at the present conditions, i.e., $(\Phi=0.0)$.

The third and final step in bed elevation modeling was to simulate the change in bed elevation using the results of suspended sediment concentration and equations (7) and (8). The bed elevation model calculates fluxes at the element scale and for each time step. To satisfy the numerical stability of the model, a time step of 10 second $(\Delta t=10 \mathrm{~s})$ was selected to calculate suspended particle concentration and bed elevation at each element. Lateral and longitudinal dispersion coefficients of $D_{L}=0.1 \mathrm{~m}^{2} / \mathrm{s}$ and $D_{T}=0.05$ $\mathrm{m}^{2} / \mathrm{s}$ (chapter 3) and an initial distribution of bed elevation (chapter 2) were used.

We assumed that suspended particles were mainly consisting of flocculent detrital organic matter (floc), that covers the bottom of the wetland, and this is the main contributor to changes in bed elevation. Larsen et al. (2009a) reported the porosity, $(\theta)$, bulk density $(\rho)$, and settling velocity $\left(v_{s}\right)$ of "floc" to be $0.9,13 \mathrm{~kg} / \mathrm{m}^{3}$, and $4.0 \times 10^{-4} \mathrm{~m} / \mathrm{s}$ respectively. These values were used in this model.

\subsection{Results and Discussion}

Several simulations were performed to test the proposed bed elevation model behavior in the study area. A one-dimensional problem was used to verify numerical stability and model response followed by the application of the two-dimensional numerical model to the study area. Sensitivity analyses were performed to assess the model response to 
changes in parameters involved in the numerical model. Each 2-D simulations reports text files consisting of coordinates and elevation data at different time steps. The results of 2-D simulation in the study area were shown as a series of raster images that represent spatiotemporal variations in bed elevation in the study area.

We applied the two-dimensional bed elevation model to the study area during an 8 -hr pulsed flow condition. The first simulation referred to normal flow conditions in the study area (LILA-cell M2). Normal daily flow condition refers to discharge of $0.32 \mathrm{~m}^{3} / \mathrm{s}$ into M2 at the inflow culvert, which generates average uniform flow velocities between $0.01 \mathrm{~m} / \mathrm{s}$ and $0.02 \mathrm{~m} / \mathrm{s}$ inside the macrocosm. This condition also represents current hydrologic conditions in the Everglades (Larsen et al., 2007; Harvey et al., 2009). The model was run for durations of eight hours to be consistent with conditional pulsed flow conditions. Fig. 4.9 illustrates results of changes in bed elevation simulation during normal flow operation. As it is shown in this figure, no changes in bed elevation are occurred when normal daily flow conditions are simulated. These results agree with the results of Larsen and Harvey (2011) and Noe et al. (2009) that no suspended particles are being transported with present day flow velocity in the Everglades, and therefore present day flow conditions are inadequate to change the bed elevation.

Fig. 4.10 represents the simulated results of changes in bed elevation over time when pulsed flow conditions are applied to the study area. As it mentioned previously, a pulsed flow (Fig. 4.7) refers to an increase in discharge into the study domain from 0.32 $\mathrm{m}^{3} / \mathrm{s}$ (normal flow condition) to $0.34 \mathrm{~m}^{3} / \mathrm{s}$ that lasted about 8 hours. Average flow 
velocity was increased from average daily of $0.01 \mathrm{~m} / \mathrm{s}$ to average of $0.03 \mathrm{~m} / \mathrm{s}$ during the pulsed flow condition. The results of this simulation indicate that no change in bed elevation occurs during the experimental pulsed flow condition. These modeling results suggests that increasing flow discharge and velocity in a form of pulsed condition over a period of time may not be sufficient to redistribute suspended particle in order to modify bed morphology.

Although these results suggest that even implementing a conditional pulsed flow may not transport the suspended particles, more studies are needed to validate and improve model outcome. These results are in contrast with the hypothesis that sediment transport may play a significant role in wetland bed morphology and that conditional pulsed flow is necessary to redistribute sediment through the region (Science Coordination Team, 2003; Laurel G. Larsen and Judson W. Harvey, 2010). However, we should take into consideration that the focus of this work was to understand how a conditional single pulsed flow might affect bed morphology in a short period of time $(8 \mathrm{hrs})$ rather than at longer periods.

\subsection{Sensitivity Analysis}

Sensitivity analysis was performed to test the robustness of the results and to increase understanding of the relation between input variables and the model output. Several scenarios were made on each of the input variables: resuspension rate $\left(\varepsilon_{\text {res }}\right)$, 
proportionality factor $(F)$, and vegetation filtration $(\Phi)$. Each variable was individually manipulated to conduct the sensitivity analysis.

Resuspension Rate, $\varepsilon_{\text {res }}$

Lago et al. (2010) estimated $\varepsilon_{\text {res }}$ to be $2.0 \times 10^{-11} \mathrm{~kg} / \mathrm{m}^{2} \mathrm{~s}$ in the Everglades. We increased $\varepsilon_{\text {res }}$ to $2.0 \times 10^{-10} \mathrm{~kg} / \mathrm{m}^{2} \mathrm{~s}$ by a factor of 10 . The results showed that erosion starts when the resuspension rate is increased to at least $10^{5}$ times more than the measured value (Fig. 4.11). This indicates that the model is practically insensitive to changes in the resuspension rate.

\section{Erosion-Deposition Proportionality Factor, F:}

Lago et al. (2010) estimated the erosion-deposition proportionality factor, $F$, of $1.504 \times$ $10^{-10} \mathrm{~kg} / \mathrm{m}^{2} \mathrm{~s}$. We started with $F$ value of $1.504 \times 10^{-11} \mathrm{~kg} / \mathrm{m}^{2} \mathrm{~s}$ and increased the value by factors of 10. The results (Fig. 4.12) indicate that changes in bed elevation will not happen when lower values of $F$ are used (Fig. 4.12-1). The model however shows little erosion in the area very closed to inflow and outflow of study area when estimated value of $F=1.504 \times 10^{-10} \mathrm{~kg} / \mathrm{m}^{2} \mathrm{~s}$ is used (Fig. 4.12-2). Increasing $F$ by 10 magnitudes will cause erosions up to $12 \mathrm{~mm}$ and depositions up to $4 \mathrm{~mm}$ within deep sloughs (Fig. 4.123). This indicates that the model is highly sensitive to changes in the erosion-deposition proportionality factor. Referring to equation (5), $F$ is directly proportional to square of flow velocity (Manning's equation) therefore, increasing $\mathrm{F}$ by factor of 10 will translate to three times more in flow velocity. This means that average pulsed flow velocity of $0.03 \mathrm{~m} / \mathrm{s}$ must be increase to an average pulsed flow velocity as large as $0.09 \mathrm{~m} / \mathrm{s}$ over 
period of pulsed condition. Although generating such a pulsed flow condition may be impossible, certain extreme events may create such a flow condition.

\section{Vegetation Filtration, $\Phi$}

A stated above, we assumed that vegetation filtration $(\Phi)$ is negligible under the flow conditions simulated in the pulsed flow experiment. Vegetation filtration may become important when the suspended particle concentrations are high enough to be filtered when passing though dense vegetation. Fig. 4.13 illustrates the results of a scenario when high concentrations of particles (because of high velocity and high resuspension rate) are present in the system. Fig. 4.13-1 is the results of simulation the when only resuspension rate is high and Fig. 4.13-2 shows the simulation when both a high velocity and high a resuspension rate are imposed. However, the value of vegetation filtration coefficient in these simulations is very small compare to those of Huang et al., (2008).

\subsection{Conclusion}

The purpose of study was to develop a two-dimensional mathematical bed elevation model to numerically simulate high-resolution changes in bed elevations in wetlands with low topographic gradient and high vegetation density. The model consists of three parts: simulation of hydrology (flow depth and velocity), simulation of sediment transport, and simulation of bed elevation. The results of hydrologic simulation (chapter 2) were used to simulate spatiotemporal variation of suspended sediment concentration (chapter 3). Bed elevation was simulated by using results of suspended sediment concentration and 
hydrology over time. The developed model was applied to a pulsed flow condition to simulate changes in bed elevation during a conditional flow.

The simulation results for no pulsed flow conditions show that present day hydrological condition in the Everglades (flow velocity of $0.02 \mathrm{~m} / \mathrm{s}$ ) will not entrain suspended particles and no changes in bed elevation will occur. These results agree with those of Noe et al. (2009). The results of maximum increase in flow velocity up to $0.03-0.05 \mathrm{~m} / \mathrm{s}$ as a pulsed condition also is not sufficient to change the bed elevation in the study area and therefore, higher flow velocity and larger pulsed flow conditions would be necessary to cause changes in bed elevation. Because of the experimental capabilities existing in the LILA study area inflow and outflow, it was not practically possible to achieve higher flow discharge and velocity.

Sensitivity analyses indicated that the model was not sensitive to increasing resuspension rates. This means that in general, resuspension rate depending on external activities such as rewetting of dry areas with a lower bulk density than water (Davis, 1994), gas production in the peat layer, wind waves, animal activity, etc. may not be important in sediment redistribution and changing bed elevation. These analyses however show that the model is highly sensitive to change in erosion-deposition proportionality factor, which is directly proportional to square of flow velocity. These results also support the idea that hydrologic conditions (flow depth and velocities) have the greatest affect sediment transport and changes in bed elevation. Higher velocity will cause higher net changes in bed elevation. Although these results demonstrate the significance of 
hydrologic conditions, they also suggest that to produce slight erosion and subsequent deposition of sediments, it is necessary to implement a pulsed flow condition with flow velocity of $0.09 \mathrm{~m} / \mathrm{s}$, at least three times higher than what was implemented in the present study. Higher flow velocities and larger pulsed flow conditions are necessary to produce sufficient changes in bed elevation at the site. Sensitivity analyses on vegetation filtration also reveal that vegetation may not affect any filtration in the system because the suspended sediment concentrations are too low to be filtered through vegetation stems and this factor does not play any significant role in suspended particle redistribution and changes in bed elevation. Vegetation filtration coefficient may become important when higher suspended sediment concentration is produced.

The results of this modeling effort indicate that despite of previous hypothesizes emphasizing the importance of sediment transport on bed morphology in wetland landscapes such as ridge and slough (Science Coordination Team, 2003; Laurel G. Larsen and Judson W. Harvey, 2010), sediment transport may not play an important role in maintenance and stability of wetland bed morphology, and implementing pulsed flow conditions to enhance sediment transport may not be as effective as it was previously thought.

One major assumption in this study was that "floc" particles could contribute to bed elevation changes. Flocculent detrital material (floc) is highly organic, loose nonconsolidated layer that covers on top of consolidated peat at the bottom of wetlands such as the Everglades. The approximate thickness of floc varies from $0 \mathrm{~cm}$ to $30 \mathrm{~cm}$ (Science 
Coordination Team, 2003; Scinto et al., 2009). Our sensitivity analyses estimate the highest amount of erosion and deposition occurred in the system to be $4.3 \mathrm{~cm}$ and $1.1 \mathrm{~cm}$ respectively (Fig. 4.12 and Fig. 4.13). These results confirm that only floc is being eroded and deposited inside the study and in order to erode consolidated peat soil, higher velocity is required which may not practically possible. The numerical model simulation results demonstrates the occurrence of changes in bed elevation (as a result of floc movement and entrainment) under particular flow conditions, but it is not clear whether floc may contribute into changes in bed elevation.

There are factors that influence the model results. Sediment transport mechanism is highly affected by hydrologic conditions such as flow velocities, which are directly controlled by topography and vegetation coverage. Uncertainties in these factors may result in deviation form actual values. Lack of bed elevation measurements is a major setback in our modeling effort that prevents our model from being calibrated or validated. It should also be considered that measuring bed elevation with such a high spatial resolution $(5 \mathrm{~m})$ and vertical accuracy $(0.001 \mathrm{~m})$ in wetlands is extremely difficult and may not be possible.

In general, the results show that the developed bed elevation model is able to simulate changes in bed elevation using a high-resolution numerical grid in the wetland and can be used as a tool to investigate changes in bed elevation in wetlands with high vegetation density and low topographic gradients where experimental study and measurement of bed elevation is difficult. 


\subsection{References}

Baldwin, M., and Hawker, H. W., 1915, Soil survey of the Fort Lauderdale area, Florida.

Belyea, L. R., and Lancaster, J., 2002, Inferring landscape dynamics of bog pools from scaling relationships and spatial patterns: Journal of ecology, v. 90, no. 2, p. 223234.

Davis, S. M., 1994, Phosphorus inputs and vegetation sensitivity in the Everglades: Everglades: The ecosystem and its restoration, p. 357-378.

Foster, D., King, G., Glaser, P., and Wright, H., 1983, Origin of string patterns in boreal peatlands.

Garcia-Martinez, R., Saavedra, I. C., De Power, B. F., Valera, E., and Villoria, C., 1999, A two-dimensional computational model to simulate suspended sediment transport and bed changes: Journal of Hydraulic Research, v. 37, no. 3, p. 327344.

Guo, Q.-C., and Jin, Y.-C., 1999, Modeling sediment transport using depth-averaged and moment equations: Journal of Hydraulic Engineering, v. 125, no. 12, p. 12621269.

Harvey, J. W., Schaffranek, R. W., Noe, G. B., Larsen, L. G., Nowacki, D. J., and O'Connor, B. L., 2009, Hydroecological factors governing surface water flow on a low-gradient floodplain: Water Resources Research, v. 45, no. 3, p. n/a-n/a.

Huang, Y. H., Saiers, J. E., Harvey, J. W., Noe, G. B., and Mylon, S., 2008, Advection, dispersion, and filtration of fine particles within emergent vegetation of the Florida Everglades: Water Resources Research, v. 44, no. 4, p. 13.

Lago, M. E., Miralles-Wilhelm, F., Mahmoudi, M., and Engel, V., 2010, Numerical modeling of the effects of water flow, sediment transport and vegetation growth on the spatiotemporal patterning of the ridge and slough landscape of the Everglades wetland: Advances in Water Resources, v. 33, no. 10, p. 1268-1278.

Larsen, L. G., and Harvey, J. W., 2010a, How vegetation and sediment transport feedbacks drive landscape change in the Everglades and wetlands worldwide: The American Naturalist, v. 176, no. 3, p. E66-E79.

Larsen, L. G., and Harvey, J. W., 2010b, How vegetation and sediment transport feedbacks drive landscape change in the everglades and wetlands worldwide: Am Nat, v. 176, no. 3, p. E66-79. 
Larsen, L. G., and Harvey, J. W., 2011, Modeling of hydroecological feedbacks predicts distinct classes of landscape pattern, process, and restoration potential in shallow aquatic ecosystems: Geomorphology, v. 126, no. 3-4, p. 279-296.

Larsen, L. G., Harvey, J. W., and Crimaldi, J. P., 2007, A Delicate Balance: Ecohydrological Feedbacks Governing Landscape Morphology in a Lotic Peatland: Ecological Monographs, v. 77, no. 4, p. 591-614.

Larsen, L. G., Harvey, J. W., and Crimaldi, J. P., 2009a, Morphologic and transport properties of natural organic floc: Water Resources Research, v. 45, no. 1, p. n/an/a.

Larsen, L. G., Harvey, J. W., and Crimaldi, J. P., 2009b, Predicting bed shear stress and its role in sediment dynamics and restoration potential of the Everglades and other vegetated flow systems: Ecological Engineering, v. 35, no. 12, p. 1773-1785.

Larsen, L. G., Harvey, J. W., Noe, G. B., and Crimaldi, J. P., 2009c, Predicting organic floc transport dynamics in shallow aquatic ecosystems: Insights from the field, the laboratory, and numerical modeling: Water Resources Research, v. 45, no. 1, p. n/a-n/a.

Laurel G. Larsen, and Judson W. Harvey, 2010, How Vegetation and Sediment Transport Feedbacks Drive Landscape Change in the Everglades and Wetlands Worldwide: The American Naturalist, v. 176, no. 3, p. E66-E79.

Leonard, L., Croft, A., Childers, D., Mitchell-Bruker, S., Solo-Gabriele, H., and Ross, M., 2006, Characteristics of surface-water flows in the ridge and slough landscape of Everglades National Park: implications for particulate transport: Hydrobiologia, v. 569, no. 1, p. 5-22.

Lin, P.-n., Huan, J., and Li, X., 1983, Unsteady transport of suspended load at small concentrations: Journal of Hydraulic Engineering, v. 109, no. 1, p. 86-98.

Lindsay, R. A., Riggall, J., and Burd, F., 1985, The use of small-scale surface patterns in the classification of British peatlands.

Noe, G. B., Harvey, J. W., and Saiers, J. E., 2007, Characterization of suspended particles in Everglades wetlands: Limnology and Oceanography, v. 52, no. 3, p. 1166.

Noe, G. B., Harvey, J. W., Schaffranek, R. W., and Larsen, L. G., 2009, Controls of Suspended Sediment Concentration, Nutrient Content, and Transport in a Subtropical Wetland: Wetlands, v. 30, no. 1, p. 39-54.

O'Brien, J. S., Julien, P. Y., and Fullerton, W. T., 1993, Two-dimensional water flood and mudflow simulation: Journal of hydraulic engineering, v. 119, no. 2, p. 244-261. 
Ogden, J. C., 2005, Everglades ridge and slough conceptual ecological model: Wetlands, v. 25 , no. 4 , p. $810-820$.

Rietkerk, M., Dekker, S., Wassen, M., Verkroost, A., and Bierkens, M., 2004, A putative mechanism for bog patterning: The American Naturalist, v. 163 , no. 5, p. 699708.

Sakaguchi, Y., 1980, On the genesis of banks and hollows in peat bogs: an explanation by a thatch line theory: Bulletin of the department of Geography University of Tokyo, v. 12, p. 35-58.

Science Coordination Team, S. F. E. R. W. G., 2003, The role of flow in the Everglades ridge and slough landscape: USGS.

Scinto, L., Price, R., and Ross, M., 2009, LILA (Loxahatchee Impoundment Landscape Assessment) Tree Island, Ridge, Slough Studies and Site Management. May 1, 2005 to September 4, 2009, Final Report submitted to SFWMD, Aug 17, 2009, $11 \mathrm{pp}$

Wright, J. O., 1912, Everglades of Florida [microfilm].

Wu, W., Shields, F. D., Bennett, S. J., and Wang, S. S., 2005, A depth - averaged two dimensional model for flow, sediment transport, and bed topography in curved channels with riparian vegetation: Water Resources Research, v. 41, no. 3. 


\subsection{Figures}

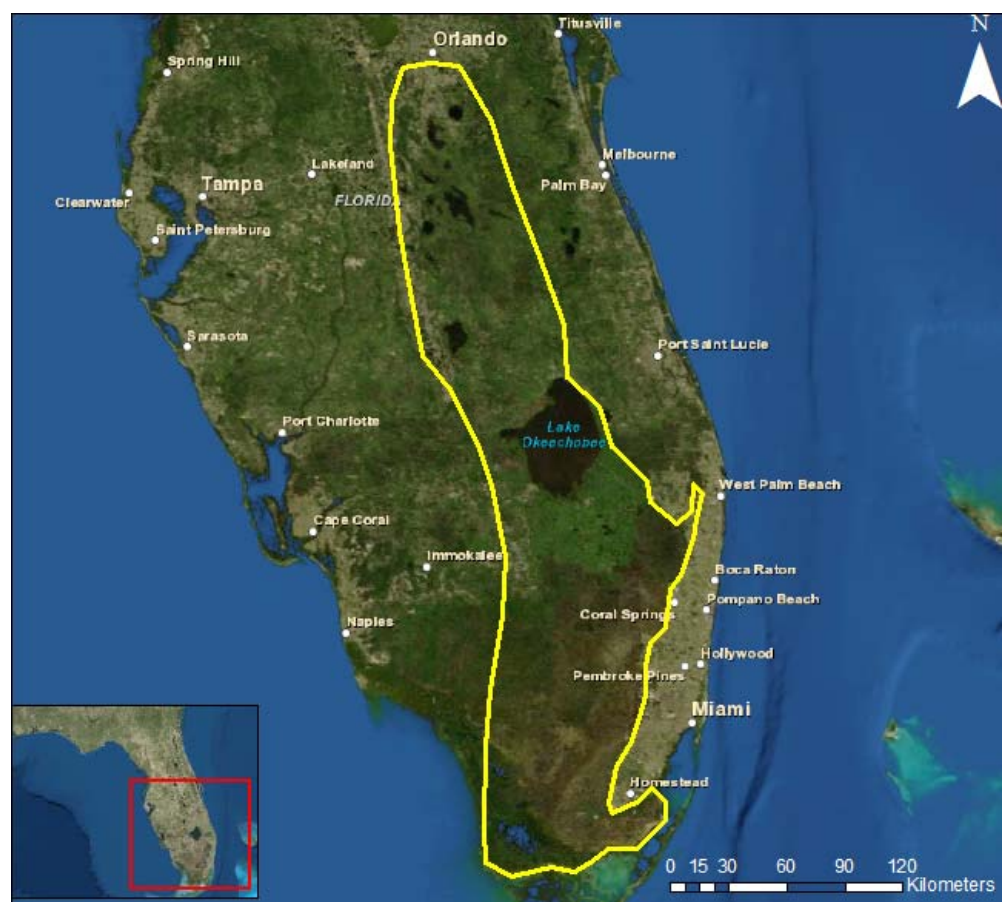

Fig. 4.1: The Everglades wetland boundary (yellow polygon) in South Florida. It starts from Orlando and ends at Florida Bay 


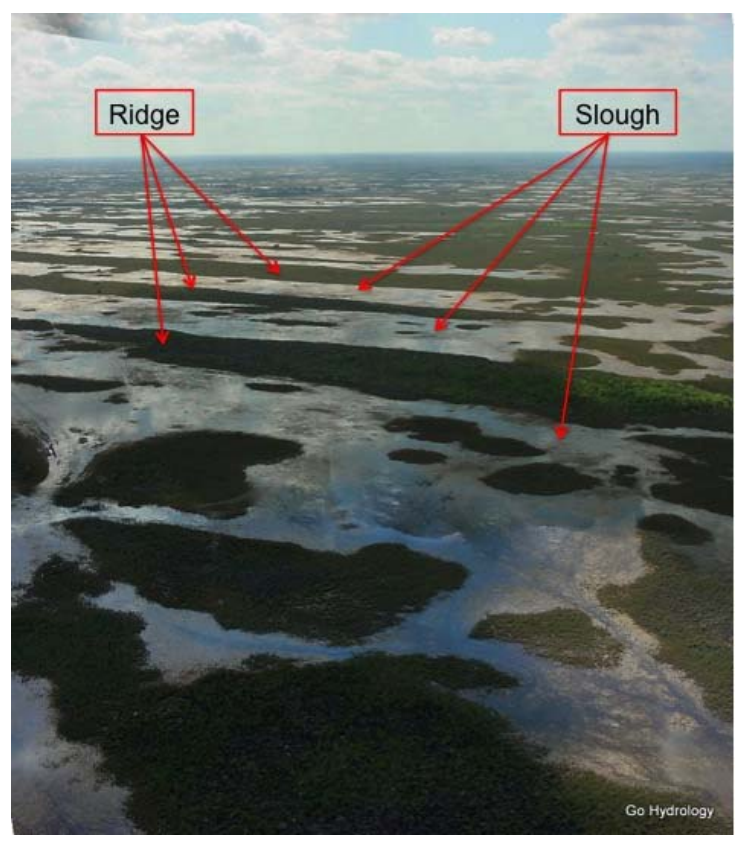

Fig. 4.2: Ridge and Slough of the Everglades photographed by: Robert Sobczak (www.gohydrology.org) 


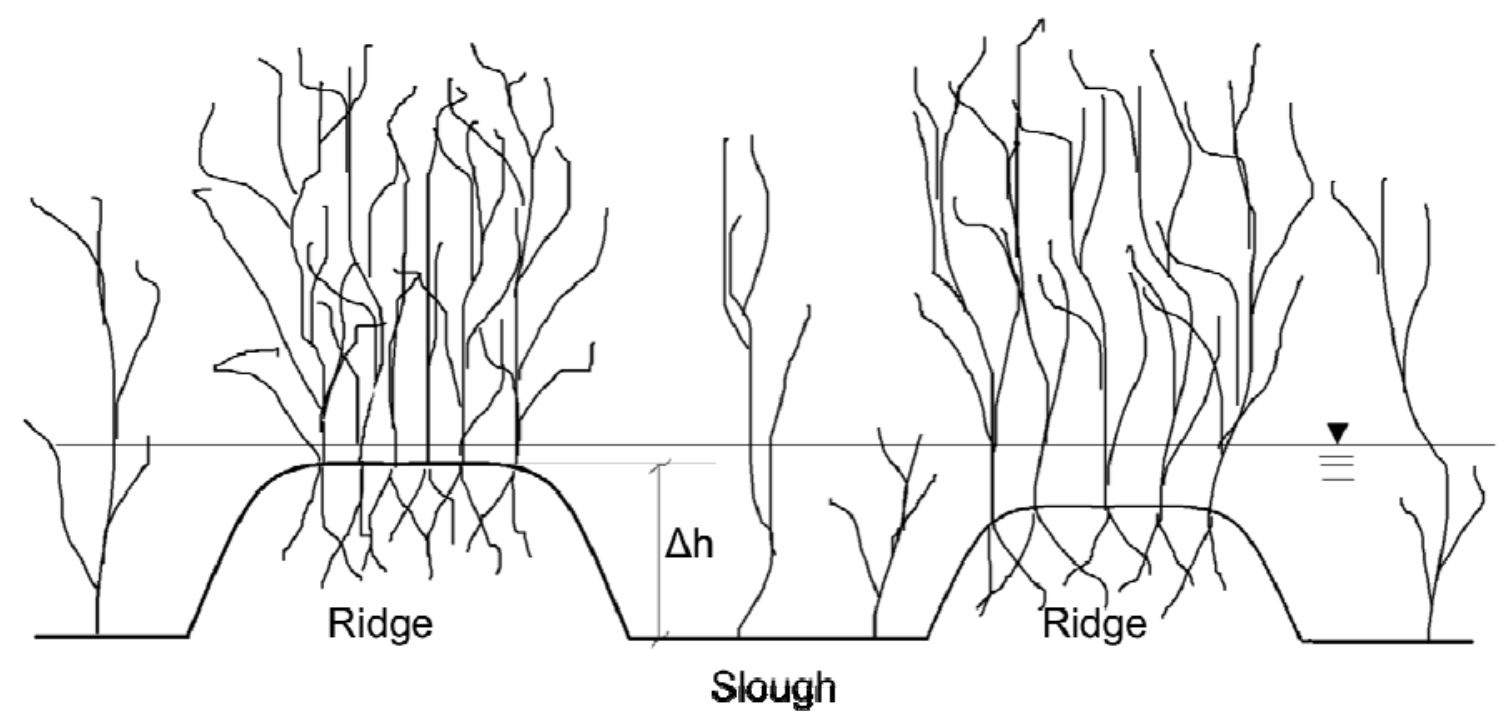

Fig. 4.3: Cross section schematic of ridge and slough illustrating the elevation difference between top of a ridge and bottom of a slough $(\Delta \mathrm{h})$ 


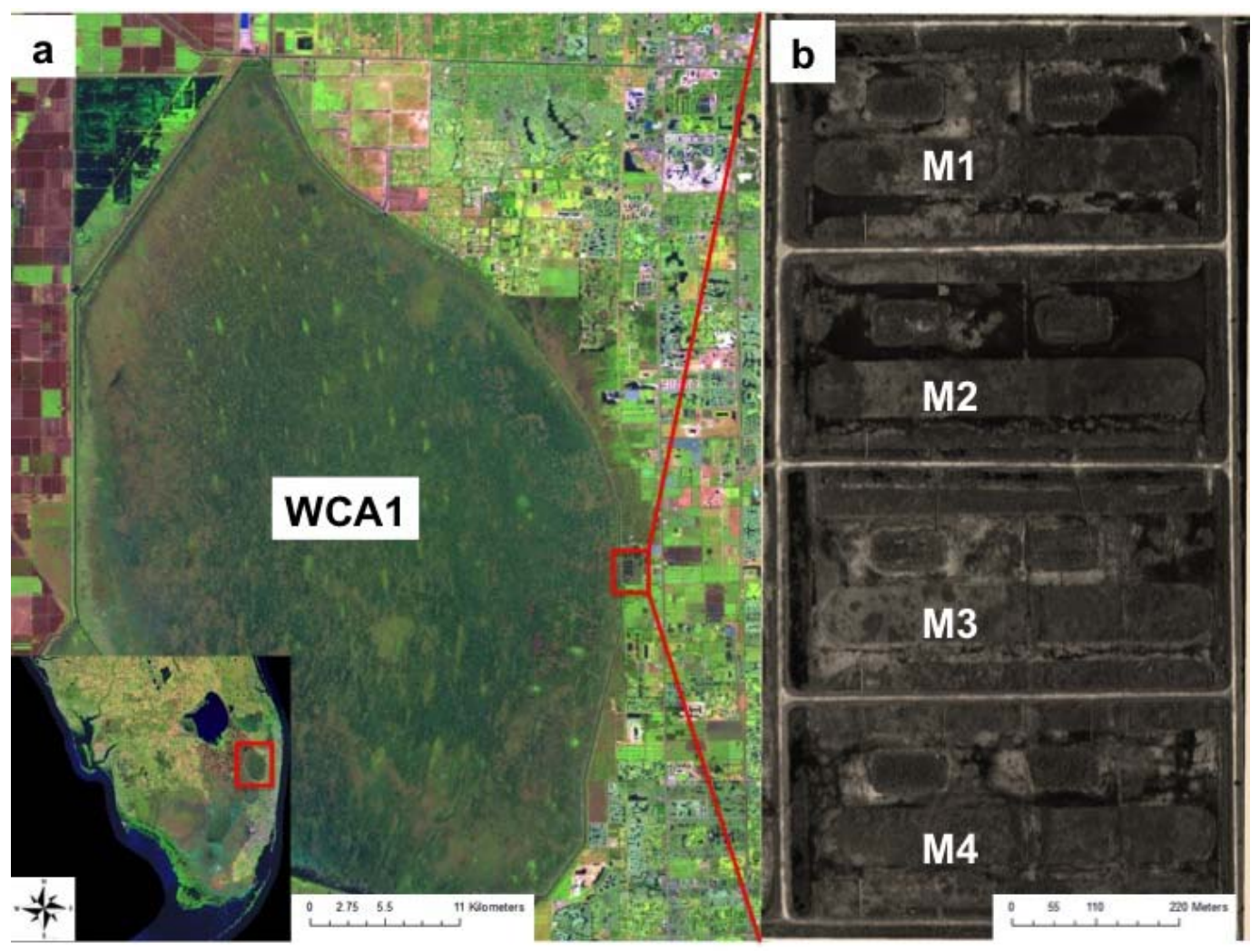

Fig. 4.4: (a) LILA location at the eastern boundary of WCA-1. The location with respect to southern Florida is shown in the insert. (b) Air plot showing the four macrocosms of LILA 


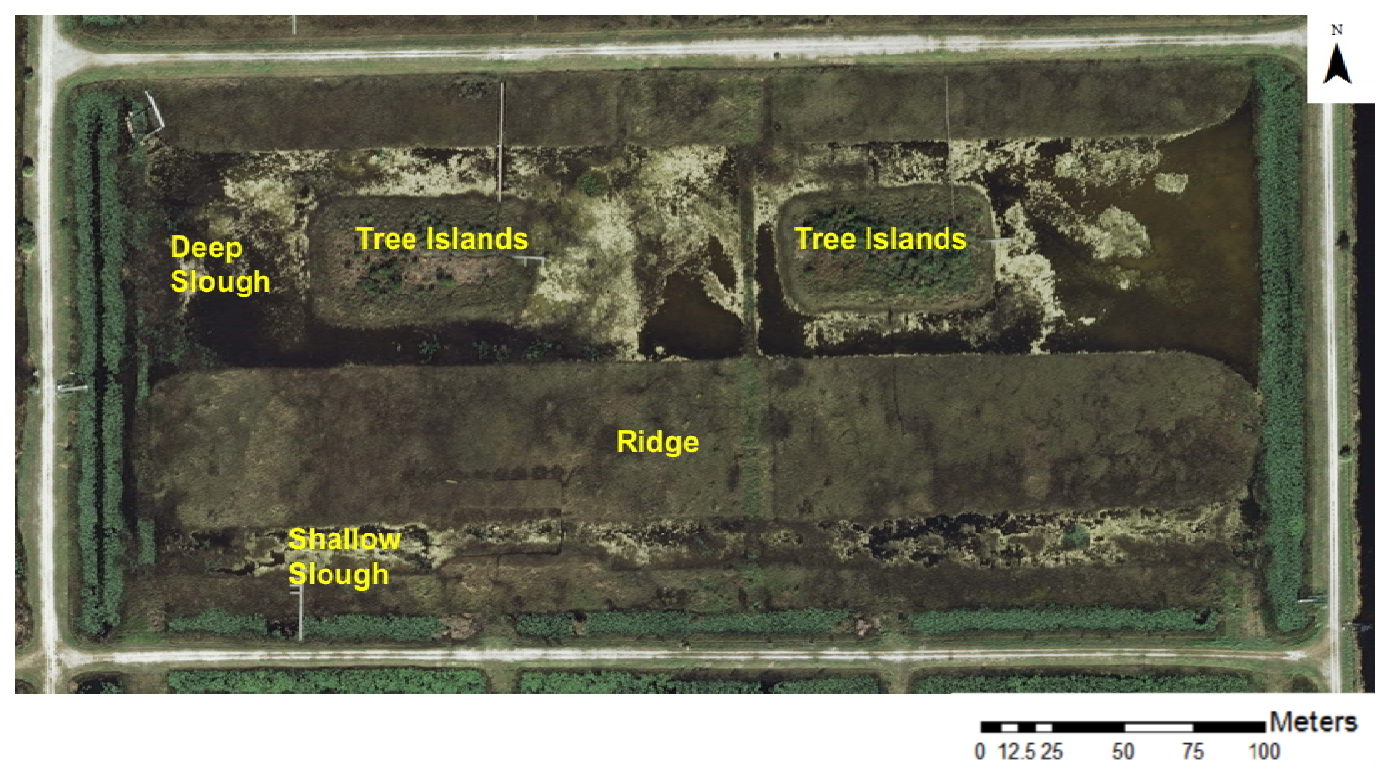

Fig. 4.5: LILA features

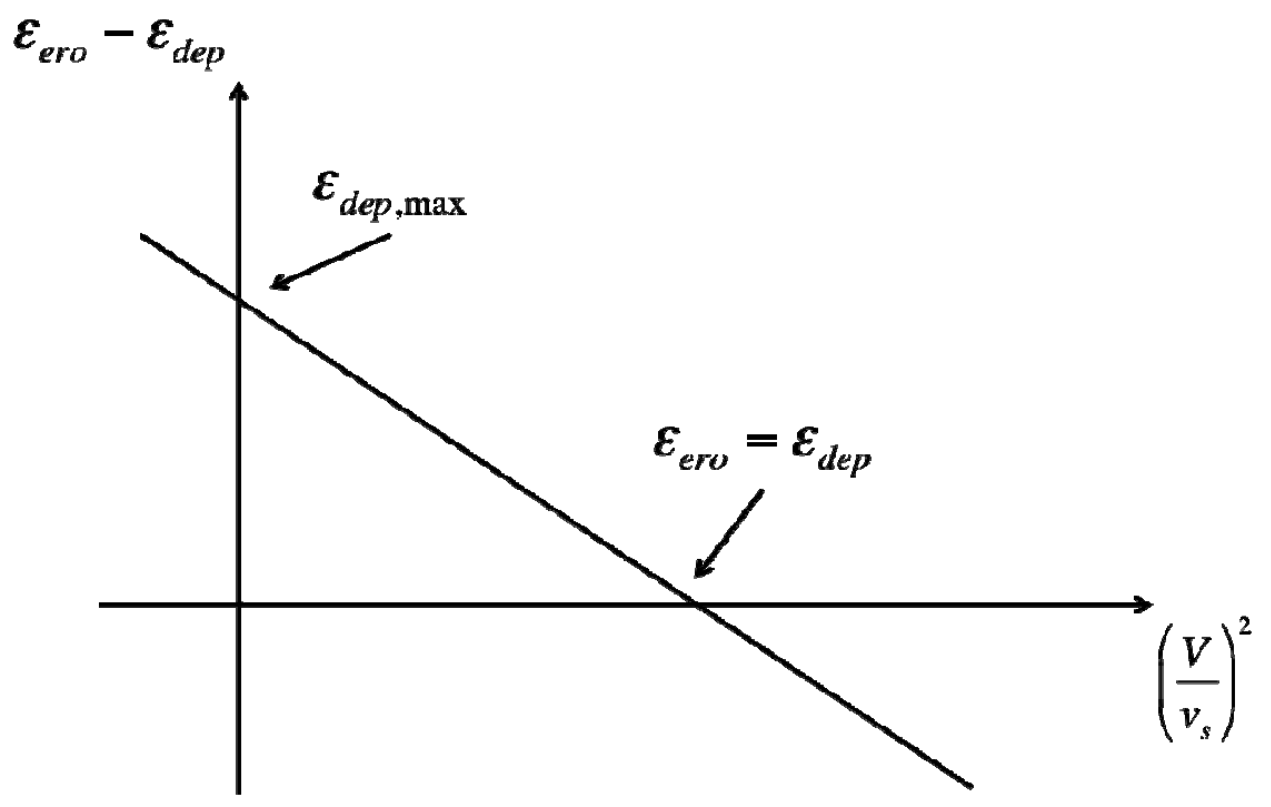

Fig. 4.6: Erosion-deposition proportionality factor (F) relation with erosion and velocity (Lago et al., 2010) 


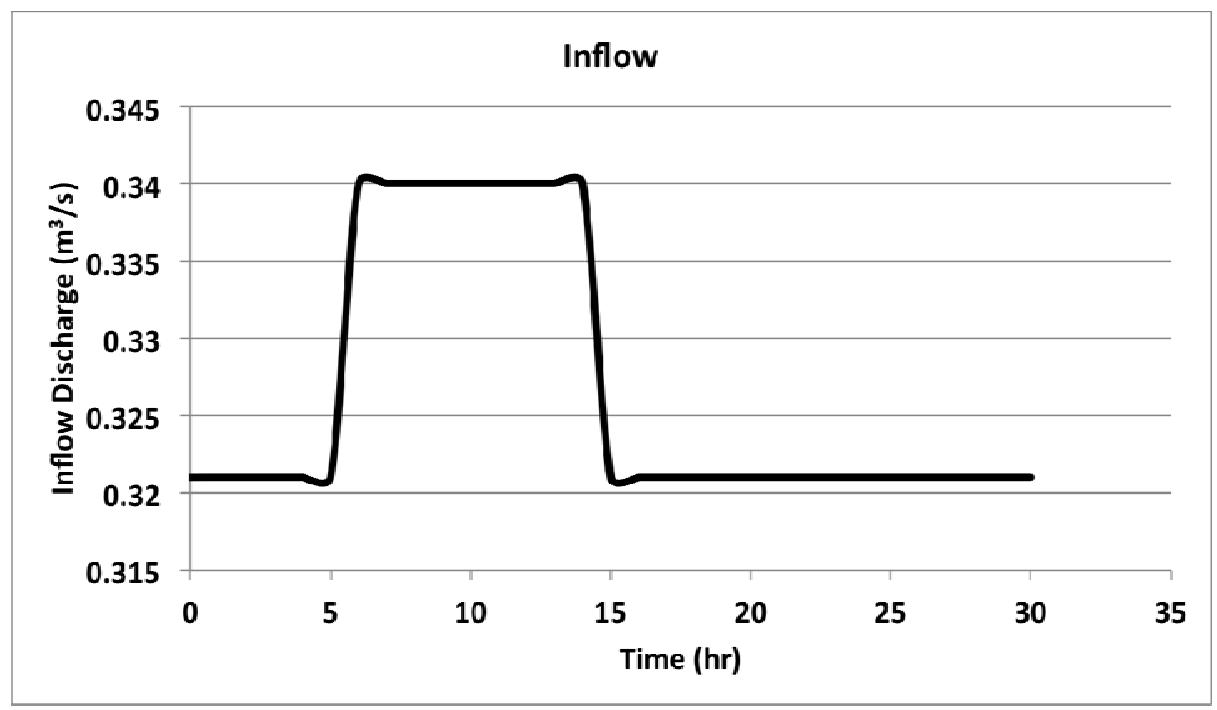

Fig. 4.7: Pulsed flow condition imposed at inflow location in LILA macrocosm 2 


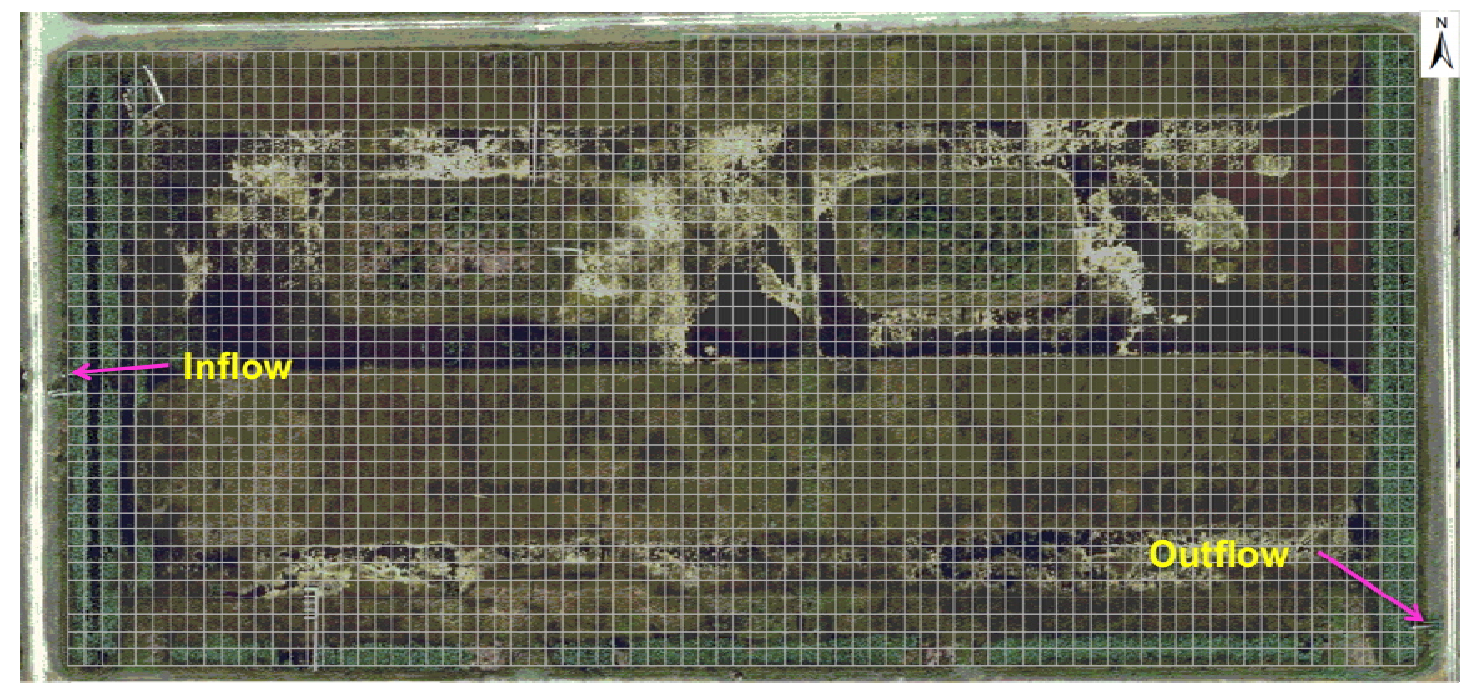

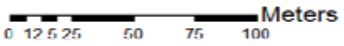

Fig. 4.8: Air photo showing macrocosm 2 (M2), grid system, and inflow/outflow locations

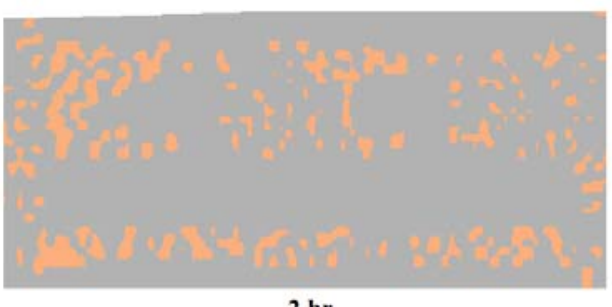

$2 \mathrm{hr}$

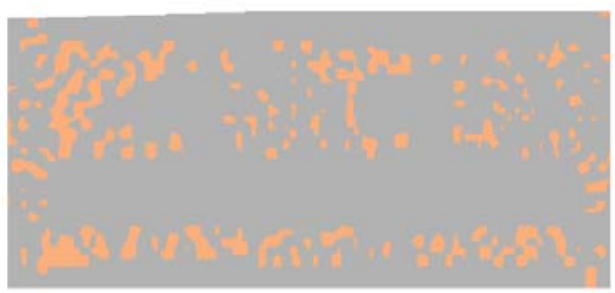

$4 \mathrm{hr}$

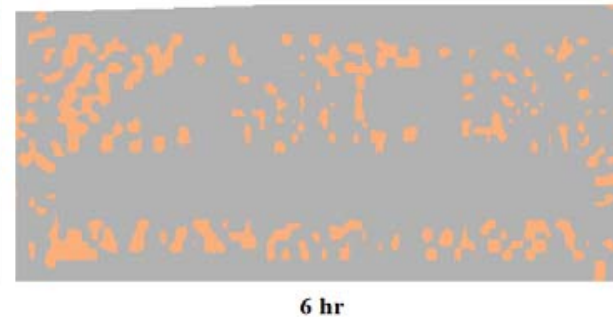

$6 \mathrm{hr}$

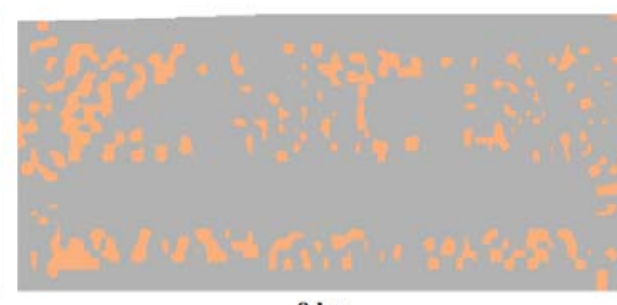

$8 \mathrm{hr}$
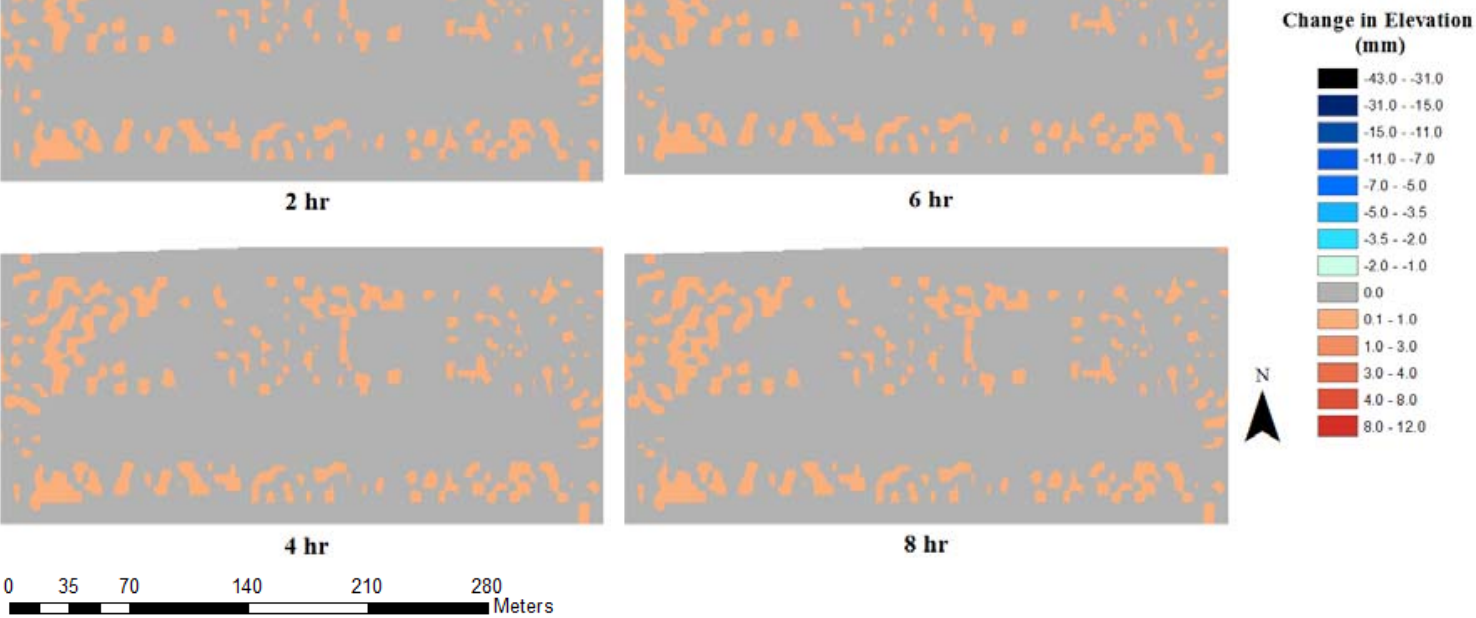

Fig. 4.9: Changes in bed elevation during normal flow conditions 


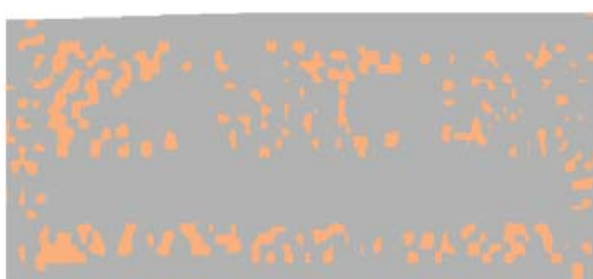

$2 \mathrm{hr}$

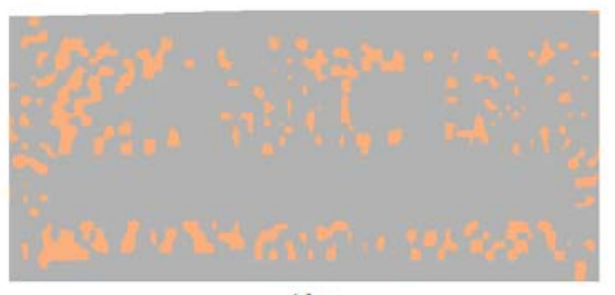

$4 \mathrm{hr}$

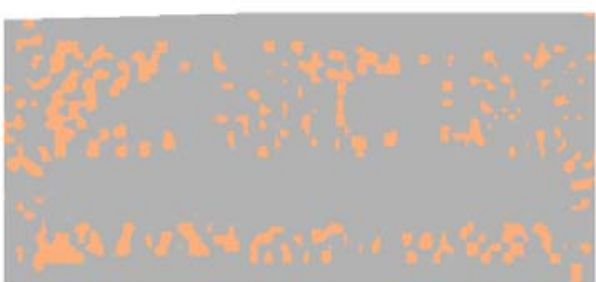

$6 \mathrm{hr}$

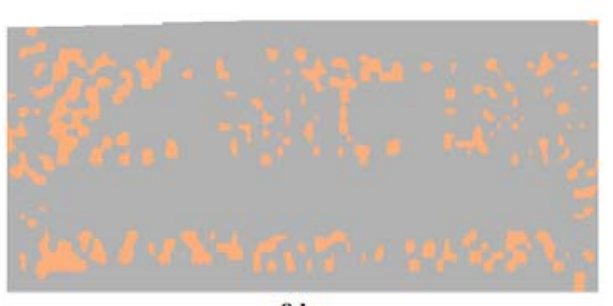

$8 \mathrm{hr}$
Change in Elevation (mm)

$-430 .-310$

$-31.0 \cdots 15.0$
$-15.0 \cdots 11.0$ $-11.0-7.0$ $-7.0--5.0$ $-50 .-35$ $-3.5 \cdot 2.0$ ? $20 \cdots 1.0$ 0.0 $0.1-10$ 1.0 .30

$\hat{\wedge}$

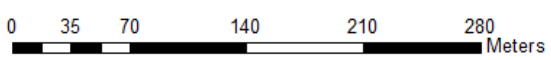

Fig. 4.10: Changes in bed elevation when an 8-hour pulsed flow condition is applied 

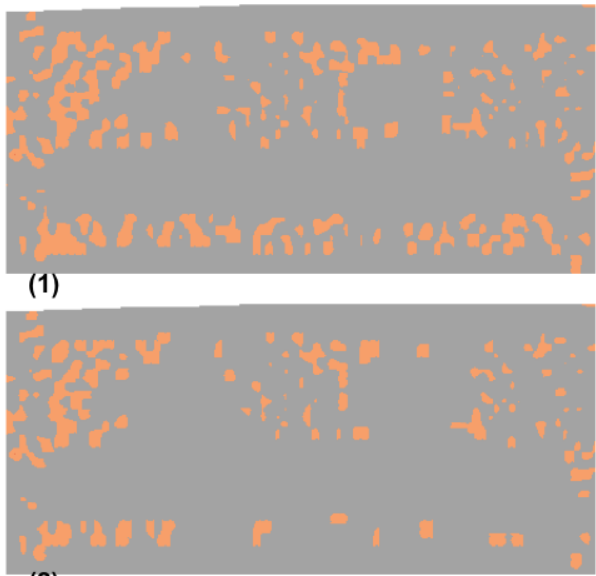

(2)
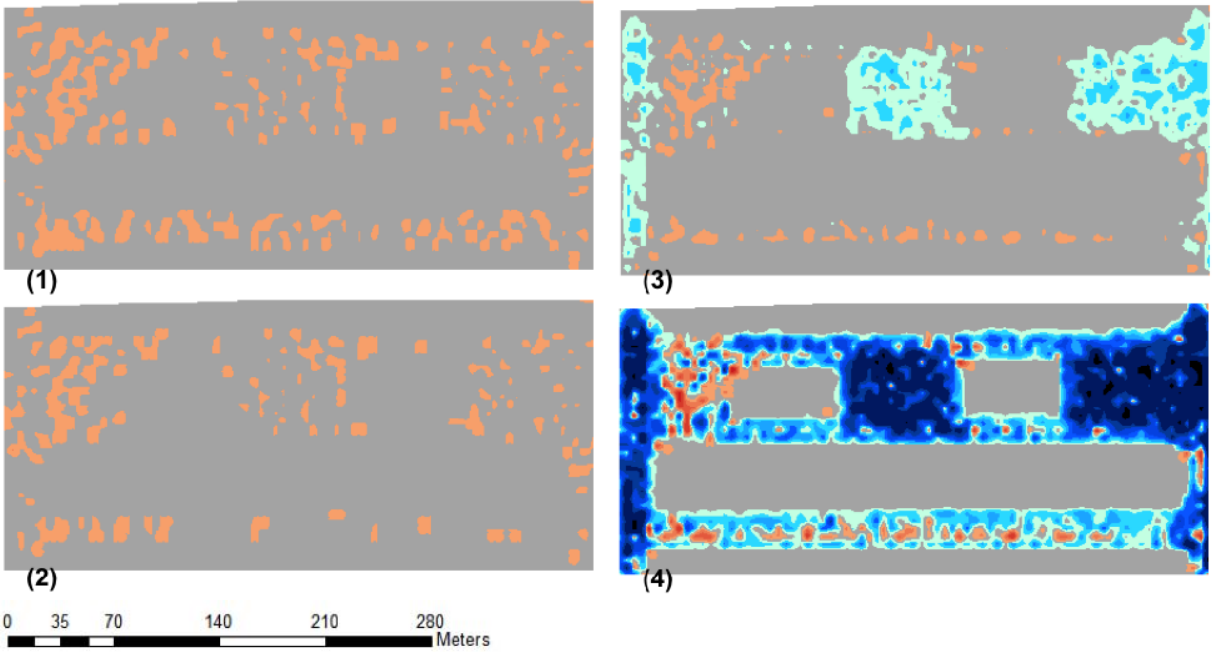

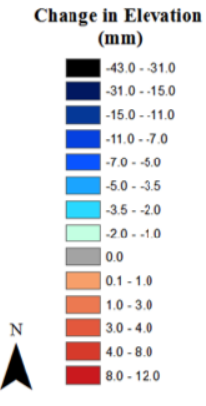

Fig. 4.11: Results of simulation with various Resuspension rate while Proportionality factor and vegetation filtration is zero. (1) $\varepsilon_{r e s}=2.0 \times 10^{-11} \mathrm{Kg} / \mathrm{m}^{2} \mathrm{~s}$, (2) $\varepsilon_{\text {res }}=2.0 \times 10^{-9}$ $\mathrm{Kg} / \mathrm{m}^{2} \mathrm{~s}$, (3) $\varepsilon_{\text {res }}=2.0 \times 10^{-6} \mathrm{Kg} / \mathrm{m}^{2} \mathrm{~s}$, (4) $\varepsilon_{\text {res }}=2.0 \times 10^{-5} \mathrm{Kg} / \mathrm{m}^{2} \mathrm{~s}$ 


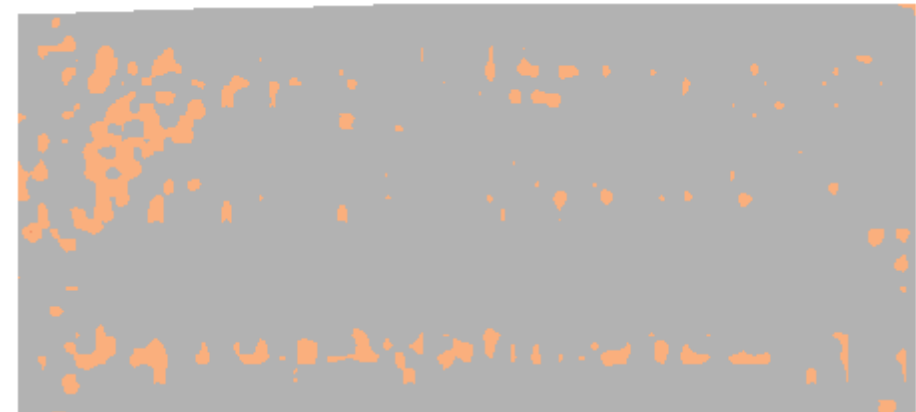

(1)

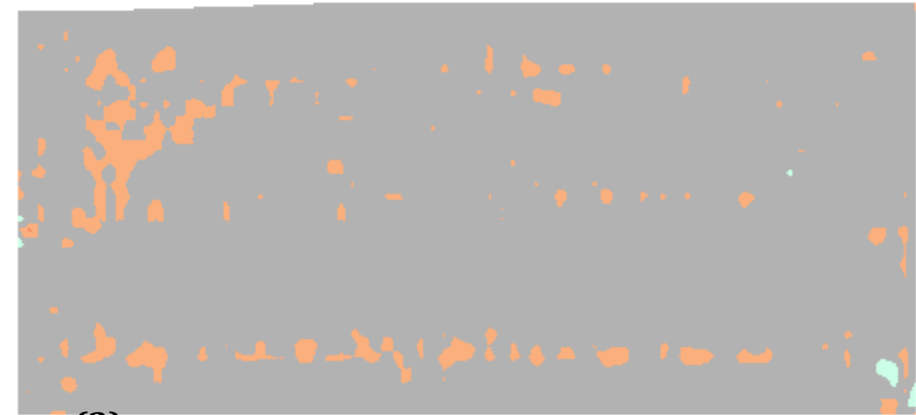

(2)

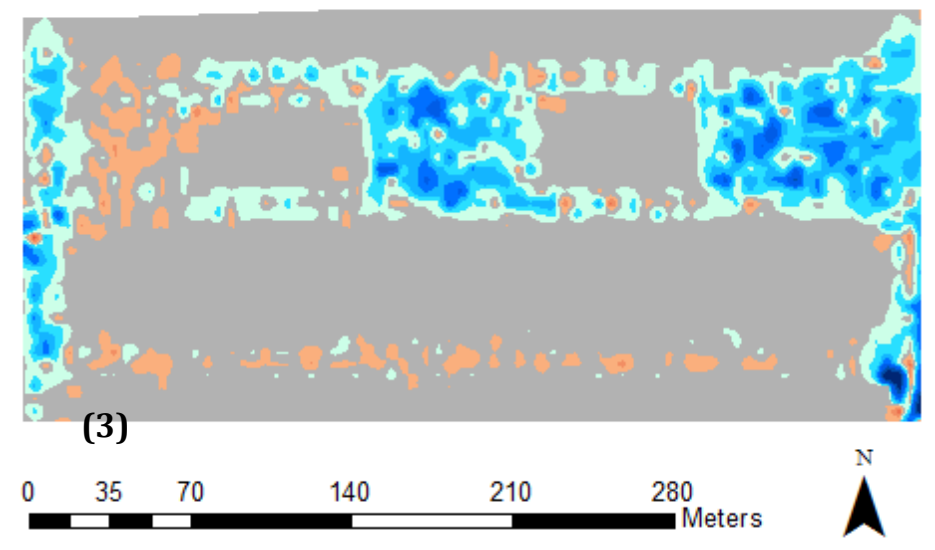

Elevation Change

(mm)

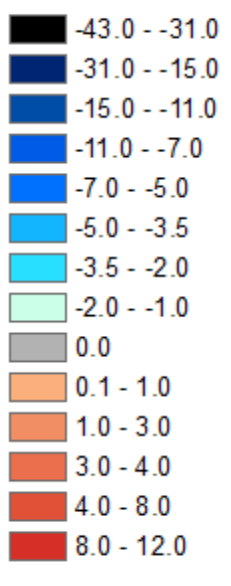

Fig. 4.12: Changes in Proportionality Factor while Resuspension and vegetation filtration are zero. (1) $F=1.5 \times 10^{-11} \mathrm{Kg} / \mathrm{m}^{2} \mathrm{~s}$, (2) $F=1.5 \times 10^{-10} \mathrm{Kg} / \mathrm{m}^{2} \mathrm{~s}$, (3) $F=1.5 \times 10^{-9}$ $\mathrm{Kg} / \mathrm{m}^{2} \mathrm{~s}$ 


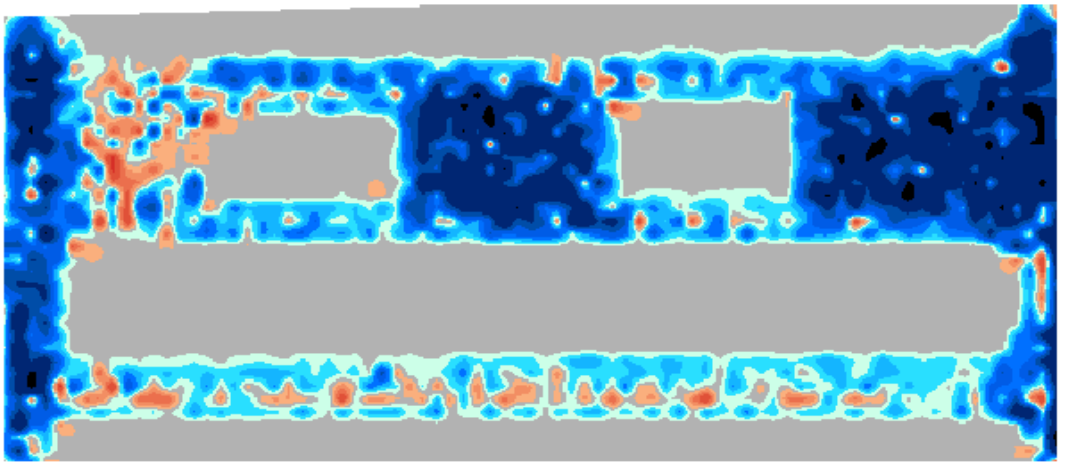

(1)

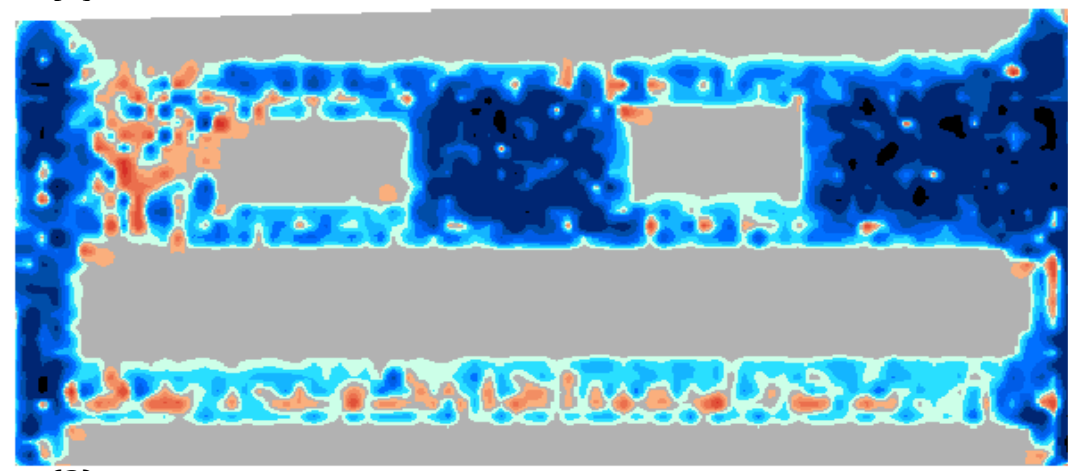

(2)
Change in E levation (mm)

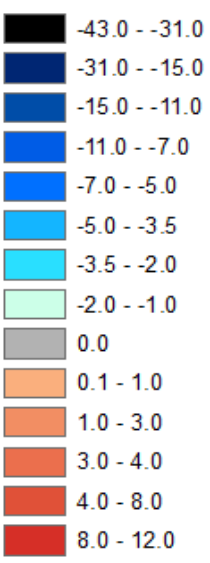

i

Fig. 4.13: The effect of vegetation filtration factor. (1) $F=0.0, \varepsilon_{r e s}=2.0 \times 10^{-5} \mathrm{Kg} / \mathrm{m}^{2} \mathrm{~s}$, $\Phi=3 \times 10^{-11} \mathrm{~s}^{-1}(2) F=1.5 \times 10^{-10} \mathrm{Kg} / \mathrm{m}^{2} \mathrm{~s}, \varepsilon_{r e s}=2.0 \times 10^{-5} \mathrm{Kg} / \mathrm{m}^{2} \mathrm{~s}, \Phi=3 \times 10^{-11} \mathrm{~s}^{-1}$ 


\section{CHAPTER 5: SUMMARY AND CONCLUSION}

Wetland bed morphology and its temporal variation is one of the most complex and least studied mechanisms involved in wetland landscape formation, stability and maintenance. In this work, a numerical model of sediment transport was developed to simulate spatiotemporal changes in bed elevation through bed erosion and suspended particles deposition in the wetland with high vegetation density and low topographic gradient such as the Everglades. This model was particularly used to simulate the changes in bed elevation in ridge and slough landscape of the Everglades when a specific hydrologic condition, such as pulsed flow, was applied.

A two-dimensional hydrology model using FLO-2D was developed and applied to the study area to explain spatiotemporal variation of water flow depth and velocity during a pulsed flow condition in the study area, LILA. Because of structural limitations in LILA, we were only able to create a low-pulsed flow condition, which produced flow velocity values that were as low as $0.02 \mathrm{~m} / \mathrm{s}$ and varied in direction, creating areas of mixing inside deep slough. Under a hypothetical high-pulsed flow, simulated flow velocity values were high $(0.1 \mathrm{~m} / \mathrm{s})$ but they were also uniform indicating east-to-west flow direction toward the downstream inside deep slough. The high spatial resolution of this modeling effort may also be another reason to reveal mixing zones inside the deep slough where flow direction varies. This may affect transport of sediments and nutrients and cause nutrient trapping and accumulation of substances within these areas. Further 
investigations are needed to support the existence of these "mixing zones" and whether they may significantly alter transport mechanisms.

A two-dimensional solute transport model of advection-dispersion was developed to simulate the spatiotemporal distribution of solute concentration in wetlands with high vegetation density and low topographic gradient. The model was used to simulate transport of a nonreactive dissolved dye under low-pulsed flow conditions and was applied to a tracer test at LILA. The dissolved plume transport simulated results were compared with aerial images taken during the tracer test. Visual comparison between numerical results and the images indicate that the model was in a good agreement with the observed dye movement, and that the model was capable of simulating the solute transport and further suspended sediment. The simulation results also supported the existence of areas within the domain where the mixing processes happen. These areas may cause that nutrients and suspended particles stay longer time rather than entraining toward downstream and exiting the system. The developed model can be further used to simulate erosion and deposition processes, which may cause changes in bed elevation and morphology in areas where ground data collection is difficult.

Finally, we developed a two-dimensional numerical model to simulate high-resolution changes in bed elevation through erosion and deposition processes when a pulsed flow condition is implemented. The simulation results for no pulsed flow conditions show that present day hydrological condition in the Everglades (flow velocity of $0.02 \mathrm{~m} / \mathrm{s}$ ) is not enough to entrain suspended particles and no changes in bed elevation will occur. The 
results of maximum increase in flow velocity up to $0.03-0.05 \mathrm{~m} / \mathrm{s}$ as a pulsed condition also was not sufficient to change the bed elevation in the study area and therefore, higher flow velocity and larger pulsed flow conditions would be necessary to cause changes in bed elevation. Because of the experimental capabilities existing in the LILA study area inflow and outflow, it was not practically possible to achieve higher flow discharge and velocity. The results confirmed that changes in bed elevation may not happen under current condition, and higher velocity is required. This also supports the idea that hydrologic conditions (flow depth and velocities) have the greatest effect on sediment transport and changes in bed elevation. Higher velocity will cause higher net changes in bed elevation. Although these results demonstrate the significance of hydrologic conditions, they also suggest that to produce slight erosion and subsequent deposition of sediments, it is necessary to implement a pulsed flow condition with flow velocity of 0.09 $\mathrm{m} / \mathrm{s}$, at least three times higher than what was implemented in this study. Higher flow velocities and larger pulsed flow conditions are necessary to produce sufficient changes in bed elevation at the site.

The findings from this work provide insights of how changes in hydrologic conditions may affect suspended particle transport and eventual changes in bed elevation by erosion and deposition processes. This work also evidences that under current conditions, pulsed flow may not increase erosion or deposition rate. As a result, changes in bed elevation may not occur or the rate is too small to be detected. This can lead to creating doubt in significance of the role of sediment transport in wetland landscape morphology. 
The work presented in the previous 3 chapters explored the significance of sediment transport in wetland landscape morphology, but there are rooms to improve. Further field investigations are needed to evaluate the hydrology and transport processes in the study area. In addition, the influence of mixing zones on particle entrainment or entrapment and is unclear. More field works is required to validate the existence and the effect of these areas in wetland landscape morphology. 
APPENDIX 


\section{Discretization of Sediment Transport and Bed Elevation Equations}

The advection-dispersion equation used in this work as suspended sediment transport equation is as follow:

$\frac{\partial(\mathrm{hC})}{\partial \mathrm{t}}+\left[\mathrm{v}_{\mathrm{x}} \frac{\partial(\mathrm{hC})}{\partial \mathrm{x}}+\mathrm{v}_{\mathrm{y}} \frac{\partial(\mathrm{hC})}{\partial \mathrm{y}}\right]-\left[\mathrm{D}_{\mathrm{xx}}\left(\frac{\partial^{2}(\mathrm{hC})}{\partial \mathrm{x}^{2}}\right)+\mathrm{D}_{\mathrm{yy}}\left(\frac{\partial^{2}(\mathrm{hC})}{\partial \mathrm{y}^{2}}\right)\right]=\gamma$

Erosion and deposition are considered as source and sink and they defined by:

$$
\begin{gathered}
\gamma=\varepsilon_{\text {ero }}-\varepsilon_{\text {dep }} \\
\varepsilon_{\text {ero }}=\varepsilon_{\text {res }}+F\left(\frac{v}{v_{s}}\right)^{2} \\
\varepsilon_{\text {dep }}=v_{s} C+\Phi
\end{gathered}
$$

Bed elevation is expressed by the following equation:

$$
(1-\theta) \frac{\partial z_{b}}{\partial t}+\frac{1}{\rho} \frac{\partial(h C)}{\partial t}+\frac{\partial q_{x}}{\partial x}+\frac{\partial q_{y}}{\partial y}=0
$$

The Finite Difference Upwinding discretization in time and space results in the following approximate time derivative difference equations:

$$
\frac{\partial(h C)}{\partial t}=\frac{h_{i, j}^{n+1} C_{i, j}^{n+1}-h_{i, j}^{n} C_{i, j}^{n}}{\Delta t}
$$

where, $n$ denotes time step number and $\Delta t$ is the length of time interval. Advection in $\mathrm{x}$ and y directions ( $a d v x$ and $a d v y)$ at time step n and element $(i, j)$ are discretized using first order upwind as follows: 


$$
\begin{aligned}
& a d v x=v_{x} \frac{\partial(h C)}{\partial x}= \begin{cases}v_{x}(i, j)\left(\frac{h_{i, j}^{n} C_{i, j}^{n}-h_{i-1, j}^{n} C_{i-1, j}^{n}}{\Delta x}\right) & v_{x}(\mathrm{i}, \mathrm{j})>0 \\
v_{x}(i, j)\left(\frac{h_{i+1, j}^{n} C_{i+1, j}^{n}-h_{i, j}^{n} C_{i, j}^{n}}{\Delta x}\right) & v_{x}(\mathrm{i}, \mathrm{j})<0\end{cases} \\
& a d v y=v_{y} \frac{\partial(h C)}{\partial y}= \begin{cases}v_{y}(i, j)\left(\frac{h_{i, j}^{n} C_{i, j}^{n}-h_{i, j-1}^{n} C_{i, j-1}^{n}}{\Delta y}\right) & v_{y}(\mathrm{i}, \mathrm{j})>0 \\
v_{y}(i, j)\left(\frac{h_{i, j+1}^{n} C_{i, j+1}^{n}-h_{i, j}^{n} C_{i, j}^{n}}{\Delta y}\right) & v_{y}(\mathrm{i}, \mathrm{j})<0\end{cases}
\end{aligned}
$$

Dispersion in $\mathrm{x}$ and $\mathrm{y}$ directions (dispx and dispy) at time step $\mathrm{n}$ and element $(i, j)$ is approximated with second order differences:

$$
\begin{aligned}
& \text { dispx }=\frac{\partial^{2}(h C)}{\partial x^{2}}=\frac{h_{i-1, j}^{n} C_{i-1, j}^{n}-2 h_{i, j}^{n} C_{i, j}^{n}+h_{i+1, j}^{n} C_{i+1, j}^{n}}{\Delta x^{2}} \\
& D_{x}(i, j)=D_{L}\left(\frac{v_{x}^{2}(i, j)}{v(i, j)}\right)+D_{T}\left(\frac{v_{y}^{2}(i, j)}{v(i, j)}\right) \\
& D_{y}(i, j)=D_{T}\left(\frac{v_{x}^{2}(i, j)}{v(i, j)}\right)+D_{L}\left(\frac{v_{y}^{2}(i, j)}{v(i, j)}\right) \\
& \operatorname{dispy}=\frac{\partial^{2}(h C)}{\partial y^{2}}=\frac{h_{i, j-1}^{n} C_{i, j-1}^{n}-2 h_{i, j}^{n} C_{i, j}^{n}+h_{i, j+1}^{n} C_{i, j+1}^{n}}{\Delta y^{2}}
\end{aligned}
$$

Erosion and deposition are formulated as:

$$
\begin{aligned}
& \varepsilon_{e r o, i, j}^{n}=\varepsilon_{r e s, i, j}^{n}+F_{i, j}\left(\frac{v_{i, j}^{n}}{v_{s}}\right)^{2} \\
& \varepsilon_{d e p, i, j}^{n}=v_{s} C_{i, j}^{n}+\Phi_{i, j} \\
& \gamma_{i, j}^{n}=\varepsilon_{e r o, i, j}^{n}-\varepsilon_{d e p, i, j}^{n}
\end{aligned}
$$

Rewriting equation (A.1) results in: 


$$
\begin{aligned}
& \frac{h_{i, j}^{n+1} C_{i, j}^{n+1}-h_{i, j}^{n} C_{i, j}^{n}}{\Delta t}=\gamma_{i, j}^{n}-(a d v x+a d v y)+\left(D_{x} d i s p x+D_{y} d i s p y\right) \\
& h_{i}^{n+1} C_{i}^{n+1}=h_{i}^{n} C_{i}^{n}+\Delta t\left[\gamma_{i, j}^{n}-(a d v x+a d v y)+\left(D_{x} d i s p x+D_{y} d i s p y\right)\right]
\end{aligned}
$$

The above equation can be rearranged to produce:

$$
C_{i, j}^{n+1}=\frac{h_{i}^{n}}{h_{i, j}^{n+1}} C_{i, j}^{n}+\frac{\Delta t}{h_{i, j}^{n+1}}\left[\gamma_{i, j}^{n}-(a d v x+a d v y)+\left(D_{x} d i s p x+D_{y} d i s p y\right)\right]
$$

Change in bed elevation is discretized as follow:

$$
\begin{array}{ll}
\frac{\partial\left(z_{b}\right)}{\partial t}=\frac{z_{b, i, j}^{n+1}-z_{b, i, j}^{n}}{\Delta t} & \\
q_{x, i}=\frac{\mathrm{v}_{x, i, j}^{n} h_{i, j}^{n} C_{i, j}^{n}}{\rho} & q_{y, i}=\frac{v_{y, i, j}^{n} h_{i, j}^{n} C_{i, j}^{n}}{\rho} \\
\text { Fluxx }=\frac{q_{x, i, j}-q_{x, i-1, j}}{\Delta x} & \text { Fluxy }=\frac{q_{y, i, j}-q_{y, i, j-1}}{\Delta y} \\
\text { Fluxx }=\frac{q_{x, i, j}-q_{x, i-1, j}}{\Delta x} & \text { Fluxy }=\frac{q_{y, i, j}-q_{y, i, j-1}}{\Delta y}
\end{array}
$$

Substituting equations (A.19) through (A.22) in equation (A.5) results in:

$$
\begin{gathered}
(1-\theta) \frac{z_{b, i, j}^{n+1}-z_{b, i, j}^{n}}{\Delta t}+\frac{1}{\rho} \frac{h_{i, j}^{n} C_{i, j}^{n}-h_{i, j}^{n-1} C_{i, j}^{n-1}}{\Delta t}+(\text { Fluxx }+ \text { Fluxy })=0 \\
z_{b, i, j}^{n+1}=z_{b, i, j}^{n}-\left(\frac{\Delta t}{1-\theta}\right)\left[\left(\frac{1}{\rho}\right)\left(\frac{h_{i, j}^{n} C_{i, j}^{n}-h_{i, j}^{n-1} C_{i, j}^{n-1}}{\Delta t}\right)+(\text { Fluxx }+ \text { Fluxy })\right]
\end{gathered}
$$


VITA

\section{MEHRNOOSH MAHMOUDI}

1968

2014

2007

1993

2009 - present

$2007-2009$

$2005-2007$

$1994-2004$
Born, Tehran, Iran

$\mathrm{PhD}$ Candidate, Geosciences, Department of Earth and Environment, Florida International University, Florida, USA

M.Sc. Environmental Engineering, Department of Civil and Environmental Engineering, Florida International University, Florida, USA

B. Sc. Chemical Engineering, College of Chemical Engineering, Isfahan University of Technology, Isfahan, Iran

Research Assistant, Department of Earth and Environment, Florida International University, Florida, USA

Research Consultant, Applied Research Center, Florida International University, Florida, USA

Research Assistant, Department of Civil and Environmental Engineering, Florida International University, Florida, USA

Process Engineer, Iran Chemical Investment, Inc., Isfahan, Iran

\section{PUBLICATIONS AND PRESENTATIONS}

Mehrnoosh Mahmoudi, Miralles-Wilhelm, F., Garcia R., Wdowinski S. (2014) "High Resolution Two-Dimension Modeling of Flow Pulses Discharge into Wetlands" Horologic Engineering (under review)

Mehrnoosh Mahmoudi, Miralles-Wilhelm, F., Garcia R., Wdowinski S. (2014) "Numerical Modeling of Solute Transport In Wetlands: Qualitative Approach to a Tracer Test at the Loxahatchee Impoundment Landscape Assessment (LILA) Site" International Journal of Numerical Methods and Experimental Measurements (under review)

Mehrnoosh Mahmoudi, Miralles-Wilhelm, F., Garcia R., Scinto L., Rivero R., (2014) "Sediment transport dictates spatiotemporal variation of bed morphology in wetlands: Case study in Loxahatchee Impoundment landscape Assessment (LILA) Site" Journal of Hydraulic Research (under review) 
2014 Scholarly Forum, Florida international University, Miami, FL, February 2014. Mehrnoosh Mahmoudi, Miralles-Wilhelm, F., Garcia R. "The Effect of Sediment Transport on Spatiotemporal Variation of Bed Elevation in Wetlands Landscape: Case Study in Loxahatchee Impoundment landscape Assessment (LILA)"

2013 American Water Resources Association (AWRA), Portland, Oregon, November 2013. Mehrnoosh Mahmoudi, Miralles-Wilhelm, F., Garcia R. "Numerical Modeling of the Effect of Hydrologic Conditions, Vegetation Drag, and Sediment transport in Wetlands Patterning"

2013 American Geophysics Union (AGU) Meeting Of America (MOA), Cancun, Mexico, May 2013. Mehrnoosh Mahmoudi, Miralles-Wilhelm, F., Garcia R. "The Effect of Manning's Roughness Calibration on Flow and Sediment transport in Wetlands: Vegetation Drag Approach"

2012 American Geophysics Union (AGU), San Francisco, CA, November 2012. Mehrnoosh Mahmoudi, Miralles-Wilhelm, F., Garcia R. "The Effect of Sediment Transport and Hydrological Conditions on Wetlands Bed Elevation: A numerical Approach in Loxahatchee Impoundment Landscape Assessment (LILA)"

2012 Geology Society of America (GSA), Charlotte, North Carolina, October 2012. Mehrnoosh Mahmoudi, Miralles-Wilhelm, F., Garcia R. "Hydrology modeling of the effect of pulse flow condition on wetland sheet flow: Application FLO2D in LILA"

2012 International Wetland Conference collaboration with Greater Everglades Ecosystem Restoration, INTECOL-GEER, Orlando, Florida, June 2012. Mehrnoosh Mahmoudi, Miralles-Wilhelm, F., Garcia R. "Effect of Hydrologic Conditions and Sediment transport on Wetland Patterning" 